\title{
Censusing and modeling the dynamics of a population of eastern hemlock (Tsuga canadensis L.) using remote sensing
}

\author{
W. Robert Lamar \\ West Virginia University
}

Follow this and additional works at: https://researchrepository.wvu.edu/etd

\section{Recommended Citation}

Lamar, W. Robert, "Censusing and modeling the dynamics of a population of eastern hemlock (Tsuga canadensis L.) using remote sensing" (2003). Graduate Theses, Dissertations, and Problem Reports. 1925.

https://researchrepository.wvu.edu/etd/1925

This Dissertation is protected by copyright and/or related rights. It has been brought to you by the The Research Repository @ WVU with permission from the rights-holder(s). You are free to use this Dissertation in any way that is permitted by the copyright and related rights legislation that applies to your use. For other uses you must obtain permission from the rights-holder(s) directly, unless additional rights are indicated by a Creative Commons license in the record and/ or on the work itself. This Dissertation has been accepted for inclusion in WVU Graduate Theses, Dissertations, and Problem Reports collection by an authorized administrator of The Research Repository @ WVU.

For more information, please contact researchrepository@mail.wvu.edu. 
Censusing and modeling the dynamics of a population of eastern hemlock (Tsuga canadensis $\mathbf{L}$.) using remote sensing.

W. Robert Lamar

Dissertation submitted to the Eberly College of Art and Sciences at West Virginia University in partial fulfillment of the requirements for the degree of

Doctor of Philosophy in Biology

Approved by

James B. McGraw, Ph.D., Committee Chairperson

Richard Thomas, Ph.D.

William Peterjohn, Ph.D.

Charles Yuill, Ph.D. Timothy Warner, Ph.D.

Department of Biology

\section{Morgantown, West Virginia 2003}

Keywords: remote sensing, hemlock, population, demography, matrix models Copyright 2003 W. Robert Lamar 


\begin{abstract}
Censusing and Modeling the Dynamics of a Population of Eastern Hemlock (Tsuga canadensis L.) Using Remote Sensing
\end{abstract}

\author{
W. Robert Lamar
}

A population of eastern hemlock (Tsuga canadensis L.) was censused from the ground using traditional field methods and from the air using large scale, high-resolution, aerial imagery in the early spring of 1997,1998 and 1999. A manual crown survey map of the population, prepared from aerial imagery, was compared to a traditional field census. Over $60 \%$ of the individuals measured on the ground were not detected in the aerial census. Tree size, crown density and crown position all played roles in determining a crown's visibility from the air. Nearly all large, upper canopy hemlocks were visible in the aerial census. An important minority of small, lower canopy hemlocks were also visible in the aerial census. An automated spatial segmentation procedure was developed to identify and measure individual population units, or blobs, within the forest population. A blob was defined as a distinct portion of crown segmented from its neighbors on the basis of size, shape, and connectivity. To ensure the comparability of multi-year segmentation maps, an automated blob reconciliation procedure was also developed to make certain that no hemlock pixels were assigned to different blobs in different years. Following spatial segmentation and reconciliation, a large majority of hemlock blobs ( $\sim 64-72 \%)$ were found to be closely associated with ground referenced, manually delineated, individual hemlock crowns. The remaining blobs consisted of spatially distinct parts of a crown or closely clumped multiple crowns. Matrix population models were constructed from the ground-derived and aerial-derived population data. Matrix analysis produced a number of useful population characteristics including overall population growth rate $(\lambda)$, stable stage distributions, reproductive values, and sensitivity values. $\lambda$ 's calculated from the aerial and ground-derived matrices were compared using randomization tests. While providing a different perspective and description of a population than traditional ground studies, demographic studies using remote sensing provide some promising advantages. The spatially explicit nature of the data permits more biologically realistic modeling of the population and the investigation of potential environmental influences on population dynamics. Automated extraction of demographic or megademographic data from remotely sensed images represents an important first step toward scaling population analysis to the landscape and regional levels. 


\section{ACKNOWLEDGMENTS}

I would like to thank Jim McGraw for his enthusiasm, patience, guidance, wisdom and friendship throughout the course of this project. I would also like to thank Tim Warner for his most helpful insights and review of the different sections of this dissertation. Bill Peterjohn, Richard Thomas, and Charlie Yuill also provided very useful ideas and criticism in their review of the draft dissertation. For all these good people, I am most grateful.

Jim Akerson, of the National Park Service, provided initial guidance during the site selection process.

This research was supported by a NSF ESPCoR grant and NSF grant DBI-9808312. 


\section{TABLE OF CONTENTS}

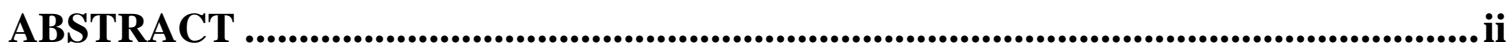

ACKNOWLEDGMENTS...................................................................................................... iii

TABLE OF CONTENTS ................................................................................... iv

LIST OF FIGURES ............................................................................................ vii

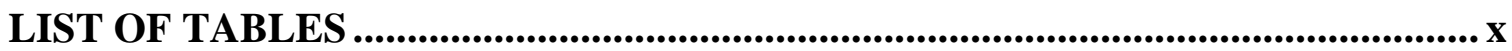

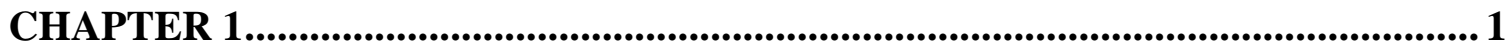

General Introduction ...................................................................................... 1

References ......................................................................................................6 6

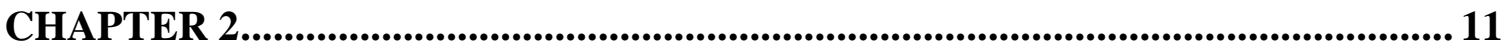

A comparison of a population census of eastern hemlock (Tsuga canadensis L.) on the ground and using aerial photography...................................................................... 11

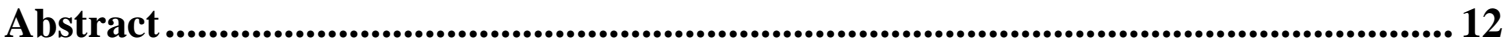

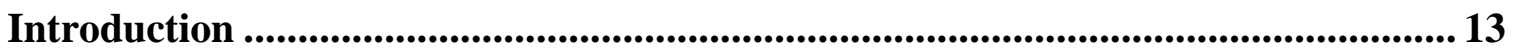

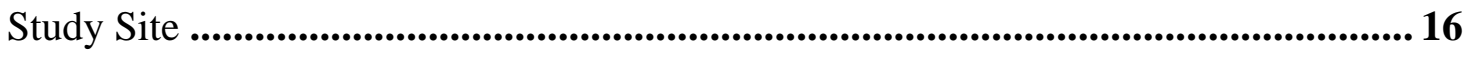

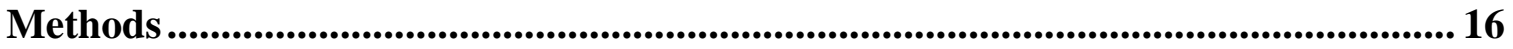

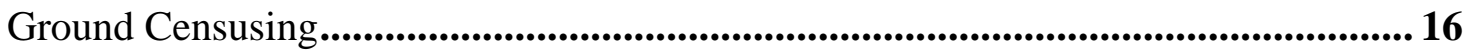

Aerial Censusing - Image Collection, Pre-processing and Crown Segmentation......... 17

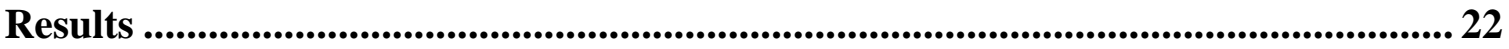

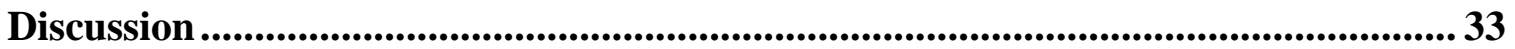

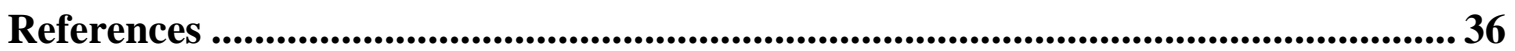

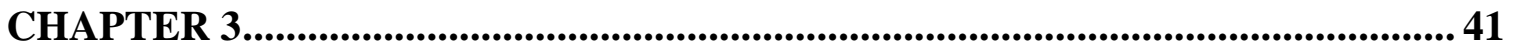

Multitemporal censusing of a population of eastern hemlock (Tsuga canadensis L.) from remotely sensed imagery using an automated segmentation and reconciliation procedure. .................................................................................................4 41 


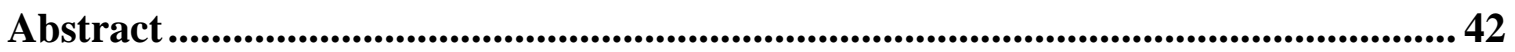

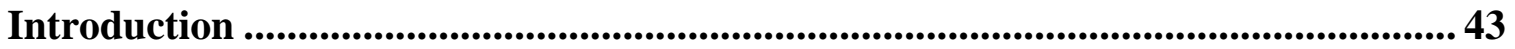

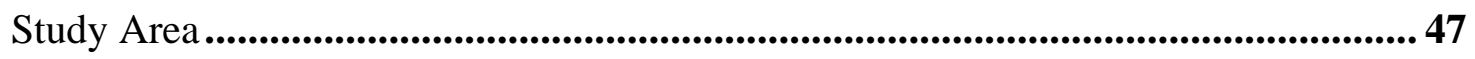

Methods ................................................................................................................. 48

Image Collection, Pre-processing, and Ground Data Collection.................................... 48

Manual Crown Segmentation ........................................................................ 48

Automated Spatial Segmentation............................................................................. 49

Shadow Thresholding.............................................................................................................. 50

EDM Construction and Manipulation.................................................................5 51

Watershed Segmentation .........................................................................5 52

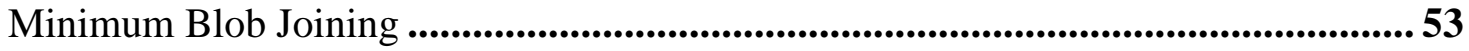

Automated Crown Reconciliation ................................................................................ 58

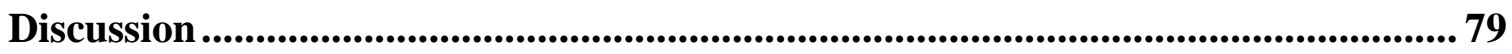

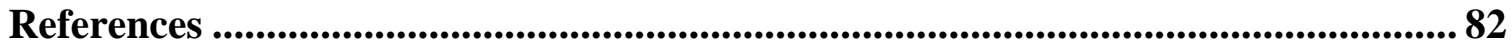

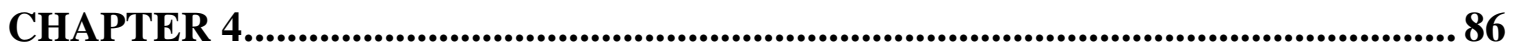

A comparison of population models for eastern hemlock (Tsuga canadensis $\mathbf{L}$.)

derived from ground and remotely sensed data. .......................................................... 86

Abstract ......................................................................................................... 87

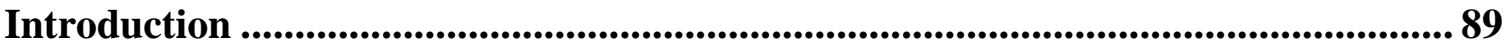

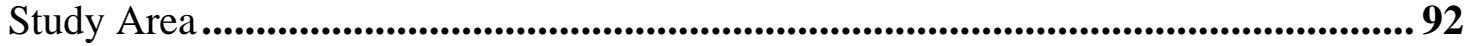

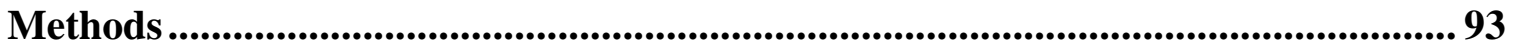

Data Set Development - Ground.............................................................................93

Data Set Development - Remote Sensing ..............................................................94

Matrix Model.................................................................................................96

Life Cycle Comparisons................................................................................97

Parameter Estimates - Ground ....................................................................... 100

Parameter Estimates - Remote Sensing ..................................................................... 103

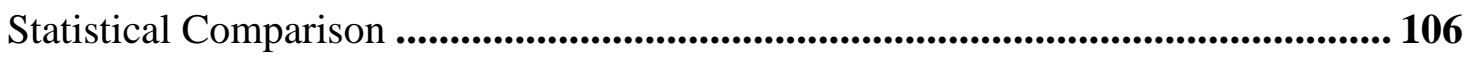

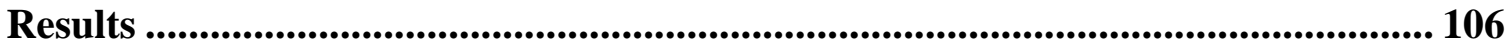


Discussion .......................................................................................................... 118

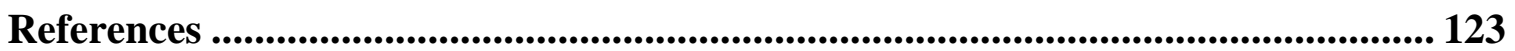

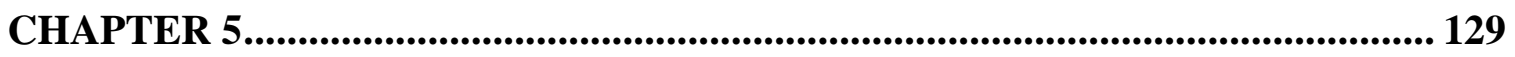

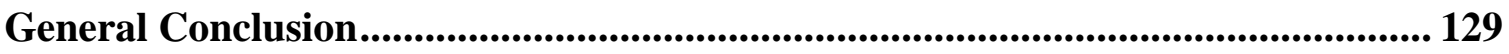

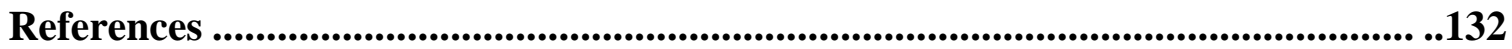

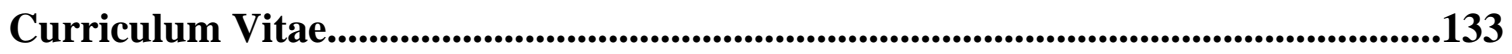




\section{LIST OF FIGURES}

\section{CHAPTER 2}

Figure 2.1. Section of study site from March, 1997 image

Figure 2.2. Size distribution of hemlock population - ground census........................ 28

Figure 2.3. Hemlock crown position - ground census......................................... 29

Figure 2.4 Size distribution of hemlock population - aerial census......................... 30

Figure 2.5. Size comparison of hidden and visible layers of the hemlock population -

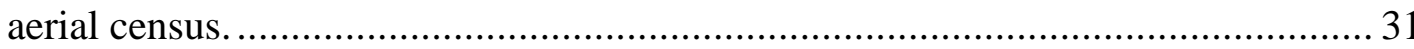

Figure 2.6. Crown density comparison of hidden and visible layers of hemlock population - aerial census.

Figure 2.7. Crown position comparison of hidden and visible layers of hemlock population - aerial census.

\section{CHAPTER 3}

Figure 3.1. Hemlock clump following Euclidean distance mapping, a) 3-D view with arrows pointing to false maxima, b) 2-D view.

Figure 3.2. Effects of EDM manipulations, a) original, b) smoothing ,c) elevation. ....... 56

Figure 3.3. 3X3 moving window in watershed segmentation considers fate of the central pixel based on a table of the 256 possible configurations of its 8 neighbors. In examples, a) pixel turned "off" to prevent connection between currently separated features, b) pixel turned "on" due to previous diagonal connection between hemlock feature. Light squares represent non-hemlock cover. Darker squares represent hemlock cover. 
Figure 3.4. Reconciliation process. a) non-reconciled blobs from both time periods, b) overlaid pixels classified as joint-year (green) single-year - 1997 only (red) or single-year - 1998 only (blue), c) patches of pixels combined into parcels (black) and subject to reconciliation, $\mathrm{d}$ ) reconciled blobs from both time periods

Figure 3.5. Reconciliation decision making. Solid lines represent actions of dual-year parcels. Dash lines represent actions of the single parcels

Figure 3.6. Reconciliation procedure considers a parcel (black) that has been segmented into different crown blobs for 1997 and 1998. The difference in blob assignment between image years is due to the change in size and shape of blob B in 1998 due to an ice storm. Measurements (in pixels) of parcel size and common boundary sizes for both years are shown. Dual connectivity (using Equations \#1 and \#2) is calculated as $13 * 10^{5}$ with blob A and $7.4 * 10^{5}$ with blob B. Since the parcel's greatest connectivity $\left(13 * 10^{5}\right.$ with blob A) $\geq \Psi_{1}$, the joint parcel was assigned to blob A on both 1997 and 1998 maps (see Figure 3.4d)...

Figure 3.7. Accuracy assessment using 1:1 correspondence. a) overlays manual crowns on automated blobs, arrows point to blobs which contain $\geq 50 \%$ of overlaid crown, Aerial accuracy $=(1)$ 1:1 Corresponding Blob/ 3 Total Blobs $=33 \%$, b) overlays automated blobs on manual crowns, arrows point to crowns which contain $\geq 50 \%$ of overlaid blob, Field accuracy $=(1)$ 1:1 corresponding crown/3Total crowns $=33 \%$. Total accuracy $=(2)$ 1:1 corresponding blobs and crowns/ 6 Total blobs and crowns $=33 \%$. Interestingly and, perhaps misleadingly, whole plot accuracy for this example is $100 \%$ (3 crowns/3 blobs)..

Figure 3.8. Effect of varying threshold shadow size on overall accuracy, training plot, 1998 data from 1998/1997 image pair and 1998/99 image pair

Figure 3.9. Effect of varying minimum blob size on 0:1 correspondences for automated blobs and manual delineated crowns, 1998 hemlocks (1998-99 image pair).............76 


\section{CHAPTER 4}

Figure 4.1. Life cycle of a) individuals censused from ground and b) blobs censused from

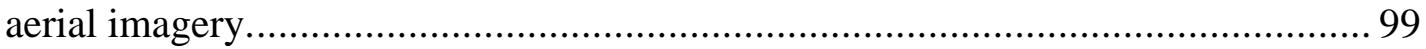

Figure 4.2. Blob size distribution. Note the relative balance between numbers of blobs on either side of category boundaries.............................................................. 113

Figure 4.3. Comparison of total hemlock pixels classified from the aerial imagery, 199798 and 1998-99 image pairs.

Figure 4.4 Hemlock canopy density changes between 1997-98 and 1998-99, ground data. 


\section{LIST OF TABLES}

\section{CHAPTER 2}

Table 2.1. Assessing the spectral classification accuracy of the Evergreen Vegetation class using the global fusion and single independent classification methods, 1998 image.

Table 2.2. Composition of Evergreen Vegetation class (from the global fusion classification method) as determined by ground referencing. 26

\section{CHAPTER 3}

Table 3.1. Automated reconciliation procedure. $\Psi_{1}, \Psi_{2}, \Psi_{5}$ were estimated from training data and represent a threshold connectivity value that resulted in the highest measure of overall accuracy. $\Psi_{3}$ and $\Psi_{4}$ were calculated from $\Psi_{1}$ and $\Psi_{2}$ respectively, both sharing the same type of connectivity equation and parcel type. $\Psi_{3}$ and $\Psi_{4}$ reflect the added boundary scanning areas of these two measures: $\boldsymbol{\Psi}_{3}=\boldsymbol{\Psi}_{1} * 0.51$ and $\boldsymbol{\Psi}_{4}=\boldsymbol{\Psi}_{2} *$ 0.36 .

Table 3.2. Accuracy assessment - automated blob segmentation procedure (1998 data for 1997/1998 image pair) 76

Table 3.3. Accuracy assessment - automated blob segmentation procedure (1998 data for 1998/1999 image pair)

Table 3.4. Threshold connectivity values $(\Psi)$ for reconciliation procedure. $\Psi$ values shown equal $\Psi_{\mathrm{X}} 10^{5}$

Table 3.5. Accuracy assessment - automated blob reconciliation procedure (1998 data for 1997/1998 image pair) 78 
Table 3.6. Accuracy assessment - automated blob reconciliation procedure (1998 data for

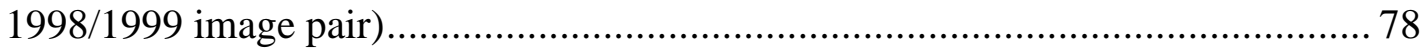

\section{CHAPTER 4}

Table 4.1. Hemlock population matrices derived from aerial data sets......................... 111

Table 4.2. Hemlock population matrices derived from ground data sets....................... 112

Table 4.3. Effect on $\lambda$ of balanced growth and regression transitions between adjacent size classes, 1998-99 aerial derived matrix. ......................................................... 113

Table 4.4. Population characteristics predicted from aerial derived matrices................ 114

Table 4.5. Population characteristics predicted from ground derived matrices. ............ 115 


\section{CHAPTER 1}

\section{General Introduction}

The collection of basic demographic data for assessing population dynamics is of immediate importance regarding species conservation (Lande 1988). Given the alarming rise in the number of threatened species, conservation biologists face an increasing challenge to gather this basic demographic information (Schemske et al. 1994). One of the problems facing conservationists is the large investment in time and money that the typical demographic study demands (Silvertown et al. 1996). Consequently, the numbers of demographic studies conducted are few in comparison to the scientific needs of the conservation community. The demographic studies that are completed typically are characterized by small sample sizes and sampling areas.

Remote sensing provides ecologists with a powerful tool to rapidly obtain spatially explicit data on the vegetation of a large area. At community, landscape, and regional scales, many studies have used imagery from space-based sensors to describe the structure and dynamics of vegetation (Tucker et al. 1985, Ustin et al. 1986, Congalton et al. 1993). Investigations at the level of the plant population have been far more limited (McGraw et al. 1998). At present, high spatial resolution imagery provided by aircraftbased photographic systems appears to provide data at a scale most feasible for the study of vegetation at the population level (Gougeon 1995b, Niemann 1995), although recently launched space-based platforms (i.e. IKONOS and QuickBird) are approaching the resolution required to discern individuals (Kramer 2002). 
The lack of quantitative descriptions of plant populations from both the aerial and ground perspective reflects both the scarcity of population-level investigations that have been conducted using remote sensing and the shortage of accurate and appropriate ground data; a problem that for many remote sensing applications has resulted in the lack of its acceptance in many areas of study (Congalton 1991). A fundamental step towards the increased use of air and space-based sensors to collect demographic data on tree populations is the understanding of the similarities and differences of population censuses conducted from both the aerial and ground perspective.

Given the potential size of remotely sensed data sets and the extensive time requirements of ground referenced, manually delineated crown segmentation methods, there exists a basic need to develop an automated segmentation procedure to delineate the individual components of a population. For different forested imagery, the interaction between forest canopy and incident sunlight can result in a variety of different attributes to assist in the separation of individual tree crowns. Local minima reflectance values, due to shadows between individual crowns (Gougeon 1995b), local maxima reflectance values representing the tops of upper canopy trees (Pinz 1991), crown size (Lahav-Ginott et al. 2001) and crown shape characteristics (Pollock 1998) have all been used to segment individual tree crowns. Often a multi-step procedure utilizing more than one crown attribute has proven most effective (Pinz 1991, Gougeon 1995b, Brandtberg and Walter 1998, Pollock 1998). 
Repeated measurements of the same features over time allow for the investigation of the vegetation dynamics of an area. "Post-classification comparison" change detection techniques have been used to investigate the dynamics of wetlands (Jenson et al. 1995), large-scale deforestation (Malingreau and Tucker 1988) and forest succession (Hall et al. 1991).

Tree population dynamics can be investigated through repeated measurements of individuals within a population over time (Usher 1972, Hartshorn 1975, Enright and Ogden 1979, Martinez-Ramos 1989). The challenge to an ecologist is how to adapt the traditional methods of description and classification to be compatible with the nature of remotely sensed data (Graetz 1990). The basic unit traditionally used to describe populations has been the individual. Yet, the modular, as opposed to unitary, construction of most plants has long been recognized (Harper 1976). Using this modular approach the fundamental unit of a tree population may be regarded as any repeating unit of construction such as a tree branch or branches (Huenneke and Marks 1987, McGraw 1989).

Matrix population models have become the framework of choice in plant demographic studies due, in part, to the number of informative statistics provided by matrix analysis (Silvertown et al. 1996). Matrix models have been used to investigate the conservation of rare and threatened species (Menges 1990, Allphin and Harper 1997, Kaye et al. 2001), the control of invasive species (Golubov et al. 1999, Parker 2000), evolutionary change (Baptista et al. 1998) and species persistence in rapidly changing environments (Silvia et 
al. 1991). In constructing the matrix model, matrix elements usually describe the transition probability of individuals between life stages. Matrix models have also been constructed to describe the transition probabilities of plant parts (Huenneke and Marks 1987, McGraw 1989), pixels (Hall et al. 1991), and spatial units (Guàrdia et al. 2000).

This dissertation represents the first attempt to use remotely sensed imagery to describe and model the dynamics of a plant population. In the first study, a population of eastern hemlock (Tsuga canadensis L.) was censused on the ground using traditional field methods and from low elevation aerial photography. Sampling from the aerial imagery was completed by spectrally segmenting the evergreen vegetation from other ground covers and then manually delineating ground referenced, individual hemlock crowns on the binary image. The potential value of remote sensing in the construction of population databases for analysis of the structure and dynamics of plant populations is evaluated by comparing and contrasting these two data sets.

In the second study, a new automated spatial segmentation procedure is introduced using crown shape and size characteristics to divide the hemlock population into individual population units or blobs. This procedure was performed independently on spectrally segmented, binary images produced from low elevation color aerial photography.

To investigate population change over time, tree blobs need to be unique and comparable at different census periods. Due to hemlock shape changes between years, not all segmentation lines produced by spatial segmentation were identical; parcels of hemlock 
pixels were sometimes assigned to different blobs for different years preventing the meaningful comparison of data sets. An automated reconciliation procedure was developed to consider all such "cross identified" pixels and to re-assign them to ensure that the same pixels are assigned to the same unique blobs for comparable time periods. Reconciliation was performed on two sets of image data, 1997/1998 and 1998/1999 image pairs.

The results of the automated segmentation and reconciliation procedures were compared to ground referenced, manual segmentation methods performed on the same population. The intent of our work was to develop a set of automated procedures to extract from same scene, multi-temporal, remotely sensed imagery a series of population data sets that can be used in the monitoring and modeling of population dynamics.

In the third study, two matrix population models of the hemlock population are constructed. Parameters for one of these models were estimated from demographic data collected on the ground using traditional field methods. Parameters for the other model were estimated from demographic data extracted from low elevation aerial imagery. The results of analysis using these aerial and ground-derived matrices were compared. The ability of matrix models constructed from both perspectives to detect and quantify population change and assist in the understanding of the causes of change was evaluated. The benefits of incorporating demographic data extracted from remotely sensed imagery into future population investigations is discussed. 


\section{References}

Allphin, L., and K. T. Harper. (1997), Demography and life history characteristics of the rare kechina daisy (Erigeron kechinensis, Asteraceae). American Midland Naturalist 138:109-120.

Baptista, W. B., W. J. Plat, and R. C. Macchiavelli. (1998), Demography of a shadetolerant tree (Fagus grandifolia) in a hurricane-disturbed forest. Ecology 79:3853.

Brandtberg, T., and F. Walter. (1998), An algorithm for delineation of individual tree crowns in high spatial resolution aerial images using curved edge segments at multiple scales. in D. A. Hill and D. G. Leckie, editors. International Forum: Automated Interpretation of High Spatial Resolution Digital Imagery for Forestry. pp. 41-54 Natural Resources Canada, Victoria, British Columbia.

Congalton, R. G. (1991), A review of assessing the accuracy of classifications of remotely sensed data. Remote Sensing of Environment 37:35-46.

Congalton, R. G., K. Green, and J. Teply. (1993), Mapping old growth forests on National Forest and park lands in the Pacific Northwest from remotely sensed data. Photogrammetric Engineering and Remote Sensing 59:529-535.

Enright, N., and J. Ogden. (1979), Applications of transition matrix models in forest dynamics; Araucaria in Papua New Guinea and Nothofagus in New Zealand. Australian Journal of Ecology 4:3-23.

Golubov, J., M. D. Mandujano, M. Franco, C. Montana, L. E. Eguiarte, and J. LopezPortilla. (1999), Demography of the invasive woody perennial Prosopis glandulosa (Honey mesquite). Journal of Ecology 87:955-962. 
Gougeon, F. A. (1995), A crown-following approach to the automatic delineation of individual tree crowns in high spatial resolution aerial images. Canadian Journal of Remote Sensing 21:274-284.

Graetz, R. D. (1990), Remote sensing of terrestrial ecosystem structure: an ecologist's pragmatic view, in Remote sensing of biosphere functioning. Edited by R. J. Hobbs and H. A. Mooney. Springer-Verlag, New York pp. 7-30.

Guàrdia, R., José Raventós, and Hal Caswell. (2000), Spatial growth and population dynamics of a perennial tussock grass (Achnatherum calamagrostis) in a badland area. Journal of Ecology 88:950-963.

Hall, F. G., D. B. Botkin, D. E. Strebel, K. D. Woods, and S. J. Goetz. (1991), Largescale patterns of forest succession as determined by remote sensing. Ecology 72:628-640.

Harper, J. L. (1976), The concept of population in modular organisms, in Theoretical Ecology. Principles and Applications. Edited by R. M. May. Blackwell Scientific Publications, Oxford pp. 53-77.

Hartshorn, G. S. (1975), A matrix model of tree population dynamics, in Tropical Ecological Systems. Edited by F. B. Golley and E. Medina. Springer-Verlag, New York pp. 41-51.

Huenneke, L. F., and P. L. Marks. (1987), Stem-dynamics of the shrub Alnus incanta ssp. rugosa: transition matrix models. Ecology 68:1234-1242.

Jenson, J. R., K. Rutchey, M. S. Kock, and S. Narumalani. (1995), Inland wetland change detection in the Everglades Water Conservation Area 2A using a time series of 
normalized remotely sensed data. Photogrammetric Engineering and Remote Sensing 61:199-209.

Kaye, T. N., K. L. Pendergrass, K. Finley, and J. B. Kauffman. (2001), The effect of fire on the population viability of an endangered prairie plant. Ecological Applications 11:1366-1380.

Kramer, H. J. (2002), Observation of the Earth and its Environment - Survey of Missions and Sensors, 4th edition. Springer Verlag.

Lahav-Ginott, S., R. Kadmon, and M. Gersani. (2001), Evaluating the viability of Acacia populations in the Negev Desert: a remote sensing approach. Biological Conservation 98:127-137.

Lande, R. (1988), Genetics and demography in biological conservation. Science 241:1455-1460.

Malingreau, J. P., and C. J. Tucker. (1988), Large-scale deforestation in the southeastern Amazon Basin of Brazil. Ambio 17:49-55.

Martinez-Ramos, M., Elena Alvarez-Buylla, and Jose Sarukhan. (1989), Tree demography and gap dynamics in a tropical rain forest. Ecology 70:555-558.

McGraw, J. B. (1989), Effects of age and size on life histories and population growth of Rhododendron maximum shoots. American Journal of Botany 76:113-123.

McGraw, J. B., T. A. Warner, T. Key, and W. Lamar. (1998), Advances in high resolution remote sensing for forest ecological studies. Trends in Ecology and Evolution 13:300-301.

Menges, E. S. (1990), Population viability analysis for an endangered plant. Conservation Biology 4:52-62. 
Niemann, K. O. (1995), Remote sensing of forest stand age using airborne spectrometer data. Photogrammetric Engineering and Remote Sensing 61:1119-1127.

Parker, I. M. (2000), Invasion dynamics of Cytisus scoparius. A matrix model approach. Ecological Applications 10:726-743.

Pinz, A. J. (1991), A computer vision system for the recognition of trees in aerial photographs. in T. Tilden, editor. Multisource Data Integration in Remote Sensing. pp. 111-124 NASA Conference.

Pollock, R. (1998), Individual tree recognition based on a synthetic tree crown image model. in D. G. Leckie and D. A. Hill, editors. International Forum: Automated Interpretation of High Spatial Resolution Digital Imagery for Forestry. pp. 25-34 Natural Resources Canada, Canadian Forest Service, Victoria, British Columbia.

Schemske, D. W., B. C. Husband, M. H. Ruckelshaus, C. Goodwillie, I. M. Parker, and J. G. Bishop. (1994), Evaluating approaches to the conservation of rare and endangered plants. Ecology 75:584-606.

Silvertown, J., M. Franco, and E. Menges. (1996), Interpretation of elasticity matrices as an aid to the management of plant populations for conservation. Conservation Biology 10:591-597.

Silvia, J. F., J. Raventos, H. Caswell, and M. C. Trevisan. (1991), Population responses to fire in a tropical savanna grass. Journal of Ecology 79:345-355.

Tucker, C. J., J. R. G. Townsend, and T. E. Goff. (1985), African land-cover classification using satellite data. Science 227:369-375. 
Usher, M. B. (1972), Developments in the Leslie matrix model, in Mathematical Models in Ecology. Edited by J. N. R. Jeffers. Blackwell Scientific Publications, Oxford pp. 29-60.

Ustin, S. L., J. B. Adams, C. D. Elvidge, M. Rejmanek, B. N. Rock, M. O. Smith, R. W. Thomas, and R. A. Woodward. (1986), Thematic mapper studies of semiarid shrub communities. Bioscience 36:446-456. 


\section{CHAPTER 2}

A comparison of a population census of eastern hemlock (Tsuga canadensis $L_{\text {.) }}$ on the ground and using aerial photography. ${ }^{1}$

${ }^{1}$ This chapter formatted according to author's instructions for submission to Canadian Journal of Remote Sensing. 


\begin{abstract}
A population of eastern hemlock (Tsuga canadensis L.) was censused from the ground using traditional field methods and from the air using large scale, high-resolution, aerial photography. A spectral classification procedure combined with the manual delineation of individual tree crowns was used to extract census data from the aerial imagery. A comparison of the different censusing methods found that over $60 \%$ of the individuals measured on the ground were not detected in the aerial census. Tree size, crown density and crown position all played roles in determining a crown's visibility from the air. Both the aerial and ground census described a population whose size distribution was skewed with the smaller size classes having the greatest representation. The size measurements of hemlocks visible from the air positively correlated with the ground-based size measurements of the same individuals. Nearly all large, upper canopy hemlocks were visible in the aerial census. An important minority of small, lower canopy hemlocks were also visible in the aerial census. Although providing different information than traditional ground methods, population censusing using remotely sensed imagery has the potential to provide valuable information about the structure and dynamics of tree populations at scales unobtainable from more conventional methods.
\end{abstract}




\section{Introduction}

Remote sensing provides ecologists with a powerful tool to rapidly obtain spatially explicit data on the vegetation of a large area. At community, landscape, and regional scales, many studies have used imagery from space-based sensors to describe the structure and dynamics of vegetation (Tucker et al. 1985, Ustin et al. 1986, Congalton et al. 1993). At a more detailed scale, investigations of the structure and dynamics of plant populations have been far more limited (McGraw et al. 1998).

Understanding the factors that determine population structure and dynamics remains a central issue in ecology, with important consequences for the conservation of rare and threatened species (Menges 1990, Allphin and Harper 1997, Kaye et al. 2001), the control of invasive species (Golubov et al. 1999, Parker 2000), evolutionary analysis (Baptista et al. 1998) and species persistence in rapidly changing environments (Silvia et al. 1991). The value of basic demographic data for assessing species survival is of immediate importance (Lande 1988). Given the alarming rise in the number of threatened species, conservation biologists face an increasing challenge to gather this basic demographic information (Schemske et al. 1994).

To a large extent, the lack of remote sensing studies at a population level can be attributed to the relatively coarse spatial resolution of the commonly used space-based sensors that provide information about patterns at scales that are not easily amenable to population studies. For example, Landsat-TM, with its instantaneous field of view of 30 X 30m, precludes the extraction of information about the basic unit of many demographic 
studies, the individual. At present, high spatial resolution imagery provided by aircraftbased photographic systems appears to be more feasible than space-based sensors when attempting to obtain information about individuals within a tree population (Gougeon 1995b), although recently launched platforms (i.e. IKONOS and QuickBird) are beginning to approach the resolution required to discern individuals (Kramer 2002).

It has long been recognized that the data provided by remote sensors differs from the data collected in traditional field studies. Even using large scale, high resolution aerial imagery, visual crown detection by trained photointerpreters can differ considerably from ground censused data (Leckie and Gougeon 1998). One difference is that not all segments of a population may be detected from aerial imagery. Small individuals, and individuals located underneath the upper canopy of larger individuals, may be hidden from aerial view even in scattered populations growing in open environments (LahavGinott et al. 2001, Landenberger and McGraw 2003). Population censusing is even more problematic in closed forest environments, sometimes leading to the measurement of only the well-defined and thus, more easily distinguished, individual tree crowns within the forest (Herwitz 1998).

The challenge to an ecologist is how to adapt the traditional methods of description and classification to be compatible with the nature of remotely sensed data (Graetz 1990). At a population level, a fundamental step toward such an adaptation is understanding the similarities and differences presented by censusing a population from the air and on the ground. The lack of quantitative descriptions of plant populations from both perspectives 
exemplifies the lack of accurate and appropriate ground referenced data for many remote sensing applications; a problem which has resulted in the lack of its acceptance in many areas of study (Congalton 1991).

The effectiveness of the spectral classification of plant species from remotely sensed imagery depends on the spectral distinctiveness of the species under investigation (Gougeon 1995a). For spectrally distinctive populations, gray-level thresholding can be sufficient for successful classification (Lahav-Ginott et al. 2001). In more diverse environments, species classification can be assisted by phenological differences between different species (Key et al. 2001). Supervised classification using a maximum likelihood classification algorithm is the most common method of spectral classification of remotely sensed images (Richards 1993). The development and application of representative and distinctive spectral signatures for the classes under investigation is critical for accurate classification (Gougeon 1995a). To take advantage of multitemporal images over the same scene, the development of an effective data fusion method may improve classification accuracy compared to standard techniques applied to single-date images (Brezzone et al. 1999).

In this investigation, we census a population of eastern hemlock (Tsuga canadensis L.) on the ground using traditional field methods and from low elevation aerial photography by spectrally segmenting evergreen vegetation from other ground covers and then manually delineating the boundaries between individual hemlock crowns and between hemlock and other evergreen vegetation. By comparing and contrasting these two census 
methods we evaluate the potential value of remote sensing for population description and the investigation of population dynamics.

\section{Study Site}

A 3 ha (100 m X 300 m) study site was located in the Limberlost-Whiteoak Canyon area of Shenandoah National Park ( $38^{\circ} 34^{\prime} \mathrm{N}, 78^{\circ} 22^{\prime} \mathrm{W}$ ). This site is located in an upper elevation $(951 \mathrm{~m})$ mixed hardwood/hemlock forest. Eastern hemlock, a major component of this forest, is a large, slow-growing tree that is extremely shade tolerant. Small hemlock may be suppressed beneath an upper canopy of hemlock or hardwoods for hundreds of years and remain in good condition (Godman and Lancaster 1990). Like all hemlocks within Shenandoah, the Limberlost-White Oak Canyon population has been adversely impacted in recent years by the presence of the hemlock woolly adelgid (Adelges tsugae) whose occurrence was first reported in the park in 1988. This adelgid, which is believed to inject a toxic saliva into the hemlocks while feeding (Souto 1996), currently infests populations in many Northeastern and Mid-Atlantic states. Unlike hemlocks in other park locations, most trees within the study site had only suffered mild to moderate defoliation at the time of aerial sampling.

\section{Methods}

\section{Ground Censusing}

Hemlock trees within the study site were censused in the spring of 1997, 1998, and 1999. All hemlock trees, with a diameter at breast height $(\mathrm{dbh}$, breast height $=1.3 \mathrm{~m}) \geq 5.0 \mathrm{~cm}$, were tagged, measured (dbh), classified according to crown density class $(\leq 10 \%, 11$ - 
$50 \%,>50 \%$ ), classified according to crown position (dominant/codominant, intermediate or suppressed) and located on an X-Y grid map. Crown density was defined as the amount of foliage that blocks light visibility through the crown (Miller et al. 1992). The crown diameters of all hemlock trees $(\mathrm{dbh} \geq 5.0 \mathrm{~cm}$ ) within a 1.48 ha sub-plot of the study site were measured. Crown diameter was defined as the average horizontal distance between the widest points of the crown and its perpendicular axis and was measured on the ground by sighting a vertical line to the ground from branch tip to branch tip.

Aerial Censusing - Image Collection, Pre-processing and Crown Segmentation Large scale $(1: 3,000)$ color aerial photographs of the study site were collected on March 27, 1997, April 13, 1998, and March 31,1999 using a calibrated Leica/Wild Heerbrugg RC-30 mapping camera with a $303.860 \mathrm{~mm}$ focal-length lens. The photography was acquired before the emergence of new foliage for the deciduous forest component. The color photographs were scanned at 600 dpi using a Agfa Dual Scan scanner to produce high resolution ( $\sim 13 \mathrm{~cm} /$ pixel) digital images (Figure 2.1).

Geometric registration of the three images was performed using image to image registration with one image (1998) designated as the master image and the other two images (1997 and 1999) as slave images. Within all three multitemporal images, shared primary branch bifurcation points (BBP's) were identified as control points (Herwitz 1998). These points, located at the junction of primary tree branches and the central bole, maintain the same position over time relative to this primary bole due to the apical growth of the leading shoots of trees. Special emphasis was placed on achieving a good distribution of control points throughout the images. A total of 34 shared BBP's were 
located on the 1998-99 image pair and utilized as control points. Twenty-three shared BBP's were found and utilized on the 1997-98 image pair. After identification of control points, co-registration was performed using second order mapping polynomials and cubic convolution resampling (Research Systems 2000).

Due to differences in atmospheric conditions, sun illumination angles, and other environmental factors, the three multitemporal images exhibited different brightness values for similar locations. In order to minimize these differences between images a histogram matching procedure (Richards 1993) was applied to match the histograms of the 1997 and 1998 images to the 1999 histogram (Research Systems 2000).

The manual delineation of irregular tree crowns on large scale imagery is not an errorfree task. Measurements of isolated tree crowns using spectral segmentation procedures have been found to produce more accurate estimates of size than manual delineation (Lahav-Ginott et al. 2001). Hence, prior to the manual delineation of boundaries between individual hemlock crowns and between hemlock and other evergreen vegetation, a supervised classification procedure was used to spectrally segment the evergreen vegetation from the other ground cover classes.

The effectiveness of spectral classification methods is dependent on the accurate and representative characterization and application of the class signatures. The timing of the aerial sampling was planned to simplify the separation of deciduous and evergreen vegetation. All efforts to spectrally segment hemlock from the other evergreen 
vegetation within the plot proved unsuccessful due to the coarse spectral resolution of the imagery and the resultant overlapping spectral signatures of hemlock and the other three evergreen species present - mountain laurel (Kalmia latifolia), red spruce (Picea rubens), and white pine (Pinus strobus).

Two methods of spectral classification were evaluated, a local independent method and a global fusion method. In the first method, local class signatures were developed for and applied independently to each of the three multitemporal images. Four ground cover classes were established: Evergreen Vegetation, White Ground Cover and Branches, Brown Ground Cover and Branches, and Deep Shadows. Three band signatures for each of these four cover classes were developed. Due to illumination differences within the images, numerous training fields, located in different regions of the image, were chosen to develop the local class statistics for each ground cover class.

The second method of classification, a global fusion approach, was applied to assess the possible advantages of utilizing the multitemporal data sets over the same scene (Jeon and Landgrebe 1999). As with the previous method, local class statistics were developed for each ground cover class in each multitemporal image. Global class decisions were then reached by applying the local class statistics developed for all the multitemporal images to each image and then summarizing class decisions by cover class. For example, the global Evergreen Vegetation spectral class derived from the 1998 image was the sum of local Evergreen Vegetation class decisions derived from signatures developed from all three multitemporal images and applied to the 1998 image. Classification of all images 
was completed using a maximum likelihood classification algorithm (Research Systems 2000).

We assessed the accuracy of spectral classification using independent and fused class decisions by calculating standard "pixel-based" measures of classification accuracy (user's accuracy, producers accuracy, and overall accuracy). Ground reference data for this assessment was collected from three randomly placed transect lines located in the upper, middle, and lower thirds of the study site. The ground reference maps were prepared in the field by manually identifying hemlock pixels on the scene image. The gathering of ground reference data to assess the accuracy of remotely sensed classifications is never completely accurate (Congalton 1991, Lillesand 1994). The small size of each map pixel $\left(\sim 13 \mathrm{~cm}^{2}\right)$, the vertical nature of hemlock crowns, and the different viewing perspectives of the sensor from the air and the human on the ground, all present a significant challenge to the preparation of accurate ground reference maps. Therefore, considerable time was spent on field collection to ensure that the ground reference data was as accurate as possible.

Following spectral segmentation, the manual delineation of boundaries between individual hemlock crowns and between hemlock crowns and other types of evergreen vegetation was completed, aided by the use of multiple years of aerial images and multiple images from different viewing angles each year. The considerable intertwining of branches between adjacent crowns due to the flexible branch architecture of hemlock presented another challenge to precise delineation. A ground-referenced hemlock crown 
survey map was prepared in the spring of 1998 from the 1998 image. All comparisons of ground and aerial censuses in this study were thus made with respect to the 1998 dataset. Other data collected during the course of this investigation will be utilized in future efforts to develop an automated crown segmentation procedure.

Studies have shown a significant statistical relationship between ground measurements of tree size and aerial measurements of tree size (Minor 1951, Aldred and SaynWittgenstein 1972, Hagan 1986). These studies have often been performed in plantation settings where individual crowns are, typically, more widely and evenly spaced than the crowns of less managed forests. A clumped distribution of trees presents the potential for increased aerial measurement errors due to the shading of a portion of the crown by adjacent neighbors. The Pearson product-moment correlation was used to investigate the relationship between the two ground measurements of size (dbh and crown diameter) and the aerial measure of size (crown area).

Many of the smallest patches of Evergreen Vegetation within the aerial imagery were separated at such a distance from any identified hemlock crown that they could not be linked with certainty to any one crown. These smallest patches represent isolated hemlock branches separated from the main crown by shadows or other ground covers, crowns belonging to hemlocks with a $\mathrm{dbh}<5 \mathrm{~cm}$, or branches of Kalmia latifolia, whose canopies, because of internal shading, tend to be dissected into small, discontinuous patches. Because of the uncertain identity and relative insignificance of these smallest patches, a crown threshold size was established. Only crowns larger than this threshold 
were considered for further comparison and description. This crown threshold size was selected as the smallest crown size predicted from the minimum ground-based size measurement (dbh) of hemlock and the least squares regression of dbh and crown area.

The size distributions of the hemlock population censused on the ground and from aerial imagery were described. The crown position structure of the population, as sampled from the ground, was also described. Comparisons were made between the portion of the population hidden from the air and the portion of the population visible from the air. The size structure, crown density structure and crown position structure for both the hidden and visible portions of the population were described.

\section{Results}

Registration using second order mapping polynomials and cubic convolution resampling resulted in a root mean square (RMS) error of 2.8 pixels $(\sim 36 \mathrm{~cm})$ for the 1998-99 image pair and a RMS error of 2.6 pixels $(\sim 34 \mathrm{~cm})$ for the 1997-98 image pair.

The spectral segmentation of the Evergreen Vegetation using the global fusion classification method resulted in higher overall and user's accuracies than classification using the local independent method (Table 2.1). In general, class decisions using only local, independently applied signatures tended to result in a higher level of commission errors (classifying non-Evergreen Vegetation pixels as Evergreen Vegetation). Confusion in discriminating Evergreen Vegetation from Brown Ground Cover and Branches contributed to these errors. The additional class statistics used by the global fusion method appears to have provided a more representative description of the spectral 
variability within the Evergreen Vegetation class. Due to the higher overall accuracy of the global fusion method, the manual delineation of hemlock crowns and all further analysis was performed only on images spectrally segmented using this method.

A positive correlation was found between the measure of hemlock size from the aerial image (crown area) and the two measures of size on the ground, $d b h(r=0.7762, N=584$, $\mathrm{P}>0.0001)$ and crown diameter $(\mathrm{r}=0.7577, \mathrm{~N}=310, \mathrm{P}<0.0001)$.

The regression of crown area on dbh resulted in a regression equation of:

Crown area $($ in pixels $)=46.7124+31.6562(\mathrm{dbh}) \quad$ Equation 2.1

Substituting the minimum dbh sampling size of $5 \mathrm{~cm}$ into this regression equation, a threshold crown size of 205 pixels (diameter $\sim 2.1 \mathrm{~m}$ ) was established. On aerial images, contiguous hemlock patches below this size, many of which could not be accurately traced to any single hemlock crown, were considered noise and eliminated from further consideration.

The ground reference data showed that a large majority of the spectrally classified Evergreen Vegetation in the aerial image was hemlock (Table 2.2). Of this hemlock cover, $97.02 \%$ could be traced to a specific hemlock crown. The remaining $2.98 \%$ of the hemlock ground cover could not be traced back to any one individual crown but, rather, 
belonged to small, clumped hemlock trees whose interspersing branches made crown segmentation impossible despite field efforts.

Within the study site, 1,401 hemlock individuals ( $\mathrm{dbh} \geq 5 \mathrm{~cm}$ ) were censused on the ground in 1998. The size distribution of this population (Figure 2.2) is consistent with the known life history of hemlock, a slow growing, and shade tolerant species with a lengthy suppressed sapling stage. Seventy-five percent of the hemlocks sampled in the study site were located in the forest lower canopy (Figure 2.3).

A total of 547 hemlock crowns were manually delineated in the aerial censusing. Like the same population censused from the ground, the size distribution of the aerially censused hemlocks was skewed with smaller sized individuals making up the majority of the population (Figure 2.4). Many hemlocks censused on the ground were not visible from the air; $\sim 61 \%$ percent of the hemlock individuals sampled on the ground were hidden in the aerial image. Most of these hidden hemlock trees were members of the smallest size classes and located under an upper canopy of dense and/or large hardwood branches, hemlock crowns, and shadows (Figure 2.5). In contrast, most larger hemlocks trees ( 279 of 294 individuals with a dbh $>25 \mathrm{~cm}$ ) were visible from the air.

Although size was an important factor in determining a tree's visibility from the air, other crown characteristics played roles as well. Trees with sparse crowns were less likely to be detected from the air than trees with more dense crowns (Figure 2.6). Of the larger hemlocks ( $\mathrm{dbh}>25 \mathrm{~cm}$ ) hidden in the aerial censusing, over $45 \%$ had a crown density of 
$\leq 10 \%$ and over $80 \%$ of these trees had a crown density of $\leq 50 \%$. In contrast, only 4 of 547 hemlocks visible in the aerial image had a crown density of $\leq 10 \%$. Of these four individuals, three had lost a large portion of their crowns as a result of a severe ice storm the previous winter.

A tree's crown position in the forest canopy was a factor in determining its visibility from the air (Figure 2.7). Nearly all (253 of 255) individuals classified as having a dominant or co-dominant crown were visible from the air. Most $(87 \%)$ of the trees with intermediate crowns were also detected in the air imagery. Less than $20 \%$ of the hemlocks with suppressed crowns, however, were detected in the air census. Due to the large overall number of suppressed hemlocks in the population, however, these suppressed, yet, visible hemlocks within the forest understory (207 individuals) comprised a significant minority $(37.8 \%)$ of the total air census. 
Table 2.1. Assessing the spectral classification accuracy of the Evergreen Vegetation class using the global fusion and single independent classification methods, 1998 image.

\begin{tabular}{lll}
\hline & Global Fusion (\%) & Single Independent (\%) \\
\hline User's Accuracy (Evergreen) & 90.1 & 79.4 \\
Producer's Accuracy (Evergreen) & 87.9 & 89.7 \\
Overall Accuracy (Evergreen) & 92.3 & 88.1 \\
\hline
\end{tabular}

Table 2.2. Composition of Evergreen Vegetation class (from the global fusion classification method) as determined by ground referencing.

\begin{tabular}{lc}
\hline Species & Ground Cover Area (\% of Total) \\
\hline Pinus strobus & $0.26 \%$ \\
Picea rubens & $0.28 \%$ \\
Kalmia latifolia & $1.62 \%$ \\
Kalmia/Tsuga Mix & $0.90 \%$ \\
Tsuga canadensis & $96.94 \%$ \\
\hline
\end{tabular}


Figure 2. 1. Section of study site from March, 1997 image.

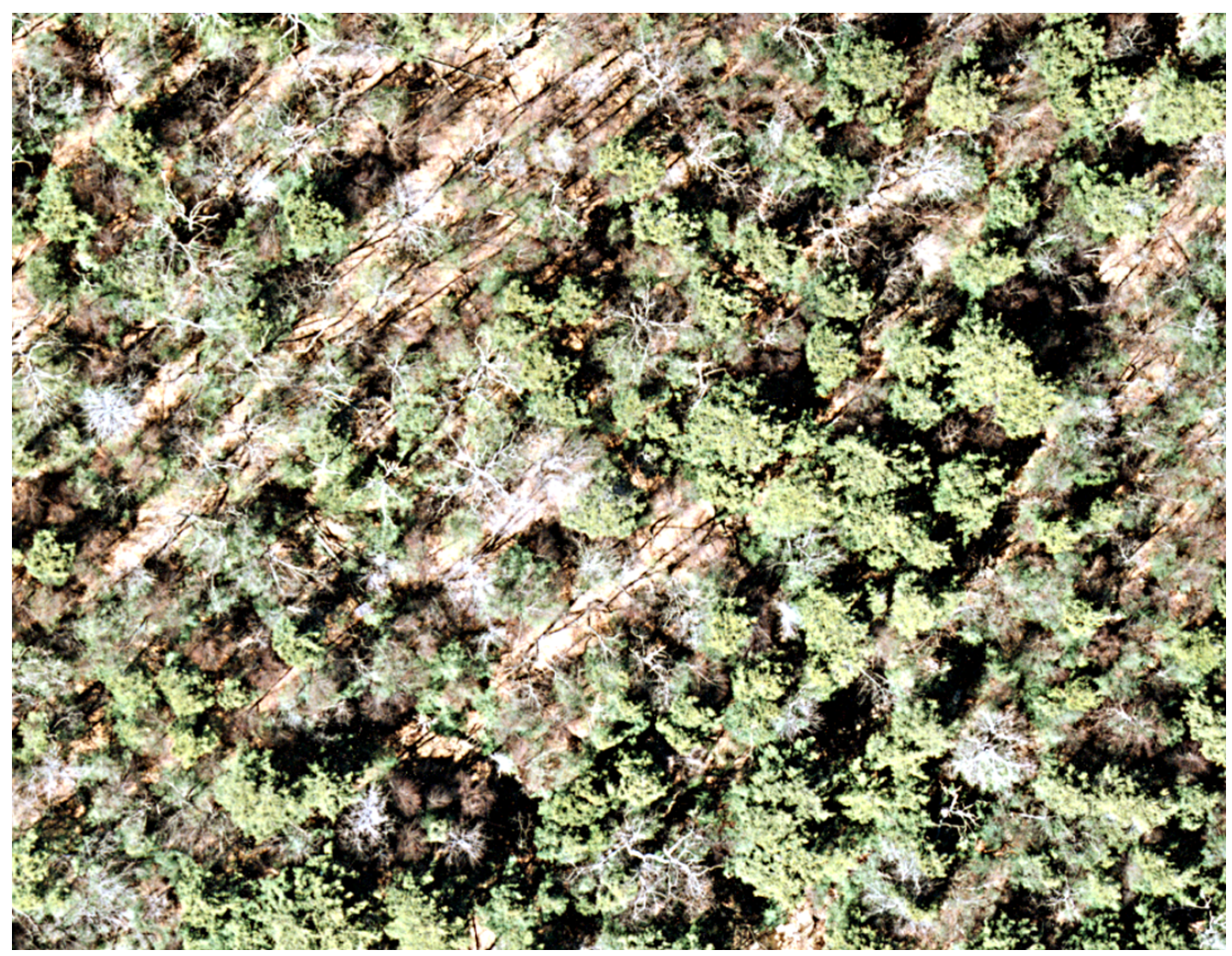


Figure 2.2. Size distribution of hemlock population - ground census.

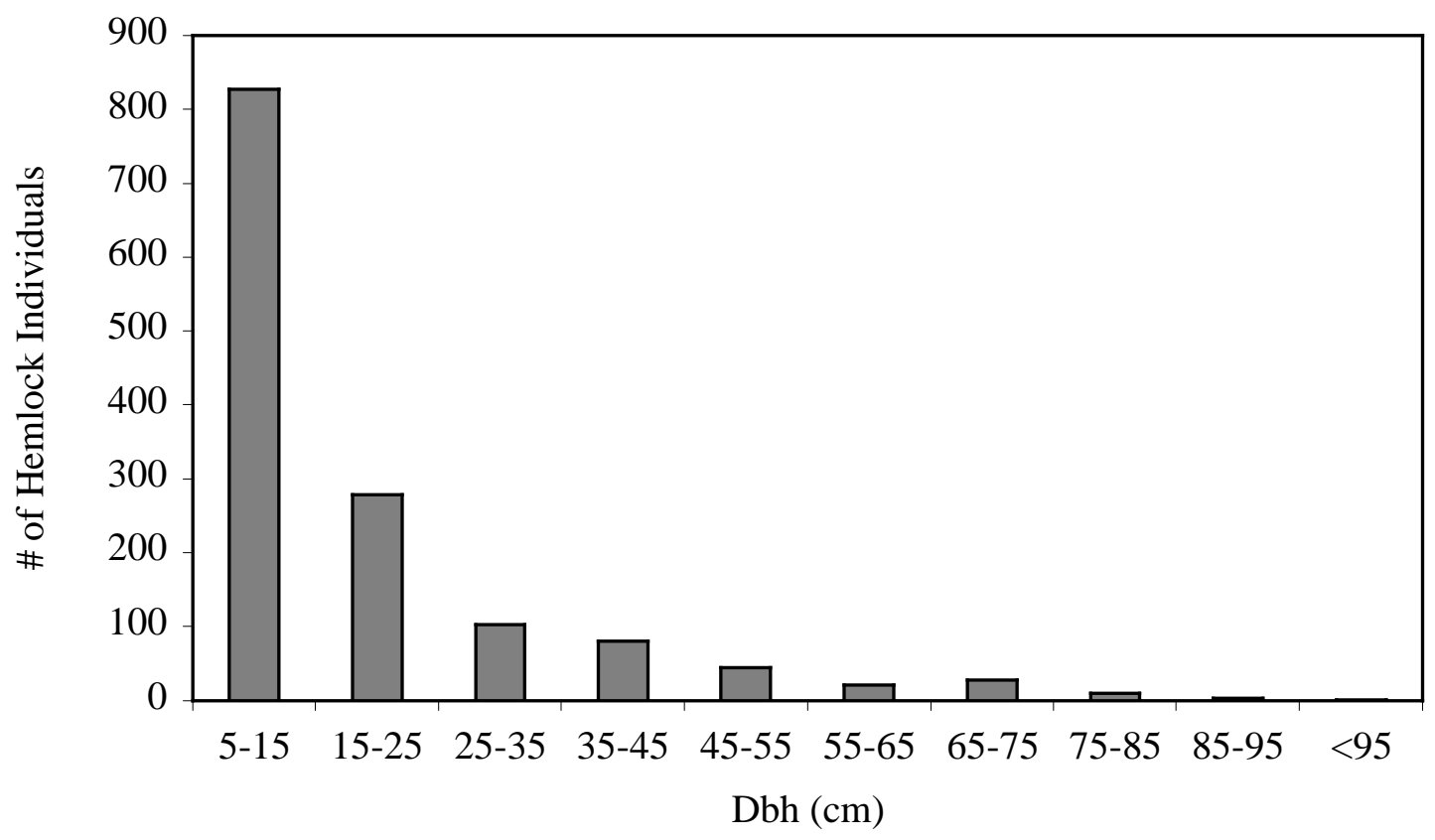


Figure 2.3 Hemlock crown position - ground census.

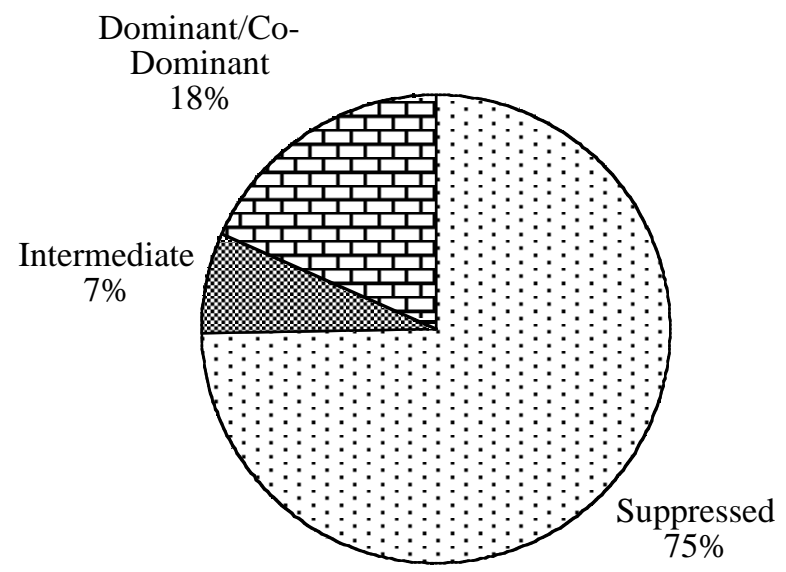


Figure 2.4 Size distribution of hemlock population - aerial census.

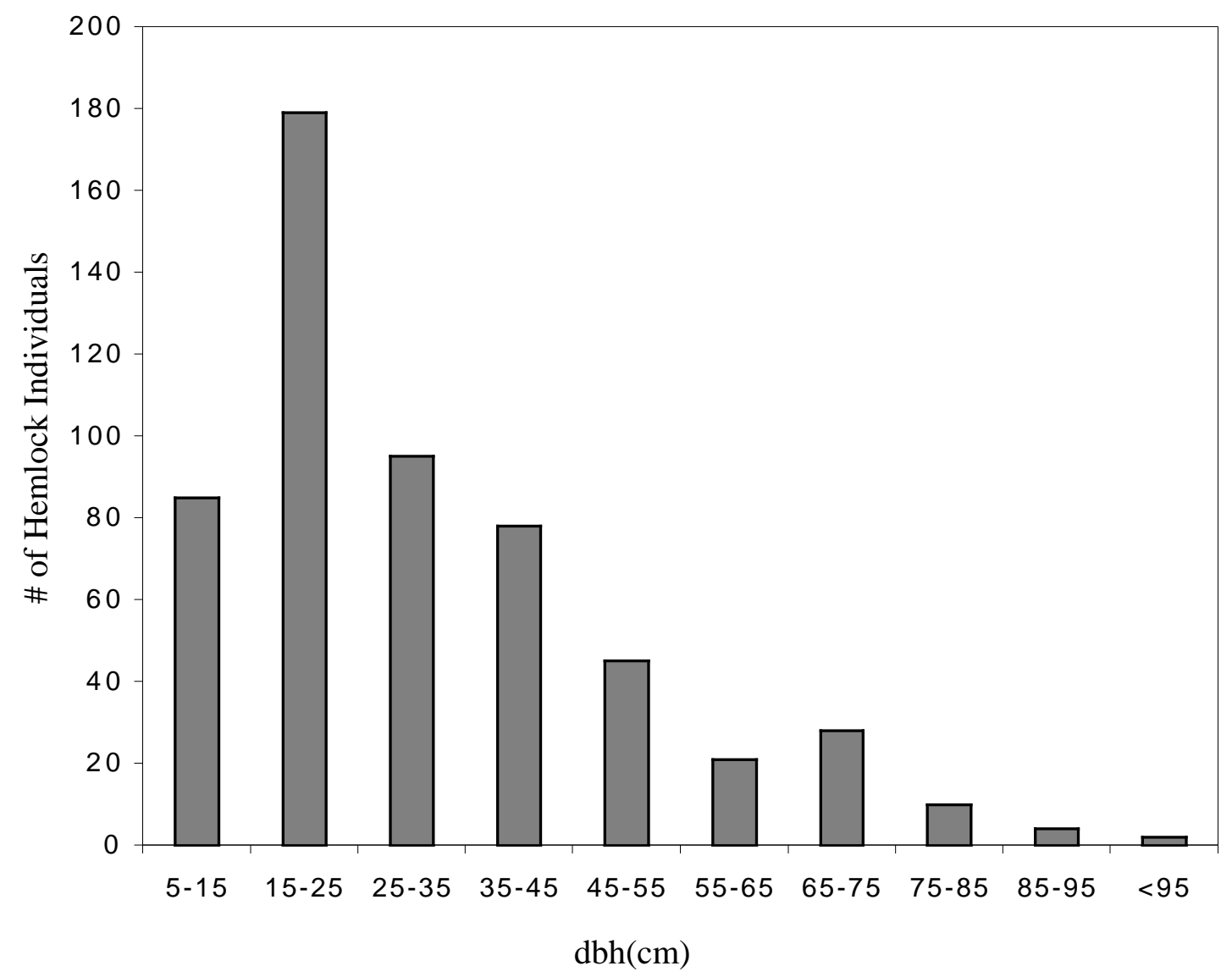


Figure 2.5. Size comparison of hidden population - aerial census.

and visible layers of the hemlock

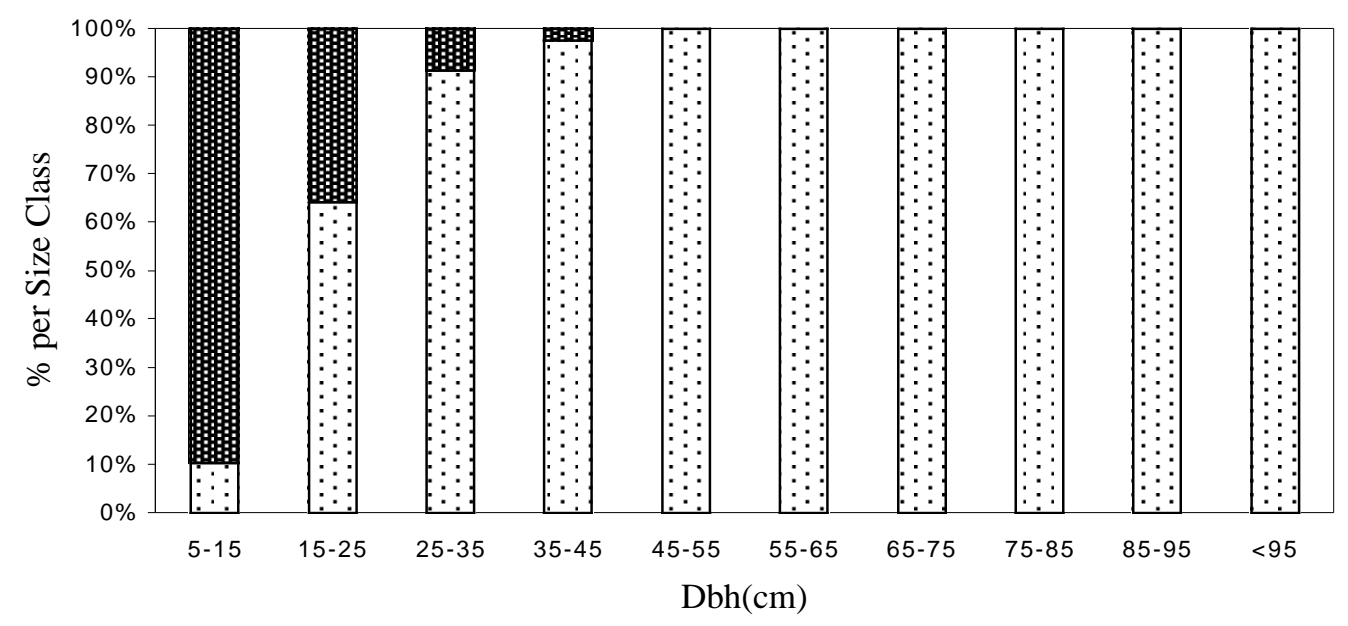

Figure 2.6. Crown density comparison of hidden hemlock population - aerial census. and visible layers of

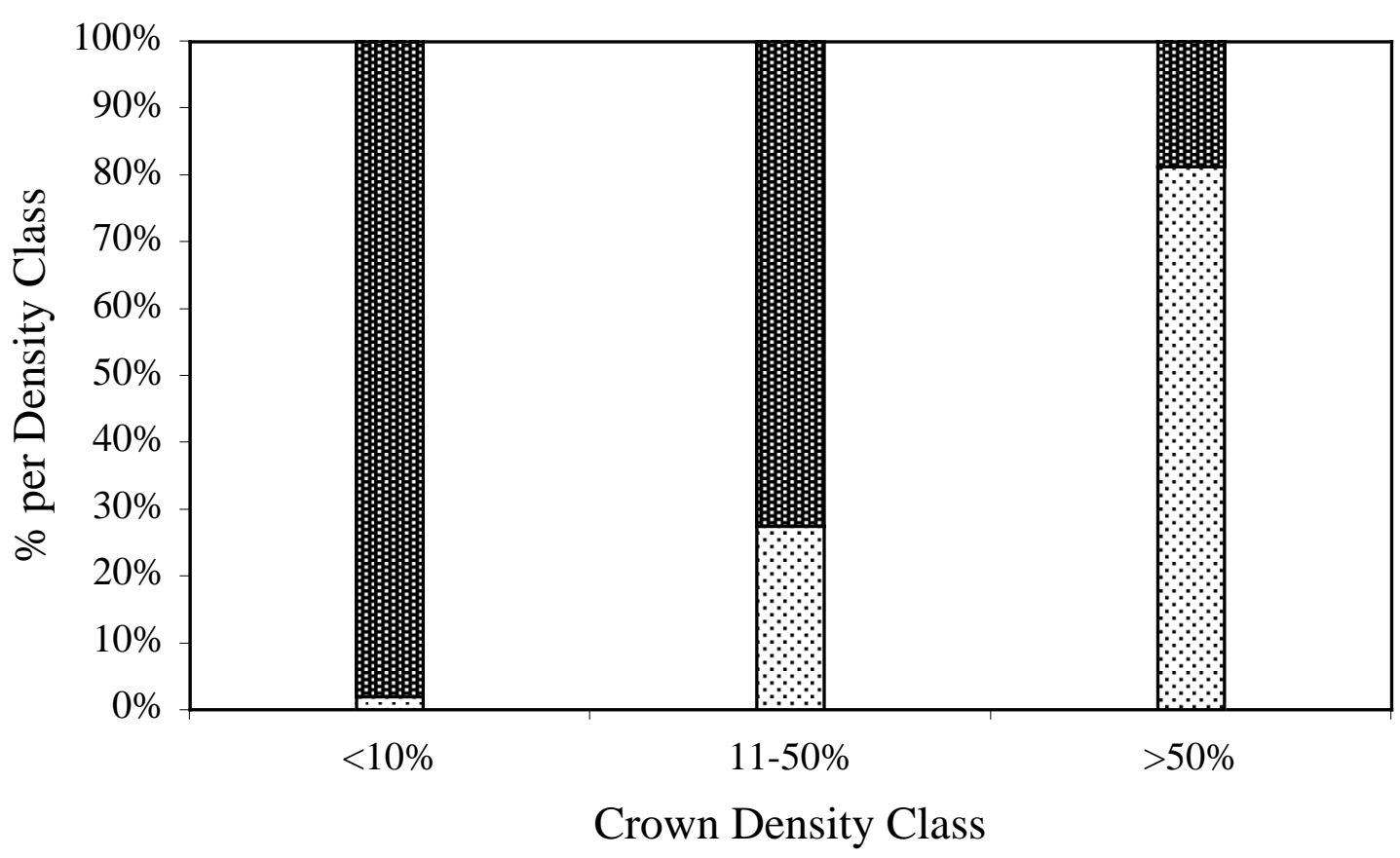


Figure 2.7. Crown position comparison of hidden layers of hemlock population - aerial census.

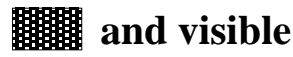

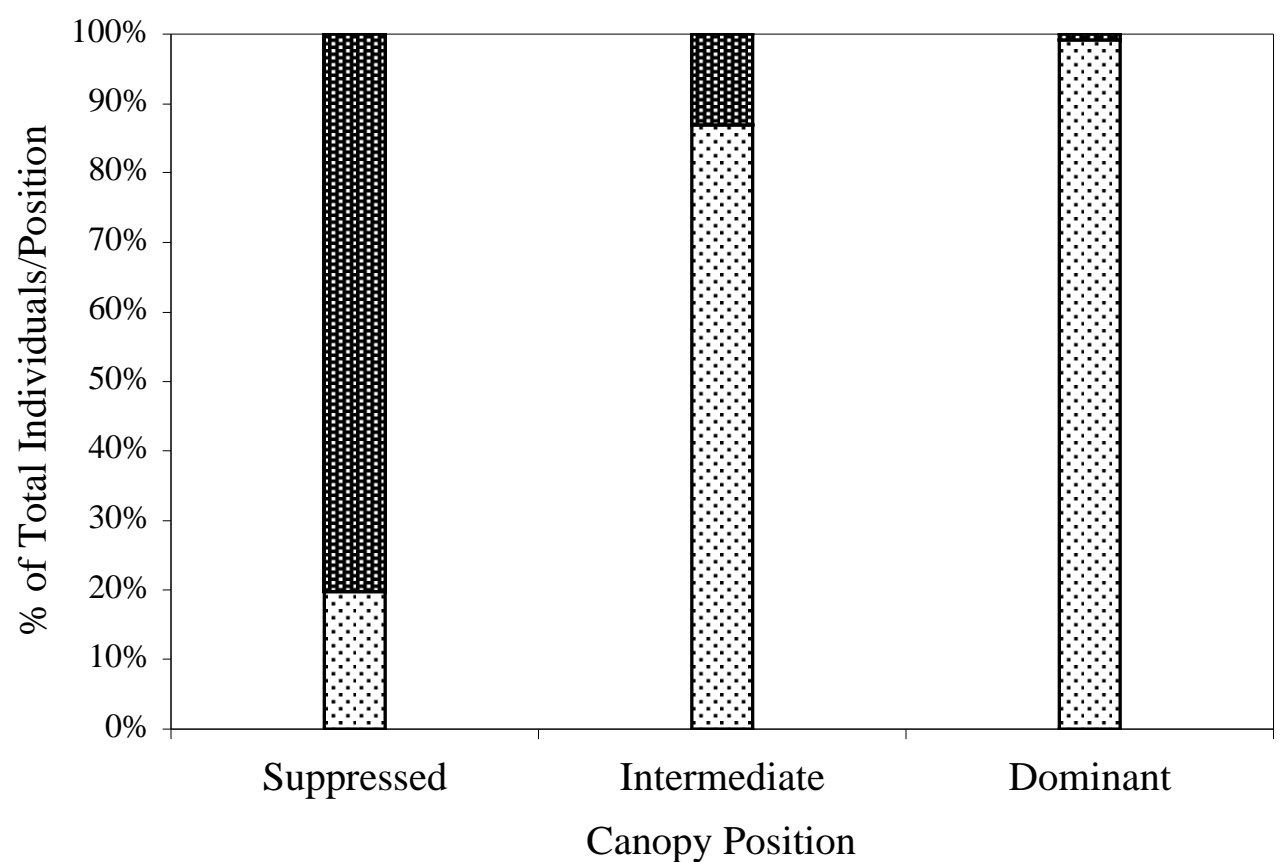




\section{Discussion}

A census of a hemlock population from the air and on the ground has revealed important similarities and differences between the two approaches. An important relationship was found between the measures of individual tree size on the ground (dbh and crown diameter) and the measure of individual tree size from the aerial image (crown area). The distributions of both populations were skewed, with the smaller size classes having the largest number of individuals.

The most obvious difference in the population data obtained from remote sensing is the absence of a large portion of the total population as censused from the ground. In our study, over $60 \%$ of the hemlock population censused on the ground was hidden in the aerial census. Most of these hidden hemlocks were small, suppressed individuals located underneath the upper canopy crowns and in shadows cast by adjacent neighbors. In the 1998 imagery, shadows comprised $9.67 \%$ of the aerial image within the study site.

The hemlock trees within the study site that were visible in aerial censusing represent several important components of the population. Nearly all large upper canopy hemlock trees were visible in the aerial imagery. Maximum carbon gain, the result of photosynthesis, is often dominated by this upper canopy layer (Chapin et al. 2002). These large adult trees, also, have been shown to have a disproportionately high influence on the future dynamics of a population (Hartshorn 1975, Enright and Ogden 1979). In addition, large individuals have disproportionately large crown areas as shown in the relationship found between dbh and crown area. Although less than $40 \%$ of the hemlock individuals were identified in the aerial image, these individuals, according to the 
predicted relationship between dbh and crown area, account for over $65 \%$ of the total hemlock crown area within the study plot.

Large hemlock trees were not the only visible segment of the population from the air. Nearly $40 \%$ of the aerially censused population was comprised of trees from the forest's lower canopy. The visibility of these smaller individuals is attributed to their location within the forest: in canopy gaps or under a sparsely branched hardwood canopy. Hemlocks located within a gap or higher light environment have been found to have an increased rate of growth while the gap persists (Hibbs 1982). The alternating periods of growth and suppression due to small but repeated disturbances in the forest upper canopy may be utilized by hemlock to reach the upper canopy level (Oliver and Stephens 1977). We would expect the small visible trees in our study site to have a better chance of contributing to future population growth than trees of similar size hidden from aerial censusing.

In addition to the challenge of ground referencing aerial features, the manual segmentation of hemlock crown boundaries in this study proved an extremely time consuming procedure. A primary appeal of censusing tree populations by remote sensing is the potential to quickly collect huge spatially explicit population data sets covering wide geographical areas. The size of such a potential data set suggests the need to develop an automated procedure to delineate individual tree crowns on the aerial imagery. Such an automated procedure would greatly expedite the time required to extract meaningful information from such a potentially large data set (Gougeon 1995b). 
Censusing a population using remote sensing produces different results than censusing the same population from the ground. The challenge for population ecologists is to determine if this data, though different, can be useful in providing further insights regarding the description of a population and its dynamics. We believe that remote sensing in this study has provided valuable information about the size and structure of several important components of the hemlock population. In the future, repeated censusing of the same individuals over time and following the fates of these individuals as well as the appearance or "birth" of new individuals could provide important insights into the dynamics of this population. 


\section{References}

Aldred, A. H., and L. Sayn-Wittgenstein. (1972), Tree diameters and volumes from large scale aerial photographs. Forest Management Institute Information Report FMRX-40, Canadian Forestry Service.

Allphin, L., and K. T. Harper. (1997), Demography and life history characteristics of the rare kechina daisy (Erigeron kechinensis, Asteraceae). American Midland Naturalist 138:109-120.

Baptista, W. B., W. J. Plat, and R. C. Macchiavelli. (1998), Demography of a shadetolerant tree (Fagus grandifolia) in a hurricane-disturbed forest. Ecology 79:3853.

Brezzone, L., F. Prieto, and S. B. Serpico. (1999), A neural-statistical approach to multitemporal and multisource remote-sensing image classification. IEEE Transactions on Geoscience and Remote Sensing 37:1350-1359.

Chapin, F. S., H. A. Mooney, and P. Matson. (2002), Principles of Terrestial Ecosystem Ecology. Springer-Verlag, New York.

Congalton, R. G. (1991), A review of assessing the accuracy of classifications of remotely sensed data. Remote Sensing of Environment 37:35-46.

Congalton, R. G., K. Green, and J. Teply. (1993), Mapping old growth forests on National Forest and park lands in the Pacific Northwest from remotely sensed data. Photogrammetric Engineering and Remote Sensing 59:529-535.

Enright, N., and J. Ogden. (1979), Applications of transition matrix models in forest dynamics; Araucaria in Papua New Guinea and Nothofagus in New Zealand. Australian Journal of Ecology 4:3-23. 
Godman, R. M., and L. Lancaster. (1990), Tsuga canadensis, in Silvics of North America USDA Forest Service Agricultural Handbook 654 pp. 604-612.

Golubov, J., M. D. Mandujano, M. Franco, C. Montana, L. E. Eguiarte, and J. LopezPortilla. (1999), Demography of the invasive woody perennial Prosopis glandulosa (Honey mesquite). Journal of Ecology 87:955-962.

Gougeon, F. A. (1995a), Comparison of possible multispectral classification schemes for tree crowns individually delineated of high spatial resolution MEIS images. Canadian Journal of Remote Sensing 21:1-9.

Gougeon, F. A. (1995b), A crown-following approach to the automatic delineation of individual tree crowns in high spatial resolution aerial images. Canadian Journal of Remote Sensing 21:274-284.

Graetz, R. D. (1990), Remote sensing of terrestrial ecosystem structure: an ecologist's pragmatic view, in Remote sensing of biosphere functioning. Edited by R. J. Hobbs and H. A. Mooney. Springer-Verlag, New York pp. 7-30.

Hagan, G. F., and James L. Smith. (1986), Predicting tree groundline diameter from crown measurements made on 35-mm aerial photography. Photogrammetric Engineering and Remote Sensing 52:687-690.

Hartshorn, G. S. (1975), A matrix model of tree population dynamics, in Tropical Ecological Systems. Edited by F. B. Golley and E. Medina. Springer-Verlag, New York pp. 41-51.

Herwitz, S. R., Robert E. Slye, and Stephen M Turton. (1998), Co-registered aerial stereopairs from low-flying aircraft for the analysis of long-term tropical 
rainforest canopy dynamics. Photogrammetric Engineering and Remote Sensing 69:397-406.

Hibbs, D. E. (1982), Gap dynamics in a hemlock-hardwood forest. Canadian Journal of Forest Resources 12:522-527.

Jeon, B., and D. A. Landgrebe. (1999), Decision fusion approach for multitemporal classification. IEEE Transactions on Geoscience and Remote Sensing 37:12271233.

Kaye, T. N., K. L. Pendergrass, K. Finley, and J. B. Kauffman. (2001), The effect of fire on the population viability of an endangered prairie plant. Ecological Applications 11:1366-1380.

Key, T., T. A. Warner, J. B. McGraw, and M. A. Fajvan. (2001), A comparison of multispectral and multitemporal information in high spatial resolution imagery for classification of individual tree species in a temperate hardwood forest. Remote Sensing of Environment 75:100-112.

Kramer, H. J. (2002), Observation of the Earth and its Environment - Survey of Missions and Sensors, 4th edition. Springer Verlag.

Lahav-Ginott, S., R. Kadmon, and M. Gersani. (2001), Evaluating the viability of Acacia populations in the Negev Desert: a remote sensing approach. Biological Conservation 98:127-137.

Lande, R. (1988), Genetics and demography in biological conservation. Science 241:1455-1460. 
Landenberger, R. E., and J. B. McGraw. (2003), Potential of digital color imagery for censusing Haleakala silverswords in Hawaii. Photogrammetic Engineering and Remote Sensing 69:915-923.

Leckie, D. G., and F. A. Gougeon. (1998), An assessment of both visual and automated tree counting and species identification with high spatial resolution multispectral imagery. in D. A. Hill and D. G. Leckie, editors. International Forum: Automated Interpretation of High Spatial Resolution Digital Imagery for Forestry. pp. 141152, Victoria, British Columbia.

Lillesand, T. M., and Ralph W. Kiefer. (1994), Remote sensing and image interpretation, 3rd edition. John Wiley \& Sons, New York.

McGraw, J. B., T. A. Warner, T. Key, and W. Lamar. (1998), Advances in high resolution remote sensing for forest ecological studies. Trends in Ecology and Evolution 13:300-301.

Menges, E. S. (1990), Population viability analysis for an endangered plant. Conservation Biology 4:52-62.

Miller, I., R. Anderson, W. Burkman, and W. Hoffard. (1992), Forest health monitoring: crown condition rating guide. United States Department of Agriculture, U.S. Forest Service.

Minor, C. O. (1951), Stem-crown diameter relations in southern pine. Journal of Forestry 49:490-493.

Oliver, C. D., and E. P. Stephens. (1977), Reconstruction of a mixed-species forest in central New England. Ecology 58:562-572. 
Parker, I. M. (2000), Invasion dynamics of Cytisus scoparius. A matrix model approach. Ecological Applications 10:726-743.

Research Systems. (2000), ENVI. Research Systems, Boulder, CO.

Richards, J. A. (1993), Remote sensing digital image analysis, 2nd edition. SpringerVerlag, Berlin.

Schemske, D. W., B. C. Husband, M. H. Ruckelshaus, C. Goodwillie, I. M. Parker, and J. G. Bishop. (1994), Evaluating approaches to the conservation of rare and endangered plants. Ecology 75:584-606.

Silvia, J. F., J. Raventos, H. Caswell, and M. C. Trevisan. (1991), Population responses to fire in a tropical savanna grass. Journal of Ecology 79:345-355.

Souto, D., Tom Luther, and Bob Chianese. (1996), Past and current status of HWA in eastern and Carolina hemlock stands. in S. M. Salom, T.C. Tigner, and R.C. Reardon, editor. Proceedings of the first hemlock woolly adelgid review. pp. 9-15 U.S. Department of Agriculture, Charlottesville, Virginia.

Tucker, C. J., J. R. G. Townsend, and T. E. Goff. (1985), African land-cover classification using satellite data. Science 227:369-375.

Ustin, S. L., J. B. Adams, C. D. Elvidge, M. Rejmanek, B. N. Rock, M. O. Smith, R. W. Thomas, and R. A. Woodward. (1986), Thematic mapper studies of semiarid shrub communities. Bioscience 36:446-456. 


\section{CHAPTER 3}

Multitemporal censusing of a population of eastern hemlock (Tsuga canadensis L.) from remotely sensed imagery using an automated segmentation and reconciliation procedure. ${ }^{1}$

${ }^{1}$ This chapter formatted according to author's instructions for submission to Remote Sensing of Environment. 


\begin{abstract}
Large scale $(1: 3,000)$ color aerial images of a population of eastern hemlock (Tsuga canadensis L.) were collected in the early spring of 1997,1998 and 1999. An automated spatial segmentation procedure was developed to identify and measure individual population units, or blobs, within the forest population. A blob was defined as a distinct portion of crown segmented from its neighbors on the basis of size, shape, and connectivity. To ensure the comparability of multi-year segmentation maps, an automated blob reconciliation procedure was also developed to make certain that no hemlock pixels were assigned to different blobs in different years. The automated segmentation and reconciliation procedures were applied to a population of naturally occurring hemlock. Following spatial segmentation, a large majority of hemlock blobs ( $64-71 \%)$ were found to be closely associated with ground referenced, manually delineated, individual hemlock crowns. The remaining blobs consisted of spatially distinct parts of a crown or closely clumped multiple crowns. Similar overall classification accuracies ( $64-72 \%)$ were found following the reconciliation of multitemporal image pairs. The development of these spatially explicit, multitemporal population data sets should prove useful to further investigations of the dynamics of and environmental influence on plant populations.
\end{abstract}




\section{Introduction}

Remote sensing provides ecologists with a powerful tool to rapidly obtain spatially explicit data on the vegetation of a large area. Repeated measurements of the same features over time allow for the investigation of the vegetation dynamics of an area. "Post-classification comparison" change detection techniques have been used to investigate the dynamics of wetlands (Jenson et al. 1995), large-scale deforestation (Malingreau and Tucker 1988) and forest succession (Hall et al. 1991). At present, high spatial resolution imagery provided by aircraft-based photographic systems appears to provide data at a scale most feasible for study of vegetation change at the population level (Gougeon 1995b, Niemann 1995), although recently launched space-based platforms (i.e. IKONOS and QuickBird) are approaching the resolution required to discern individuals (Kramer 2002).

Tree population dynamics can be investigated through repeated measurements of individuals within a population over time (Usher 1972, Hartshorn 1975, Enright and Ogden 1979, Martinez-Ramos 1989). Given the potential size of remotely sensed data sets and the extensive time requirements of ground referenced, manually delineated crown segmentation methods, there exists a basic need to develop an automated segmentation procedure to delineate the individual components of a population.

The use of remotely sensed imagery to describe and classify plant populations has numerous challenges. There have been a number of efforts to develop an automated procedure to segment individual crowns within a tree population. For different forested 
imagery, the interaction between forest canopy and incident sunlight can result in a variety of different attributes to assist in the separation of individual tree crowns. Local minima reflectance values, due to shadows between individual crowns (Gougeon 1995b), local maxima reflectance values representing the tops of upper canopy trees (Pinz 1991), crown size (Lahav-Ginott et al. 2001) and crown shape characteristics (Pollock 1998) have all been used to segment individual tree crowns. Often a multi-step procedure utilizing more than one crown attribute has proven most effective (Pinz 1991, Gougeon 1995b, Brandtberg and Walter 1998, Pollock 1998).

The spectral and spatial characteristics of the available imagery dictate the canopy attributes that can be used for segmentation. These characteristics vary considerably depending on site, sensor type, image scale, and timing of image collection. Previously, we showed that the phenological differences between hemlock (Tsuga canadensis L.) and the neighboring deciduous trees within our study site assisted in the effective spectral segmentation of the evergreen and deciduous ground covers (Lamar and McGraw submitted). The leaf-off nature of the imagery also allowed us to census a significant portion of the lower canopy segment of the population (Lamar and McGraw submitted). The presence of both sunlit and shaded hemlock crowns within the image, however, resulted in no consistent, recognizable radiometric patterns being present within individual crowns (i.e. local spectral maxima).

While there has been some success in segmenting individual trees from the air, given the resolution and angular mobility limitations of remote sensing instruments, census data 
collected from the air will differ from traditional sampling methods into the foreseeable future. The challenge to ecologists is how to adapt the traditional methods of description and classification to be compatible with the nature of remotely sensed data (Graetz 1990). The basic unit traditionally used to describe populations has been the individual. Although this description has many positives, it also presents some difficulties. The clonal nature of many plants blurs the definition of an individual between the whole plant genet and the clonally produced yet potentially independent ramet. Even in non-clonal species, the extensive and complex graft union formed between the roots of different individuals in a number of forest tree species and the subsequent role of these grafts in the translocation of resources suggests a reduced role for individualism with regard to intra-specific competition (Bormann and Graham 1959). Graham (1959) lists 19 genera and 56 species of forest trees in which natural root grafting has been observed, including eastern hemlock. Still other trees spread from their base after boles are cut or broken, resulting in multiple crown stems from one genetic individual.

The modular, as opposed to unitary, construction of most plants has long been recognized (Harper 1976). Using this modular approach the fundamental unit of a tree population may be regarded as any repeating unit of construction such as a tree branch or branches (Huenneke and Marks 1987, McGraw 1989). For this investigation we describe a natural population of hemlock as viewed from above as a population of blobs. A blob is defined as a distinct portion of crown canopy segmented from its neighbors on the basis of size, shape, and connectivity. A hemlock blob classified from aerial imagery shares many similarities with an individual tree censused on the ground. Like an individual, the fate 
of a blob can be followed over time; both blobs and individuals can be born, grow, regress, or die over time. In the case of blobs, "birth" is not the product of recent germination as is the case with individuals. Rather, a "birth" into aerial view is typically the emergence of a previously suppressed individual(s) into the canopy as the result of a canopy disturbance. Importantly, from an ecological perspective, both blobs and individuals can influence their surrounding environments and compete for resources with their neighbors.

In this paper, we present a new automated methodology to extract a population data set of hemlock blobs from remotely sensed, imagery collected in 1997, 1998, and 1999. Our segmentation procedures relied on global and local shape and size features to spatially distinguish blobs.

To investigate population change over time, tree blobs need to be unique and comparable at different census periods. Following spatial segmentation, which was independently applied to each temporal image, not all segmentation lines were identical on different images due to hemlock changes between years. Hemlock pixels assigned to different blobs in different years prevent meaningful comparison of data sets. An automated blob reconciliation procedure was developed to consider all such "cross identified" pixels and to re-assign them to the same unique blobs for comparable time periods. Reconciliation was performed on pairs of hemlock image data from 1997-98 and 1998-99. 
We compared the results from the automated segmentation and reconciliation procedures to a ground referenced, manual crown survey map completed on the same population.

\section{Study Area}

Our study area is located in the Limberlost-Whiteoak Canyon area of Shenandoah National Park ( $38^{\circ} 34^{\prime} \mathrm{N} 78^{\circ} 22^{\prime} \mathrm{W}$ ). This site is located in an upper elevation $(951 \mathrm{~m})$ mixed hardwood/hemlock forest. Hemlock is a long-lived, shade tolerant, evergreen tree found in many low disturbance eastern United States (US) forests. Established populations usually include a large bank of "saplings", small individuals that may be suppressed beneath a canopy of hemlock or hardwoods for hundreds of years and remain in good condition (Godman and Lancaster 1990). Like all hemlocks within Shenandoah, the Limberlost-White Oak Canyon population has been adversely impacted in recent years by the presence of the Hemlock Woolly Adelgid (Adelges tsugae) whose occurrence was first reported in the park in 1988. This adelgid, believed to inject a toxic saliva into the hemlocks while feeding (Souto 1996), currently infests hemlocks in many eastern US states. Unlike hemlocks in other park locations, most trees within the study site had only suffered mild to moderate defoliation at the time of aerial sampling. Within the study area, a 3 ha $(100 \mathrm{~m}$ X $300 \mathrm{~m})$ study plot and an adjoining 0.5 ha $(50 \mathrm{~m}$ X100 m) training plot were located. All parameter estimates used in the spatial segmentation and reconciliation procedures were developed using data from the training plot and then applied to the study plot for final analysis. 


\section{Methods}

Image Collection, Pre-processing, and Ground Data Collection

Large scale $(1: 3,000)$ color aerial photographs of the study area were collected on March 27, 1997, April 13, 1998, and March 31,1999 using a calibrated Leica/Wild Heerbrugg RC-30 mapping camera with a $303.860 \mathrm{~mm}$ focal-length lens. The photography was acquired before the emergence of new foliage for the deciduous forest component. The color photographs were scanned at 600 dpi using an Agfa Dual Scan scanner to produce high resolution ( $\sim 13 \mathrm{~cm} /$ pixel) digital images. To facilitate comparisons between multitemporal images, image to image geometric registration was performed. Shared primary branch bifurcation points were identified throughout the image segment as control points and images were co-registered using second order mapping polynomials and cubic convolution resampling (Lamar and McGraw submitted).

The diameter at breast height $(\mathrm{dbh}$, breast height $=1.3 \mathrm{~m})$ of all hemlock trees $(\mathrm{dbh} \geq 5.0$ $\mathrm{cm}$ ) within the study and training plots was measured in the spring of 1998 using traditional field methods.

\section{Manual Crown Segmentation}

Manual delineation of irregularly shaped tree crowns on large-scale imagery is not an error-free task. Measurements of isolated tree crowns using spectral segmentation procedures have been found to produce more accurate estimates of size than manual delineation (Lahav-Ginott et al. 2001). For this reason, initial map preparation involved spectrally separating the evergreen vegetation of the study site from other ground covers. Spectral segmentation used a maximum likelihood classification algorithm and a global, 
fused class decision making process that applied the summarized decisions of local class statistics derived from all three years of radiometrically normalized imagery to each year's image (Lamar and McGraw submitted).

The boundaries between individual hemlock crowns and the boundaries between hemlock crowns and other types of evergreen vegetation were manually delineated in the field from these spectrally segmented vegetation maps. Manual delineation was aided by the use of multiple years of aerial imagery and multiple images from different viewing angles each year. Considerable intertwining of branches between adjacent crowns due to the flexible branch architecture of hemlock added to the challenge of precise delineation. The manual crown survey map was produced in the spring of 1998 from the 1998 image. All comparisons of the automated aerial censuses in this study were thus made with respect to this 1998 manual crown survey map. A full description of the hemlock population within the study area based both on ground collected and ground referenced, aerial collected data has been previously described (Lamar and McGraw submitted).

\section{Automated Spatial Segmentation}

Our automated spatial segmentation procedure was applied independently to each of the multi-temporal spectrally segmented vegetation maps of the study site. The objective of this procedure was to divide the hemlock component of the aerial imagery into distinct population units or blobs based on shape and size. Spatial segmentation was a five-step process including shadow thresholding, Euclidean Distance Map (EDM) construction, EDM manipulations, watershed segmentation, and minimum blob joining. 


\section{Shadow Thresholding}

Shadows can both assist and hinder crown segmentation efforts. On one hand, the intercrown shadows, by providing a distinct edge around the perimeter of an individual tree crown, can greatly assist efforts to delineate that crown from its adjacent neighbors (Gougeon 1995b). Conversely, shadows can hide valuable information about the true nature of a crown's shape and size (Brandtberg and Walter 1998, Pollock 1998, Lamar and McGraw submitted). A single tree, when intercepted by intra-crown shadows, can be mistaken for several separate trees by an automated segmentation procedure.

To investigate the nature of the shading within the study area, all inter and intra-crown shadows within the training plot were identified and mapped during preparation of the manual crown survey map. The size differences between inter- and intra-crown shadows were examined using a Wilcoxon rank sum test. To distinguish inter- and intra-crown shadows, an optimal threshold shadow size was determined through a systematic trial of a range of shadow sizes to identify when overall accuracy was maximized for the smoothed EDM/watershed segmentation step. All shadows below this threshold were filled in as hemlock prior to final EDM/watershed segmentation of the study plot. These shadows were then added back to the image prior to further segmentation, reconciliation, and analysis.

For multitemporal comparisons, the presence of shadows presents another challenge. At the pixel level, the transition between hemlock and other non-shadow ground covers from one sampling time to another is considered an actual change. The transition between hemlock and shadow, however, represents an unknown. The shadow could be masking a 
hemlock pixel in which case no actual change has occurred, or the shadow could be masking an actual change between hemlock and another ground cover. Due to the level of uncertainty for these transitions, all pixels within each image pair exhibiting this transition were eliminated as hemlock prior to spatial segmentation. This had the effect of adding 1997 and 1998 shadows to both images within the 1997-98 image pair. Likewise, 1998 and 1999 shadows were added to both images of the 1998-99 image pair.

Studies have shown a significant statistical relationship between ground and aerial measurements of tree size (Minor 1951, Aldred and Sayn-Wittgenstein 1972, Hagan 1986, Lamar and McGraw submitted). Ground and aerial size measurements of hemlocks from single time-period images have been found to be positively correlated (Lamar and McGraw submitted). The addition of another year of shadows to each image within an image pair, however, could potentially increase the masking of the aerial crown measurements. The Pearson product-moment correlation was used to investigate the relationship between ground measurements of size (dbh) and aerial measures of size (crown area) for the 1998 hemlock crowns within the 1997-98 and 1998-99 image pairs.

\section{EDM Construction and Manipulation}

EDMs were constructed by assigning a brightness value to each hemlock pixel in the spectrally classified binary image corresponding to the pixel's Euclidean distance from its nearest boundary (see Russ (1995) for further description of this procedure). Local maxima on the EDM represent the center or peak of a hemlock clump; local minima represent edge pixels (Figure 3.1). Effective spatial division of an EDM using the watershed segmentation method depends on the orderly relation of gray scale pixel 
values. Typically, this pixel pattern is the result of EDM construction from convex or mostly convex shapes. Less convex shapes and local boundary irregularities lead to a surplus of local maxima and oversegmentation.

To minimize oversegmentation, a series of EDM manipulations was performed prior to watershed segmentation (Figure 3.2). The first action was a $7 \mathrm{X} 7$ smoothing filter passed three times over the gray-scale EDM. Only hemlock pixels were considered for change in smoothing operations. The smoothing filter produced a wide band of minima or near minima values near the edges of the hemlock crowns. The presence of this flat band of pixels with similar values (Figure 3.2b) presented difficulties for watershed segmentation, which is a local process based on identifying minimum values from a $3 \mathrm{X}$ 3 moving window. To eliminate these flat bands while preserving the orderly smoothing of brightness values, all the values of the EDM were elevated by a constant amount, except pixels belonging to the lowest five brightness values, which were reassigned elevations according to their distance from adjacent, elevated hemlock pixels in the image (Figure 3.2c).

\section{Watershed Segmentation}

Beucher (1979) introduced the idea that by viewing the intensity of any gray-scale image as elevation and simulating runoff, it is possible to decompose an image into watershed regions. In our study, watershed analysis was performed on a Macintosh computer using a customized version of the public domain NIH Image program (Rasband and Roervik 1999) and based on the algorithm described by Russ (1995). Watershed segmentation is essentially a dilution with the added logical restraint that no new pixels may be turned on 
if it causes a connection to form between previously separated features (Figure 3.3). Starting with the local maxima, the binary hemlock map is "grown" back to its original boundaries except for the lines of separation between blobs.

\section{Minimum Blob Joining}

Even with EDM manipulations, the watershed method produced excessive hemlock segmentation due to the presence of large, irregular crown branches and intra-crown shadows. To improve the overall classification accuracy, a minimum blob joining procedure was applied following watershed segmentation. This procedure identified an optimal minimum blob size and joined each blob below this size with its contiguous neighbor with whom it shared the largest common boundary. The optimal minimum blob joining size was determined from the training data, through a systematic trial of different blob sizes to identify a minimum threshold where overall accuracy was maximized.

The manual crown survey found that many of the smallest evergreen blobs within the aerial imagery were separated at such a distance from all identified hemlock crowns that they could not be linked with certainty to any one crown. These smallest blobs represented isolated hemlock branches cut off from the main crown by shadows or other ground covers, crowns belonging to hemlocks with a dbh $<5 \mathrm{~cm}$, or branches of mountain laurel (Kalmia latifolia) whose canopies, because of internal shading, tended to be dissected into small, discontinuous patches. Because of the uncertain identity and relative insignificance of these smallest blobs, a blob threshold size was developed. Only blobs above this threshold were considered for further comparison and description. The blob threshold was selected based on the smallest crown size predicted from the 
minimum, ground-based dbh measurement and the least squares regression of crown size and dbh. 
Figure 3.1. Hemlock clump following Euclidean distance mapping, a) 3-D view with arrows pointing to false maxima, b) 2-D view.

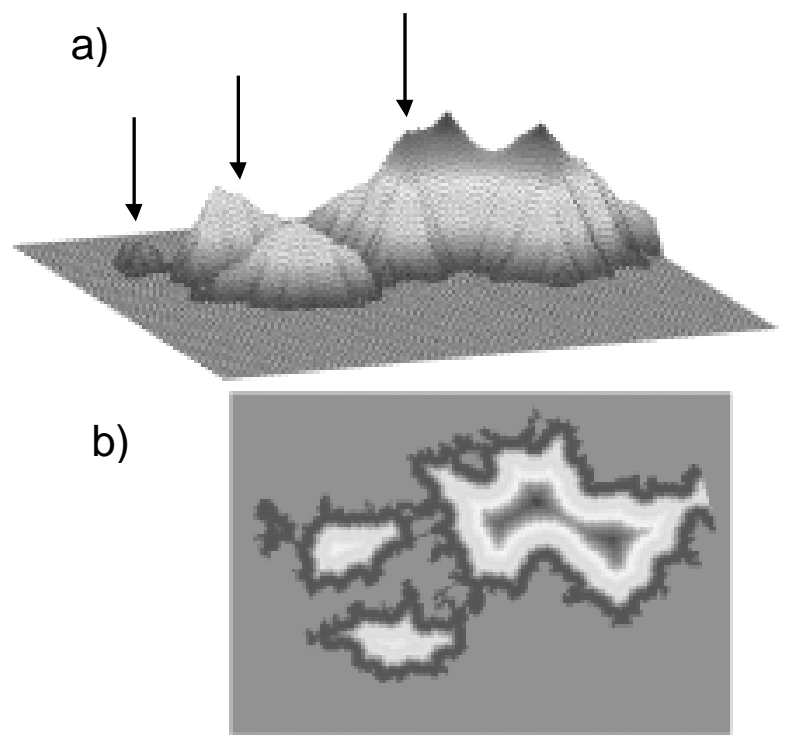


Figure 3.2. Effects of EDM manipulations, a) original, b) smoothing, c) elevation.

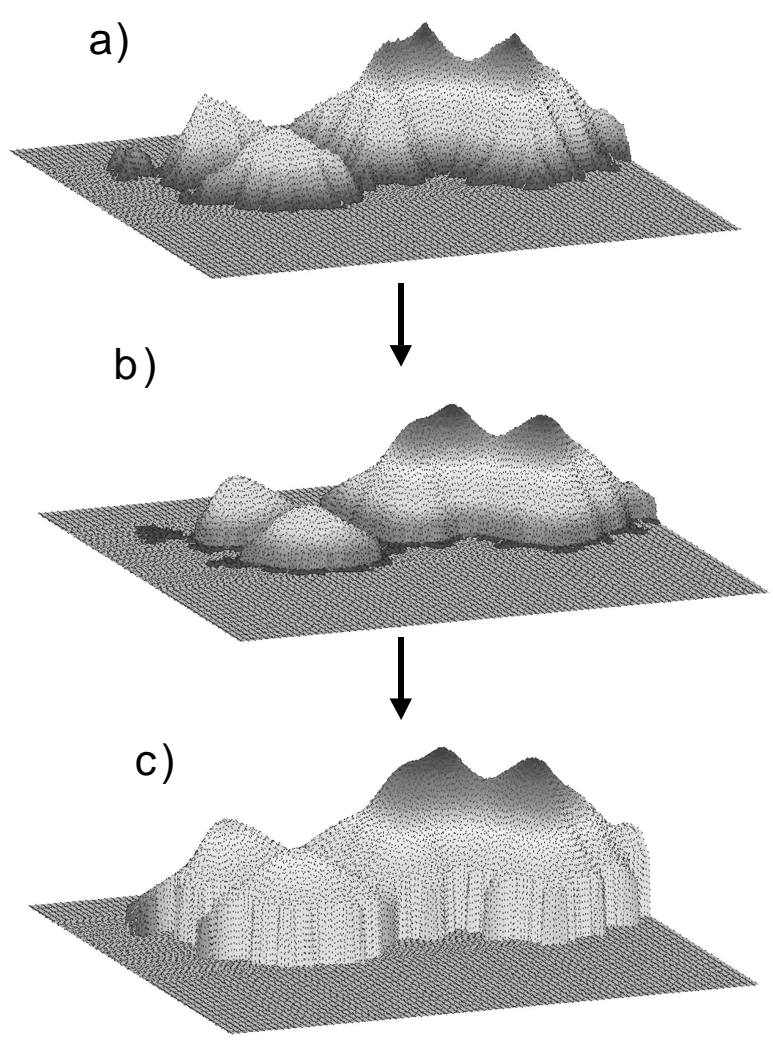


Figure 3.3. 3X3 moving window in watershed segmentation considers fate of the central pixel based on a table of the 256 possible configurations of its 8 neighbors. In examples, a) pixel turned "off" to prevent connection between currently separated features b) pixel turned "on" due to previous diagonal connection between hemlock feature. Light squares represent non-hemlock cover. Darker squares represent hemlock cover.

a)

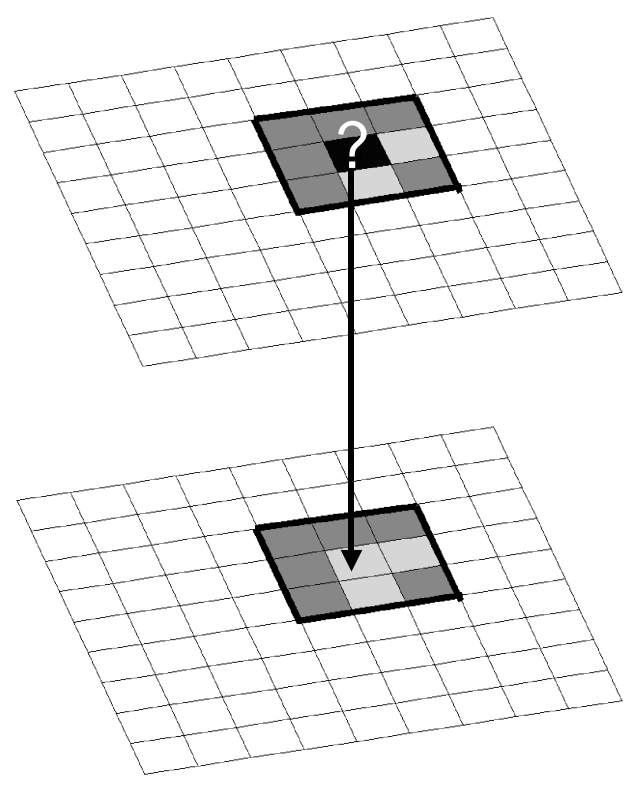

b)

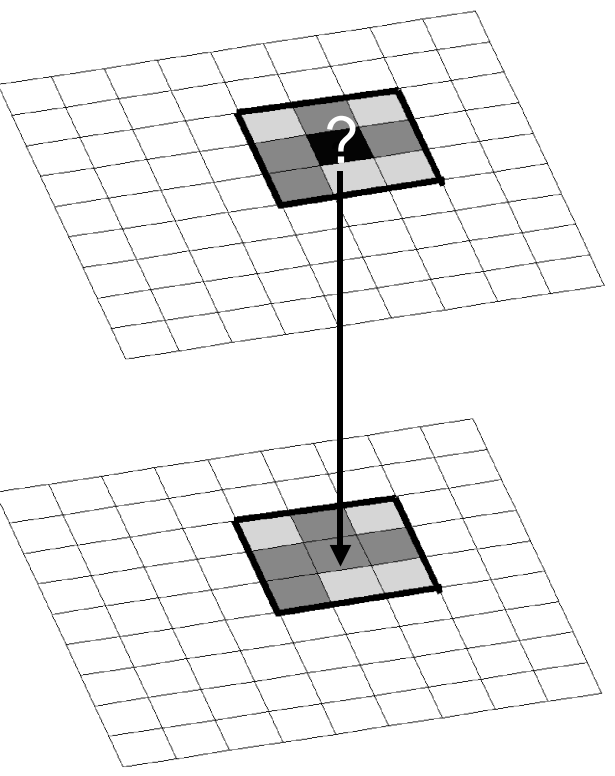




\section{Automated Crown Reconciliation}

Because of variations in viewing geometry, as well as real changes in hemlock shape, not all segmentation lines were identical in the different images and some hemlock pixels were assigned to different blobs in different years. This condition makes no biological sense, since hemlock branches cannot switch trees, and it complicates the censusing of unique blobs over time. An automated procedure, which we term blob reconciliation, was developed to reconcile patches of these cross-identified pixels, termed parcels, into the same blob for each image of an image pair. The reconciliation of these parcels considered the strength of the connection between each parcel and the parcel's neighboring blobs on both images of an image-pair.

Prior to reconciliation, both, parcels to be reconciled and pixels not requiring reconciliation were identified. As part of this identification process, images at time $t$ and $t+1$ of an image pair were overlaid (Figure 3.4a). Hemlock pixels from the overlaid map were classified according to their classification history as 1) joint-year pixels, identified as hemlock at both $t$ and $t+1$ or 2) single-year pixels, identified as hemlock at either, but not both, $t$ or $t+1$ (Figure 3.4b). No crown reconciliation was necessary for pixels classified into the same unique blobs at both time periods. These pixels, the large majority of all pixels within all image pairs (68.6 -78.6\%), were added unaltered to base maps $t$ and $t+1$ (Figure 3.4c). The remaining pixels, to be considered for reconciliation, were grouped into spatially distinct parcels.

These parcels were considered for reconciliation as part of a five- step automated procedure (Figure 3.5). At each step, reconciled parcels were added to the growing base 
map. Reconciliation decisions were based on the relationship between a parcel's greatest relative connection with a neighboring blob, termed connectivity, and a threshold connectivity value ( $(\Psi)$ that was obtained from a systematic analysis of the training data. If the parcel's greatest connectivity $<\Psi$, then the parcel, deemed lacking any significant connection with neighboring blobs, was assigned as a new and unique blob on base maps $t$ and $t+1$. If the parcel's greatest connectivity $\geq \Psi$, then the parcel was added to its greatest common neighboring blob on base map $t$ and $t+1$ (Figure 3.4d). If the parcel's greatest connectivity $=0$, the result of the parcel having different greatest common neighboring blobs at $t$ and $t+1$ and neither of these different blobs being found within the boundary scanning area at the other census time, then no decision regarding the parcel was made at that reconciliation step. The parcel was, instead, deferred to a later step, where, additional information and a growing base map may assist reconciliation efforts.

The connectivity between parcel and neighboring blob was a primary factor used for reconciliation. The nature of this connectivity varied at different reconciliation steps as other factors, such as a parcel's classification history or the size of the boundary scanning area, were considered (Table 3.1). The input of this additional information improved the correspondence between reconciled blob map and manual crown survey map.

A parcel for the first step of reconciliation, termed a dual parcel, was defined as a contiguous patch of joint-year pixels and (if present) any contiguous patches of singleyear pixels for which the joint patch was the greatest common neighboring patch (GCNP) as measured by the size of their contiguous boundary. A dual parcel thus, 
consisted of both joint-year and single-year pixels. Parcels, deferred in this initial step of reconciliation, were redefined in the second step of reconciliation, as contiguous patches of only single-year pixels and termed single parcels. For non-reconciled parcels from step one that were dominated by single-year pixels, the separate consideration of these single parcels often resulted in the identification of unique blobs that corresponded to individual hemlock crowns on the manual crown map; crowns that either were "born" or died between census periods.

Most parcels were reconciled and added to the base maps during the initial two reconciliation steps. Due to viewing geometry issues or real changes in hemlock shapes between images, some parcels remained non-reconciled. These parcels had different greatest common neighboring blobs at time $t$ and $t+1$ both of which had "moved" a large enough distance from the corresponding time period to be outside the boundary scanning area at the other census time. To give further consideration to the reconciliation of these parcels, the size of the moving window, in which the boundary size was measured, was increased. The larger boundary scanning area of later reconciliation steps permitted the reconciliation of parcels that may have belonged to the same tree on the ground but, due to geometric distortions, were slightly off-set on the image pairs.

For reconciliation steps where the considered parcel was defined as a dual parcel, connectivity, termed dual connectivity, was measured between each parcel and the parcel's greatest common neighboring blob at time $t$ and $t+1$ (Figure 3.6). Calculations of dual connectivity considered the strength of this parcel-blob connection from the 
perspective of both years of an image pair. For example, the connectivity of a parcel and its great common neighboring blob at time $t$ considers the connection between parcel and blob on the time $t$ map and, also the connection between the same two features on the time $\mathrm{t}+1$ map. Dual connectivity was measured on time $t$ map as:

Dual connectivity $(t)=\left(C B_{(t, t+1)}+C B_{(t, t)}\right) /\left(P_{t}+P_{t+1}\right)^{2} \quad$ Equation 3.1

where $\mathrm{CB}_{t, t+1}=$ Common boundary size of parcel and its greatest common neighboring

blob from time $t$ on time $t+1$ image, $\mathrm{CB}_{t, t}=$ Common boundary size of parcel and its

greatest common neighboring blob from time $t$ on time $t$ image, $\mathrm{P}_{t}=$ Size of parcel on

time $t$ image and $\mathrm{P}_{t+1}=$ Size of parcel on time $t+1$ image.

Dual connectivity measured on time $t+1$ map was calculated as:

Dual connectivity $_{(t+1)}=\left(C B_{t+1, t+1}+C B_{t+1, t}\right) /\left(P_{t}+P_{t+1}\right)^{2} \quad$ Equation 3.2

where $\mathrm{CB}{ }_{t+1, t+1}=$ Common boundary size of parcel and its greatest common

neighboring blob from time $t+1$ on time $t+1$ image and $\mathrm{CB} t+1, t=$ Common boundary size of parcel and its greatest common neighboring blob from time $t+1$ on time $t$ image. 
The patch's maximum connectivity was expressed as the larger value of Equations 3.1 and 3.2. The neighboring blob responsible for this maximum connectivity was termed the patch's greatest common neighboring blob.

For reconciliation steps where the considered parcels were defined as single parcels, a different measure of connectivity, termed single connectivity, was used. Since these parcels were comprised solely of pixels found only at one time of an image pair, single connectivity between these parcels and their greatest common neighboring blobs was measured based only on parcel size and common boundary size at that time. Single connectivity was calculated as:

Single connectivity $(t)=C B_{t, t} / P_{t}^{2}$ Equation 3.3

where $\mathrm{CB}{ }_{t, t}=$ Common boundary size of parcel and greatest common neighboring blob at time $t$ on time $t$ image and $\mathrm{P}_{t}=$ Size of parcel at time $t$.

In calculating all types of connectivity, the common boundary size between a parcel and its greatest common neighboring blob was measured as the sum of all pixels belonging to the considered parcel found within a moving window centered on the edge pixels of the neighboring blob.

Some small hemlock parcels were found to be irreconcilable after the five-step reconciliation procedure and eliminated from further analysis. These parcels were 
identified with different blobs for both image pairs; neither blob having a corresponding blob on the other image pair that was located within the maximum boundary scanning area of the reconciliation procedure. Less than $1 \%$ of hemlock pixels for each image within both image pairs were irreconcilable.

The automated blob reconciliation procedure was used to reconcile segmented hemlock blobs in each image of the 1997-98 and 1998-99 image pairs. 
Figure 3.4. Reconciliation process. a) non-reconciled blobs from both time periods, b) overlaid pixels classified as joint-year (green), single-year - 1997 only (red), or single-year - 1998 only (blue), c) patches of pixels combined into parcels (black) and subject to reconciliation, $d$ ) reconciled blobs from both time periods.

\section{$1997 \quad 1998$}

a)

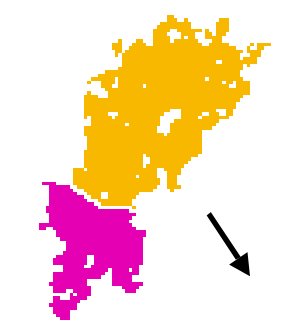

b)

c)
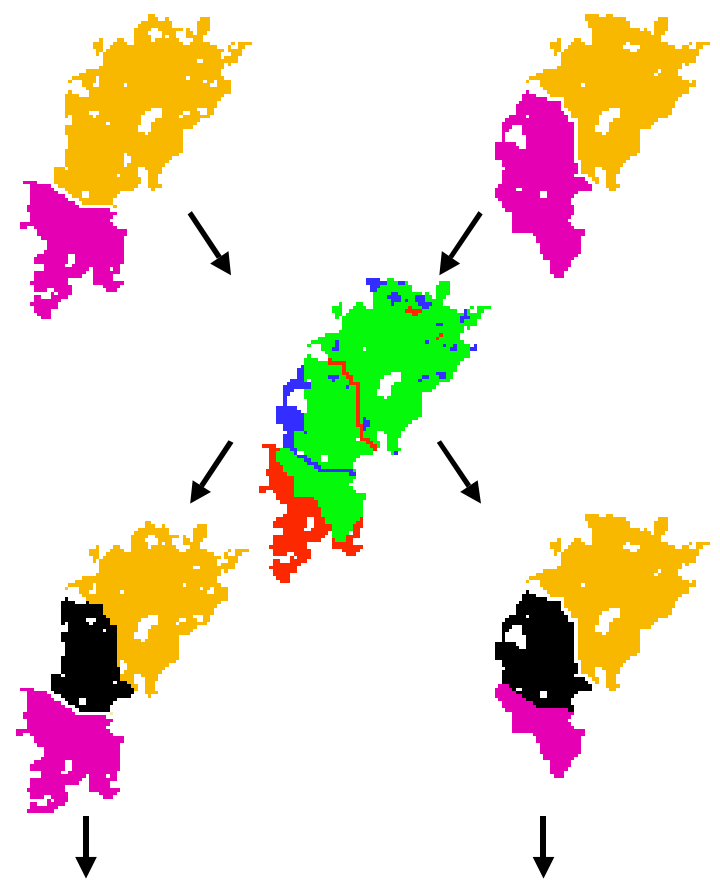

d)
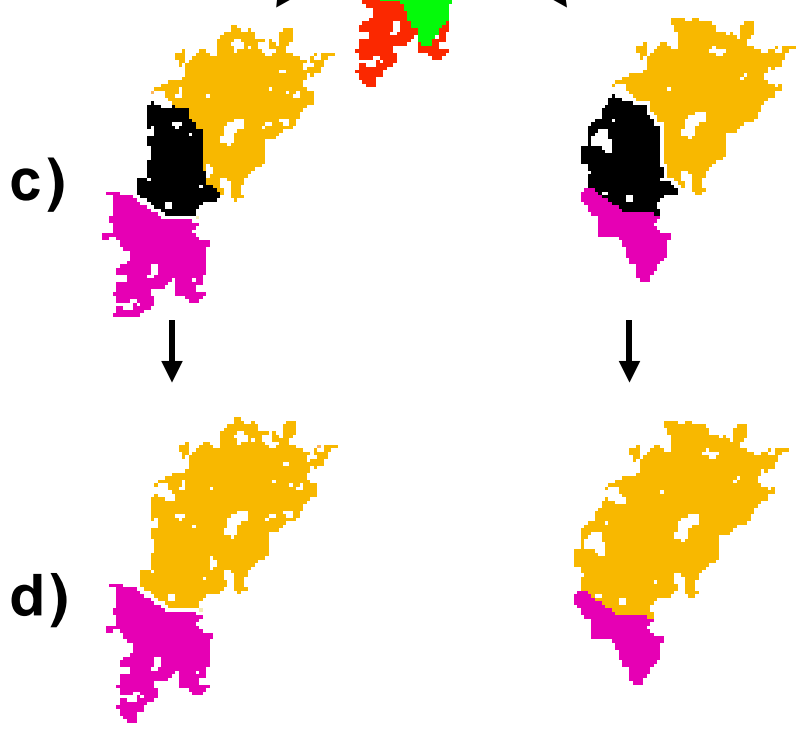
Figure 3.5. Reconciliation decision making. Solid lines represent actions of dualyear parcels. Dashed lines represent actions of the single parcels.

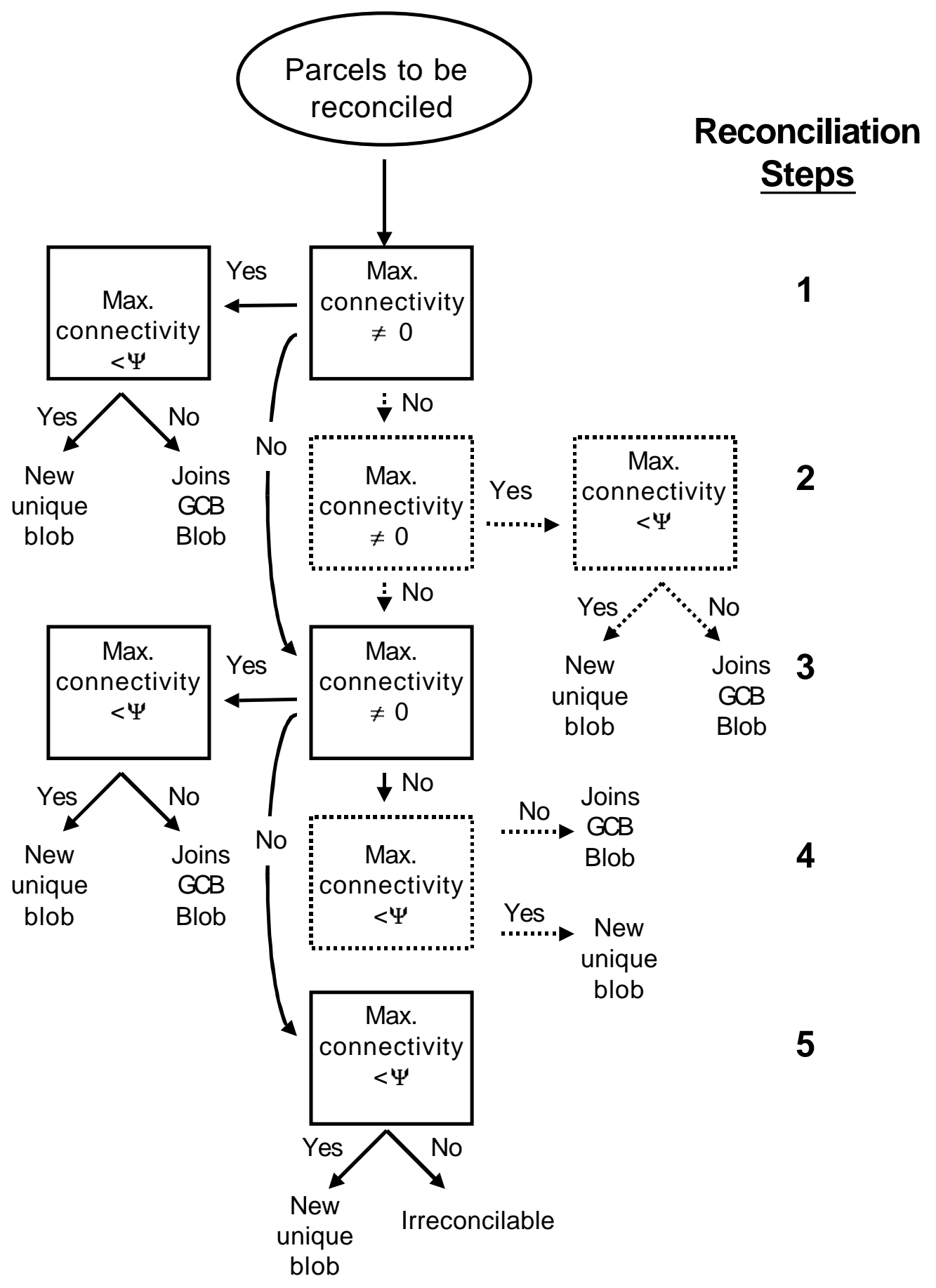


Table 3.1. Automated reconciliation procedure. $\Psi_{1}, \Psi_{2}, \Psi_{5}$ were estimated from training data and represent a threshold connectivity value that resulted in the highest measure of overall accuracy. $\Psi_{3}$ and $\Psi_{4}$ were calculated from $\Psi_{1}$ and $\Psi_{2}$ respectively, both sharing the same type of connectivity equation and parcel type. $\Psi_{3}$ and $\Psi_{4}$ reflect the added boundary scanning areas of these two measures: $\Psi_{3}=$ $\Psi_{1} * 0.51$ and $\Psi_{4}=\Psi_{2} * 0.36$.

Threshold Connectivity

\begin{tabular}{|c|c|c|c|c|}
\hline Step & Parcel Type & Scan Area & Value & Connectivity Equation \\
\hline 1 & $\begin{array}{l}\text { Dual-year + Single- } \\
\text { year GCNP }\end{array}$ & $5 \times 5$ & $\Psi_{1}$ & Dual (Equations 1 and 2) \\
\hline 2 & Single-year & $3 \mathrm{X} 3$ & $\Psi_{2}$ & Single (Equation 3) \\
\hline 3 & $\begin{array}{l}\text { Dual-year + Single- } \\
\text { year GCNP }\end{array}$ & $7 \times 7$ & $\Psi_{3}$ & Dual (Equations 1 and 2) \\
\hline 4 & $\begin{array}{l}\text { Single-year }>25 \\
\text { pixels }\end{array}$ & $5 \times 5$ & $\Psi_{4}$ & Single (Equation 3) \\
\hline 5 & Dual-year & $5 \times 5$ & $\Psi_{5}$ & Single (Equation 3) \\
\hline
\end{tabular}


Figure 3.6. Reconciliation procedure considers a parcel (black) that has been segmented into different crown blobs for 1997 and 1998. The difference in blob assignment between image years is due to the change in size and shape of blob $B$ in 1998 due to an ice storm. Measurements (in pixels) of parcel size and common boundary sizes for both years are shown. Dual connectivity (using Equations \#1 and \#2) is calculated as $13 * 10^{5}$ with blob $A$ and $8.5 * 10^{5}$ with blob B. Since the parcel's greatest connectivity $\left(13 * 10^{5}\right.$ with blob $\left.A\right) \geq \Psi_{1}$, the joint parcel was assigned to blob A on both 1997 and 1998 maps (see Figure 3.4d).
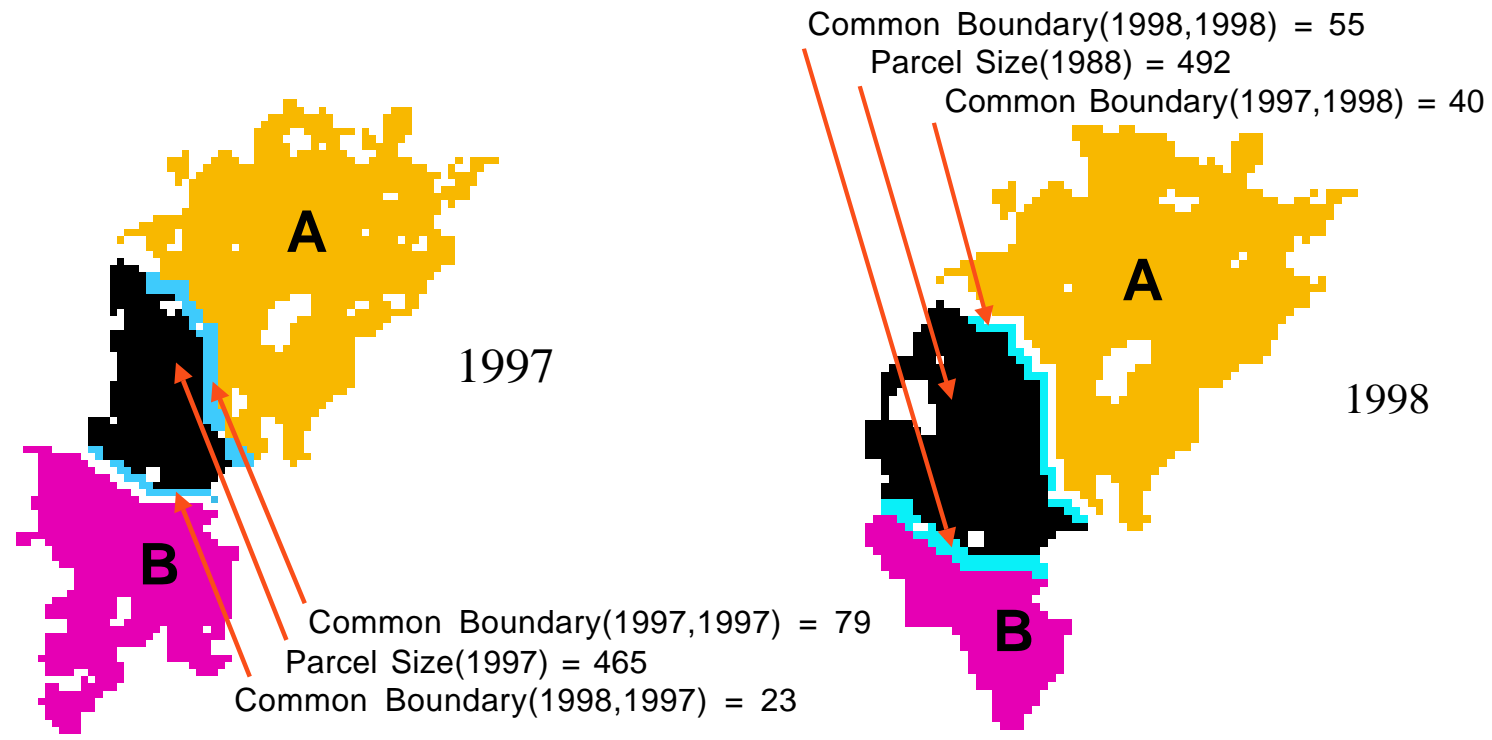


\section{Accuracy Assessment - Automated Segmentation and Reconciliation}

Unlike pixel-based accuracy assessments that have achieved at least some level of standardization over time (Congalton 1991), the accuracy assessments of object-based segmentation efforts have been quite limited and varied. The type of assessment performed is often dependent on the objectives of the study and the type of ground referenced data available for comparison. One type of assessment, which we term whole plot accuracy, compares the total number of manually delineated crowns with the total number of automatically delineated blobs within a designated area. Whole-plot assessments are often used when the only available description of the study area may be a measure or estimate of tree density. While useful for some stand level descriptions and monitoring activities, whole-plot assessments generally provide a poor measure of "true" accuracy due to the canceling actions of individual tree errors of omission and commission.

Methodologies assessing the 1:1 correspondence of "individuals" (in our case, automated blobs and manually delineated crowns) provide a much more useful measure of accuracy for demographic studies (Leckie and Gougeon 1998). Unlike pixel-based accuracy assessments, object-based assessments face added difficulties, having to make comparisons between features that lack uniform size and positional equivalency on comparison images. Given these differences, one must initially define when a crown and a blob have achieved 1:1 correspondence. In this study, we defined 1:1 correspondence as occurring when the overlap area between a manually delineated crown and an automated blob includes $\geq 50 \%$ of both features' total size. 
Using this definition, several different assessments can be made of the blob-crown relationship (Figure 3.7). One assessment, termed aerial accuracy, measures the percentage of automated blobs that achieve 1:1 correspondence with manually delineated crowns such that:

Aerial accuracy $=\frac{\# \text { of } 1: 1 \text { blobs corresponding to single crown }}{\text { Total } \# \text { blobs obtained from automated segmentation }} \quad$ Equation 3.4

Another assessment, termed field accuracy, considers accuracy from the crown's perspective, measuring the percentage of manually delineated crowns that achieve 1:1 correspondence with automated blobs such that:

Field accuracy $=\frac{\# \text { of } 1: 1 \text { crowns corresponding to single blob }}{\text { Total \# crowns obtained from manual segmentation }} \quad$ Equation 3.5

An assessment of the crown-blob relationship using either aerial or field accuracy alone can be misleading as errors of over-aggregation and over-dissection result in different blob: crown and crown: blob correspondences. For example, three manually delineated crowns aggregated into one blob results in one 3:1 crown: blob correspondence from the air perspective but three 0:1 crown: blob correspondences from the ground perspective. To more fully understand the relationship between manually delineated crowns and automated blobs it is necessary to describe this relationship from both perspectives. This accuracy assessment, which we term overall accuracy, describes the percentage of both manually delineated crowns and automated blobs that have 1:1 correspondence such that: 
Overall accuracy $=\frac{\# \text { of } 1: 1 \text { corresponding blobs }+\# \text { of } 1: 1 \text { corresponding crowns }}{\text { Total blobs }+ \text { Total crowns }}$

Equation 3.6

In this study, segmentation parameters (threshold shadow size, minimum blob joining size ) and reconciliation parameters $\left(\Psi_{1}, \Psi_{2}, \Psi_{5}\right)$ were estimated by selecting values that maximized overall accuracy in the training data. Overall accuracy is also calculated to describe the accuracy of the segmentation and reconciliation procedures for the 1997-98 and 1998-99 image pairs in comparison to the 1998 manual crown survey map. 
Figure 3.7. Accuracy assessment using 1:1 correspondence. a) overlays manual crowns on automated blobs, arrows point to blobs which contain $\geq 50 \%$ of overlaid crown, Aerial accuracy $=(1)$ 1:1 Corresponding Blob $/ 3$ Total Blobs $=33 \%$. b) overlays automated blobs on manual crowns, arrows point to crowns which contain $\geq 50 \%$ of overlaid blob, Field accuracy $=(1)$ 1:1 corresponding crown/3Total crowns $=33 \%$. Total accuracy $=(2)$ 1:1 corresponding blobs and crowns/ 6 Total blobs and crowns $=33 \%$. Interestingly and, perhaps misleadingly, whole plot accuracy for this example is $100 \%$ ( 3 crowns $/ 3$ blobs)..

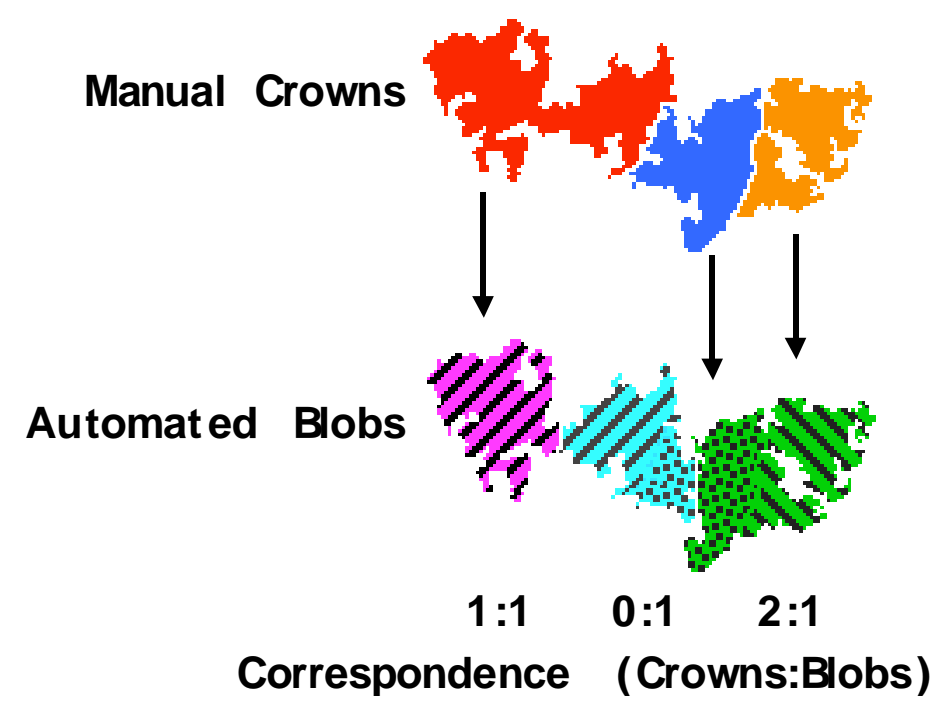

(a)

Correspondence (Crowns:Blobs)

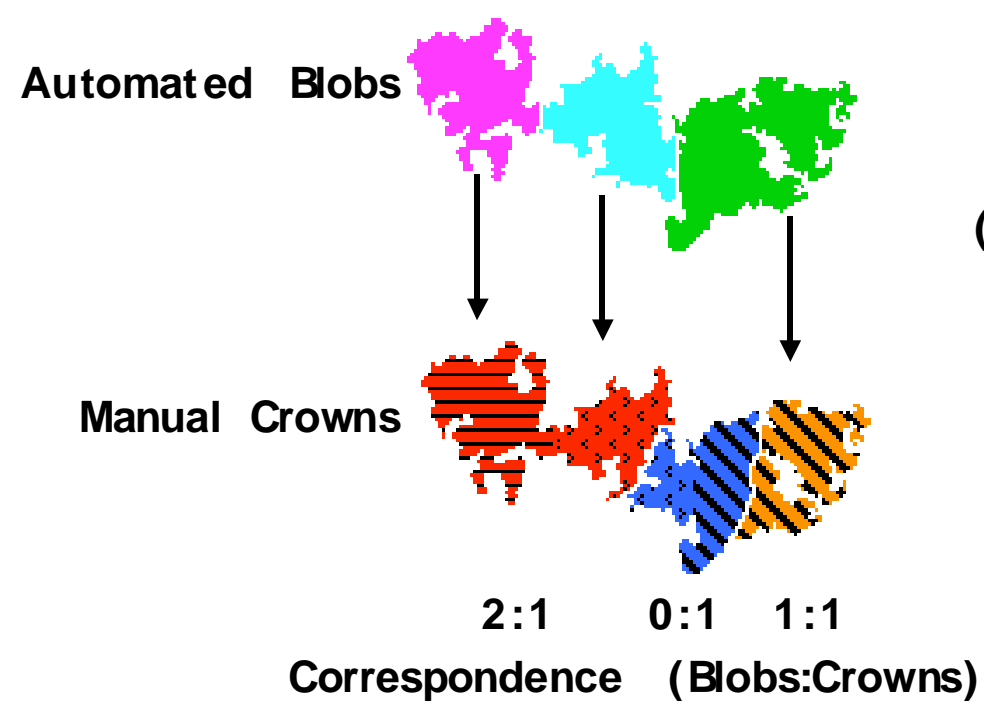

(b) 


\section{Results}

A good correlation $(r=0.759)$ was found between measurements of 1998 hemlock size in the air (crown area) on both 1997/98 and 1998/99 image pairs and on the ground (dbh) despite the elimination of all pixels exhibiting hemlock-shadow transitions within each image pair map. This correlation was similar to the correlation $(r=0.776)$ found between the same two size measures on the 1998 imagery without shadows added (Lamar and McGraw submitted).

The regression of crown area on dbh produced a regression equation of:

Crown Area (in pixels) $=37.6585+28.0415 \mathrm{dbh}$

Equation 3.7

Substituting the minimum ground sampling size $(\mathrm{dbh})$ of $5 \mathrm{~cm}$ into the regression equation, resulted in a blob threshold size of 178 pixels (diameter $\sim 2 \mathrm{~m}$ ). Contiguous hemlock patches below this size, many of which could not be accurately traced to any single hemlock crown, were considered noise and eliminated from further consideration.

The size of intra- and inter-size shadows, as identified in the training plot, differed significantly. Intra-crown shadows were found to be significantly smaller than intercrown shadows for 1998 hemlocks on both the 1997/1998 and 1998/1999 image pairs (Wilcoxon Rank Sum test, $\mathrm{p}>0.0001$ for both pairs). The results of a systematic trial of threshold shadow sizes showed overall classification accuracy to initially improve as the threshold shadow size was increased (Figure 3.8). This increased accuracy was a result of the closing of intra-crown shadows and, consequently, a decrease in the over 
dissection of manual crowns. The continued increase of threshold shadow size eventually resulted in the closure of inter-crown shadows. With these closures, overall classification accuracy began to decline as manual crown over-aggregation increased. Optimal threshold shadow size was the size that minimized both types of segmentation problems resulting in the highest overall classification accuracy for hemlocks within the training plot. This optimal size was found to be 40 pixels $($ diameter $=90 \mathrm{~cm})$ for 1997/1998 data and 55 pixels (diameter $\sim 1 \mathrm{~m}$ ) for 1998/1999 data.

The development of a minimum blob joining size also required the balancing of segmentation errors for both automated blobs and manually delineated crowns (Figure 3.9). As minimum blob size increased, the number of 0: 1 blob: crown correspondence errors decreased while the number of 0:1 crown: blob correspondence errors increased. A minimum blob size of 350 pixels (diameter $=2.68 \mathrm{~m}$ ) achieved the highest overall accuracy measurements for 1998 hemlocks of both image pairs within the training plot. All hemlock blobs smaller than this minimum size were joined to their contiguous neighbor with whom they shared the largest common boundary.

Assessing the accuracy of the automated segmentation procedure in comparison to the 1998 manual crown survey map, we found automated blobs and manually delineated crowns had 71.2\% 1:1 correspondence in the 1998-97 image pair and 64.3\% 1:1 correspondence in the 1998-99 image pair (Tables 3.1 and 3. 2). 
Threshold connectivities $\left(\Psi_{1}, \Psi_{2}, \Psi_{5}\right)$ in the reconciliation procedure were estimated from the training plot data (Table 3.3).

Assessing the accuracy of the automated reconciliation procedure in comparison to the 1998 manual crown survey map showed manually delineated crowns and automated blobs had 71.8\% 1:1 correspondence for the 1998-97 image pair and 63.3\% 1:1 correspondence for the 1998-99 image pair (Tables 3.4 and 3.5). 
Figure 3.8. Effect of varying threshold shadow size on overall accuracy, training plot, 1998 data from 1998/1997 $\quad$ - image pair and 1998/99 $\quad$ image pair

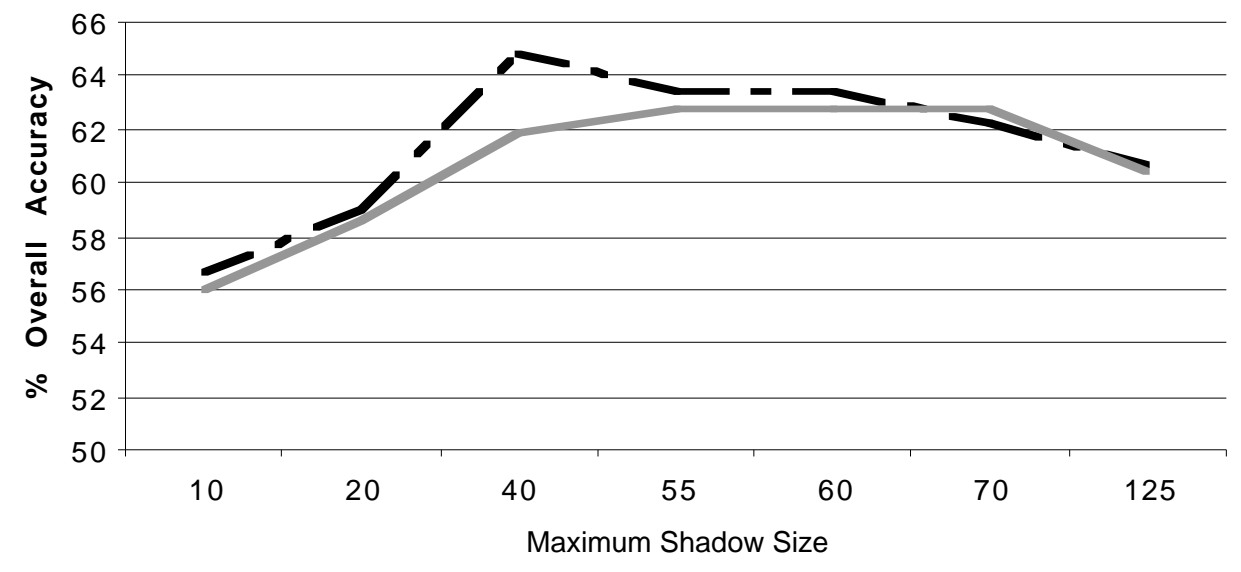


Figure 3.9. Effect of varying minimum blob size on 0:1 correspondences for automated blobs - - and manual delineated crowns, $=1998$ hemlocks (1998-99 image pair).

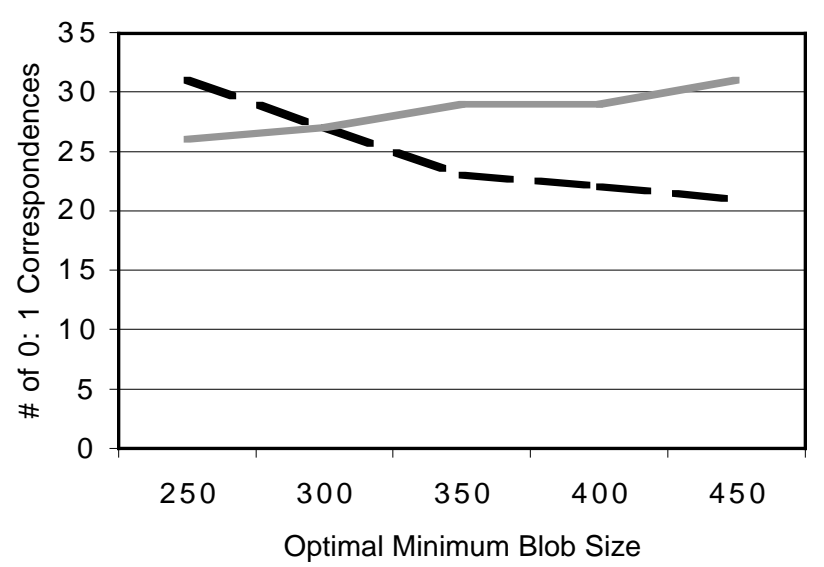

Table 3.2. Accuracy assessment - automated blob segmentation procedure (1998 data for 1997/1998 image pair)

$$
\text { Correspondence }
$$

$\begin{array}{lllll}4: 1 & 3: 1 & 2: 1 & 1: 1 & 0: 1\end{array}$

\begin{tabular}{llllll}
\hline Aerial Accuracy (Crowns: Blob) & 1 & 6 & 51 & 371 & 89 \\
Ground Accuracy (Blobs: Crown) & 0 & 3 & 57 & 372 & 93 \\
\hline
\end{tabular}

Overall Accuracy $=743 / 1043=71.2 \%$ 
Table 3.3. Accuracy assessment - automated blob segmentation procedure (1998 data for 1998/1999 image pair)

\begin{tabular}{llllll} 
& \multicolumn{7}{c}{ Correspondence } \\
\hline & $4: 1$ & $3: 1$ & $2: 1$ & $1: 1$ & $0: 1$ \\
& & & & & \\
\hline Aerial Accuracy (Crowns: Blob) & 2 & 11 & 56 & 342 & 113 \\
Ground Accuracy (Blobs: Crown) & 0 & 6 & 72 & 328 & 123 \\
\hline
\end{tabular}

Overall Accuracy $=670 / 1053=64.3 \%$

Table 3.4. Threshold connectivity values $(\Psi)$ for reconciliation procedure. $\Psi$ values shown equal $\Psi_{x} \mathbf{1 0}^{5}$.

\begin{tabular}{lll}
\hline & $1997 / 1998$ & $1998 / 1999$ \\
\hline$\Psi_{1}$ & 5 & 5 \\
$\Psi_{2}$ & 375 & 375 \\
$\Psi_{5}$ & 10 & 10 \\
\hline
\end{tabular}


Table 3.5. Accuracy assessment - automated blob reconciliation procedure (1998 data for 1997/1998 image pair)

\begin{tabular}{lccccc} 
& \multicolumn{6}{c}{ Correspondence } \\
\hline & $4: 1$ & $3: 1$ & $2: 1$ & $1: 1$ & $0: 1$ \\
\hline Aerial Accuracy (Crowns: Blob) & 0 & 11 & 49 & 359 & 79 \\
Ground Accuracy (Blobs: Crown) & 0 & 6 & 43 & 370 & 99 \\
\hline
\end{tabular}

Overall Accuracy $=729 / 1016=71.8 \%$

Table 3.6. Accuracy assessment - automated blob reconciliation procedure (1998 data for 1998/1999 image pair)

Correspondence

\begin{tabular}{lccccc}
\hline & $4: 1$ & $3: 1$ & $2: 1$ & $1: 1$ & $0: 1$ \\
\hline Aerial Accuracy (Crown: Blob) & 1 & 8 & 52 & 340 & 123 \\
Ground Accuracy (Blob: Crown) & 0 & 9 & 68 & 327 & 111 \\
\hline
\end{tabular}

Overall Accuracy $=667 / 1040=63.6 \%$ 


\section{Discussion}

The segmentation of a remotely sensed tree population into individual crowns presents a considerable challenge. While the results of this study compare favorably with other studies completed in mature natural forest stands (Leckie and Gougeon 1998), approximately $1 / 3$ of the hemlock blobs, segmented in the automated procedures, and hemlock crowns, from the manual crown survey map, did not achieve 1:1 correspondence. Numerous problems confront the spatial segmentation of individual crowns. Forked branches or crowns dissected by hardwood branches and shadows cause a spatial separation between crown segments that often leads to the over-dissection of an individual crown into multiple blobs. Conversely the lack of spatial separation between neighboring tree crowns can lead to the over-aggregation of several individual crowns as one blob. The architecture of hemlock branching, particularly the branching of individuals in the lower canopy can accentuate these segmentation problems; with the wide, spreading, and quite flexible hemlock branches often becoming intertwined with neighboring crowns. Interestingly, despite the segmentation difficulties illustrated by our correspondence assessment, whole plot accuracy levels were quite high for both the segmentation procedure $(98.7-99.1 \%)$ and reconciliation procedure $(96.1-98.3 \%)$ for both 1997-98 and 1998-99 image pairs. These high accuracy figures seem to highlight both the value of the automated procedures for some types of monitoring situations and the need to clearly describe how the accuracy of any segmentation procedure was assessed.

Previous post-classification change detection studies have encountered problems due to the compounding of classification errors for the multitemporal imagery (Pilon et al. 
1988). While pixel based errors in this study may be subject to similar error compounding, its impact is lessened by the high overall accuracy (>92\%) of spectral classification (Lamar and McGraw submitted). The accuracy of multitemporal objectbased classification can also be negatively affected by the compounding of segmentation errors from both multitemporal images into each multitemporal image. The challenge for reconciliation is to determine which contradictory segmentation lines within multitemporal image pairs should be included to maximize overall classification accuracy. We adopted a best-fit approach towards this challenge by measuring the dual connectivity of reconcilable parcels from the perspective of both multitemporal images. Reconciliation accuracy also benefits by considering a parcel's spectral classification history in reconciliation steps 2 and 4 . This allows the connectivity of single parcels, contiguous patches of pixels classified as hemlock in only one year of an image pair, to be considered independently and uniquely. The result is that overall classification accuracy for both image pairs following reconciliation is only slightly different than accuracy prior to reconciliation $(<1.0 \%)$.

Spatial resolution advances in space-based, remote sensing devices will result in future sub-continental and continental scale data sets that can be "mined" for demographic information on trees, shrubs, and other plants of interest. Therefore, explicit considerations of the relationship between "individuals" (i.e. blobs), as seen from above, and true individuals in the global population of a species will become important. In this study, we presented both an automated methodology for extracting a population data set from remotely sensing imagery and a description of the relationship between blobs 
viewed from the air and individual trees. The future availability of huge, spatially explicit, remotely sensed, population data sets should assist investigations within a number of diverse areas of study such as rare plant conservation, intraspecific plant interactions, and the effects of spatial and temporal environmental variability including global climate change effects on plant dynamics. 


\section{References}

Aldred, A. H., and L. Sayn-Wittgenstein. (1972), Tree diameters and volumes from large scale aerial photographs. Forest Management Institute Information Report FMRX-40, Canadian Forestry Service.

Bormann, F. H., and B. F. Graham. (1959), The occurrence of natural root grafting in eastern white pine, Pinus strobus and its ecological implications. Ecology 40:677691.

Brandtberg, T., and F. Walter. (1998), An algorithm for delineation of individual tree crowns in high spatial resolution aerial images using curved edge segments at multiple scales. in D. A. Hill and D. G. Leckie, editors. International Forum: Automated Interpretation of High Spatial Resolution Digital Imagery for Forestry. pp. 41-54 Natural Resources Canada, Victoria, British Columbia.

Congalton, R. G. (1991), A review of assessing the accuracy of classifications of remotely sensed data. Remote Sensing of Environment 37:35-46.

Enright, N., and J. Ogden. (1979), Applications of transition matrix models in forest dynamics; Araucaria in Papua New Guinea and Nothofagus in New Zealand. Australian Journal of Ecology 4:3-23.

Godman, R. M., and K. Lancaster. (1990), Tsuga canadensis, in Silvics of North America, Vol. 1. Conifers. US Department of Agriculture, Washington, DC pp. pp 604-612.

Gougeon, F. A. (1995), A crown-following approach to the automatic delineation of individual tree crowns in high spatial resolution aerial images. Canadian Journal of Remote Sensing 21:274-284. 
Graetz, R. D. (1990), Remote sensing of terrestrial ecosystem structure: an ecologist's pragmatic view, in Remote sensing of biosphere functioning. Edited by R. J. Hobbs and H. A. Mooney. Springer-Verlag, New York pp. 7-30.

Graham, B. F. (1959), Root-grafts in eastern white pine, Pinus strobus L; Their occurrence and ecological implications. Ph.D. Duke University, Durham, NC.

Hagan, G. F., and James L. Smith. (1986), Predicting tree groundline diameter from crown measurements made on 35-mm aerial photography. Photogrammetric Engineering and Remote Sensing 52:687-690.

Hall, F. G., D. B. Botkin, D. E. Strebel, K. D. Woods, and S. J. Goetz. (1991), Largescale patterns of forest succession as determined by remote sensing. Ecology 72:628-640.

Harper, J. L. (1976), The concept of population in modular organisms, in Theoretical Ecology. Principles and Applications. Edited by R. M. May. Blackwell Scientific Publications, Oxford pp. 53-77.

Hartshorn, G. S. (1975), A matrix model of tree population dynamics, in Tropical Ecological Systems. Edited by F. B. Golley and E. Medina. Springer-Verlag, New York pp. 41-51.

Huenneke, L. F., and P. L. Marks. (1987), Stem-dynamics of the shrub Alnus incanta ssp. rugosa: transition matrix models. Ecology 68:1234-1242.

Jenson, J. R., K. Rutchey, M. S. Kock, and S. Narumalani. (1995), Inland wetland change detection in the Everglades Water Conservation Area 2A using a time series of normalized remotely sensed data. Photogrammetric Engineering and Remote Sensing 61:199-209. 
Kramer, H. J. (2002), Observation of the Earth and its Environment - Survey of Missions and Sensors, 4th edition. Springer Verlag.

Lahav-Ginott, S., R. Kadmon, and M. Gersani. (2001), Evaluating the viability of Acacia populations in the Negev Desert: a remote sensing approach. Biological Conservation 98:127-137.

Lamar, W. R., and J. B. McGraw. (submitted), A comparison of a population census of eastern hemlock (Tsuga canadensis L) on the ground and using aerial photography. Canadian Journal of Remote Sensing Pending.

Leckie, D. G., and F. A. Gougeon. (1998), An assessment of both visual and automated tree counting and species identification with high spatial resolution multispectral imagery, in D. A. Hill and D. G. Leckie, editors. International Forum: Automated Interpretation of High Spatial Resolution Digital Imagery for Forestry. pp. 141152, Victoria, British Columbia.

Malingreau, J. P., and C. J. Tucker. (1988), Large-scale deforestation in the southeastern Amazon Basin of Brazil. Ambio 17:49-55.

Martinez-Ramos, M., Elena Alvarez-Buylla, and Jose Sarukhan. (1989), Tree demography and gap dynamics in a tropical rain forest. Ecology 70:555-558.

McGraw, J. B. (1989), Effects of age and size on life histories and population growth of Rhododendron maximum shoots. American Journal of Botany 76:113-123.

Minor, C. O. (1951), Stem-crown diameter relations in southern pine. Journal of Forestry 49:490-493.

Niemann, K. O. (1995), Remote sensing of forest stand age using airborne spectrometer data. Photogrammetric Engineering and Remote Sensing 61:1119-1127. 
Pilon, P. G., P. J. Howarth, and R. A. Bullock. (1988), An enhanced classification approach to change detection in semi-arid environments. Photogrammetric Engineering and Remote Sensing 54:1709-1716.

Pinz, A. J. (1991), A computer vision system for the recognition of trees in aerial photographs. in T. Tilden, editor. Multisource Data Integration in Remote Sensing. pp. 111-124 NASA Conference.

Pollock, R. (1998), Individual tree recognition based on a synthetic tree crown image model, in D. G. Leckie and D. A. Hill, editors. International Forum: Automated Interpretation of High Spatial Resolution Digital Imagery for Forestry. pp. 25-34 Natural Resources Canada, Canadian Forest Service, Victoria, British Columbia.

Rasband, W., and S. Roervik. (1999), NIH Image. National Institutes of Health.

Russ, J. C. (1995), The Image Processing Handbook, 2nd edition. CRC Press, Boca Raton.

Souto, D., Tom Luther, and Bob Chianese. (1996), Past and current status of HWA in eastern and Carolina hemlock stands, in S. M. Salom, T.C. Tigner, and R.C. Reardon, editor. Proceedings of the first hemlock woolly adelgid review. pp. 9-15 U.S. Department of Agriculture, Charlottesville, Virginia.

Usher, M. B. (1972), Developments in the Leslie matrix model, in Mathematical Models in Ecology. Edited by J. N. R. Jeffers. Blackwell Scientific Publications, Oxford pp. 29-60. 


\section{CHAPTER 4}

A comparison of population models for eastern hemlock (Tsuga canadensis $\mathbf{L}$. derived from ground and remotely sensed data. ${ }^{1}$

${ }^{1}$ This chapter formatted according to author's instructions for submission to Ecology. 


\section{Abstract}

Matrix population models for a population of eastern hemlock ( $\underline{\text { Tsuga canadensis }}$ L.) were constructed from population data collected on the ground using traditional field methods and analogous data extracted from low elevation aerial imagery. This aerial derived data was retrieved using spectral and spatial segmentation and reconciliation procedures. Fertility estimates for the aerial derived matrix model made use of the spatially explicit nature of remotely sensed data to estimate fertility as a function of both parental size and distance between perspective parent and newborn. Matrix analysis produced a number of useful population characteristics including overall population growth rate $(\lambda)$, stable stage distributions, reproductive values, and sensitivity values. $\lambda$ 's calculated from the aerial and ground-derived matrices were compared using randomization tests. While $\lambda$ 's of the matrices derived from ground censusing in 199798 and 1998-99 showed no significant change, $\lambda$ 's from the matrices derived from aerial imagery for this same time period showed a significant increase. Other data measured from the aerial imagery and on the ground seemed to support this population status change, the result of a damaging February 1998 ice storm. While providing a different perspective and description of a population than traditional ground studies, demographic studies using remote sensing provide some promising advantages. The spatially explicit nature of the data permits more biologically realistic modeling of the population and the investigation of potential environmental influences on population dynamics. Automated extraction of demographic or megademographic data from remotely sensed images represents an important first step toward scaling population analysis to the landscape and regional levels. 
Keywords: matrix population model, hemlock, remote sensing, population growth rate, demography, spatially explicit population data, fertility probabilities 


\section{Introduction}

The collection of basic demographic data for assessing species survival is of immediate importance regarding species conservation (Lande 1988). Given the alarming rise in the number of threatened species, conservation biologists face an increasing challenge to gather this basic demographic information (Schemske et al. 1994). One of the problems facing conservationists is the large investment in time and money that the typical demographic study demands (Silvertown et al. 1996). Consequently, the numbers of demographic studies conducted are few in comparison to the scientific needs of the conservation community. The demographic studies that are completed typically are characterized by small sample sizes and sampling areas.

Among the many environmental challenges currently facing ecologists, the invasion of exotic pest species can result in potentially devastating ecological consequences (Kareiva 1996). The impact of these invasions can often vary widely both spatially and temporally. The ability to predict patterns and severity of future invasions is of critical importance to resource management efforts (Souto 1996).

In recent years spatially explicit population models have become increasingly important in the study of population dynamics in heterogeneous environments (Shugart and Smith 1992, Busing 1995, Dunning et al. 1995, Pacala et al. 1996). Because interactions among plants are localized, population dynamics are inherently spatial (Pacala 1989). One of the chief disadvantages of such models is the difficulty of obtaining spatially explicit population data in the field (Dunning et al. 1995). 
Remote sensing allows ecologists to collect large amounts of spatially explicit information over a large geographic area in a short amount of time. At present, high spatial resolution imagery provided by aircraft-based photographic systems appears to provide data at a scale most feasible for the collection of population level demographic data (Gougeon 1995b, Niemann 1995, Lamar and McGraw submitted) although recently launched space-based platforms (i.e. IKONOS and QuickBird) are approaching the resolution required to discern individuals (Kramer 2002).

The challenge to an ecologist is how to adapt the traditional methods of description and classification to be compatible with the nature of remotely sensed data (Graetz 1990). The basic unit traditionally used to describe populations has been the individual. Yet, the modular, as opposed to unitary, construction of most plants has long been recognized (Harper 1976). Using this modular approach the fundamental unit of a tree population may be regarded as any repeating unit of construction such as a tree branch or branches (Huenneke and Marks 1987, McGraw 1989) or tree blob (Chapter 3). In this last example, a tree blob, as characterized from aerial imagery, is defined as a distinct portion of crown canopy segmented from its neighbors on the basis of size, shape, and connectivity. Using automated segmentation and reconciliation procedures, a population of eastern hemlock (Tsuga canadensis L.) blobs has been previously described and censused over a 3 year period (Chapter 3 ). This spatially explicit, multitemporal data set provides a different perspective with which to investigate population dynamics and influences. 
Matrix population models have become the framework of choice in plant demographic studies due, in part, to the number of informative statistics provided by matrix analysis (Silvertown et al. 1996). Matrix models have been used to investigate the conservation of rare and threatened species (Menges 1990, Allphin and Harper 1997, Kaye et al. 2001), the control of invasive species (Golubov et al. 1999, Parker 2000), evolutionary change (Baptista et al. 1998) and species persistence in rapidly changing environments (Silvia et al. 1991). In constructing the matrix model, matrix elements usually describe the transition probability of individuals between life stages. Matrix models have also been constructed to describe the transition probabilities of plant parts (Huenneke and Marks 1987, McGraw 1989), pixels (Hall et al. 1991), and spatial units (Guàrdia et al. 2000).

In this paper, we constructed two matrix population models for a population of hemlock. Parameters for one of these models were estimated from demographic data collected on the ground using traditional field methods. Parameters for the other model were estimated from demographic data extracted from low elevation aerial imagery. The results of these aerial and ground-derived matrices were compared. The ability of matrix models constructed from both perspectives to detect and quantify population change and assist in the understanding of the causes of change was evaluated. The benefits of incorporating demographic data extracted from remotely sensed imagery into future population investigations was discussed. 


\section{Study Area}

Our study area is located in the Limberlost-Whiteoak Canyon area of Shenandoah National Park $\left(38^{\circ} 34^{\prime} \mathrm{N} 78^{\circ} 22^{\prime} \mathrm{W}\right)$. This site is located in an upper elevation $(951 \mathrm{~m})$ mixed hardwood/hemlock forest. Hemlock is a long-lived, shade-tolerant, evergreen tree found in many low disturbance eastern United States (US) forests. Established populations usually include a large bank of "saplings", small individuals that may be suppressed beneath a canopy of hemlock or hardwoods for hundreds of years and remain in good condition (Godman and Lancaster 1990). Following a disturbance in the upper canopy layer of the forest, these hemlock saplings experience rapid increases in height and lateral branch growth (Hibbs 1982). Hemlock ring widths show evidence of many release and suppression events and it is likely that multiple disturbance episodes are often needed for the trees to grow into the upper canopy (Oliver and Stephens 1977). Hemlock seed ripening and dispersal coincides with the cones changing to a deep brown color in the fall. Seeds require a chilling period prior to germination. Spring germination is seldom delayed because of seed dormancy (Godman and Lancaster 1990).

Like all hemlocks within Shenandoah National Park, the Limberlost-White Oak Canyon population has been adversely impacted in recent years by the presence of the Hemlock

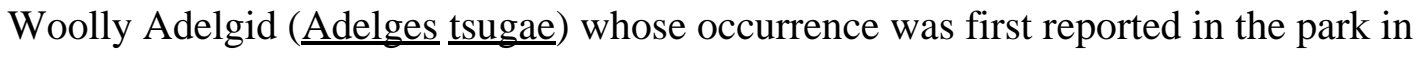
1988. This adelgid, which is believed to inject a toxic saliva into the hemlocks while feeding (Souto 1996), currently infests hemlocks in many Eastern US states. Unlike hemlocks in other park locations, most trees within the study site had only suffered mild to moderate defoliation at the time of aerial sampling. 
Within the study area, a 3 ha $(100 \mathrm{~m}$ X $300 \mathrm{~m})$ study plot and an adjoining 0.5 ha $(50 \mathrm{~m}$ $\mathrm{X} 100 \mathrm{~m}$ ) training plot were located. All parameter estimates used in the spatial segmentation and reconciliation procedures were developed using data from the training plot and then applied to the study plot for final analysis.

\section{Methods}

\section{Data Set Development - Ground}

Hemlock trees within the study site were censused in the early spring of 1997, 1998, and 1999. All hemlock trees $(\mathrm{n}=1438)$ with a diameter at breast height $(\mathrm{dbh}) \geq 5.0 \mathrm{~cm}$ within the site were tagged, dbh measured, classified according to crown density class $(\leq 10 \%$, $11-50 \%,>50 \%$ ), classified according to crown position (dominant/co dominant, intermediate or suppressed) and located on an X-Y grid map. Crown density was defined as the percentage of foliage that blocks visibility through the crown (Miller et al. 1992).

Within the study site, four 20 X 20 m sub-plots were randomly established and all smaller hemlocks $(\mathrm{dbh}<5.0 \mathrm{~cm})$ were tagged. The dbh of all hemlocks in the sub-plots was measured. Trees too small to have a central bole at breast height $(1.3 \mathrm{~m})$ were measured by height from ground to the topmost branch of its crown. All measurements of hemlock $<5 \mathrm{~cm}$ were taken in April of 1997,1998 and 1999. The number of new recruits within the four random plots were counted in 1998 and 1999 and used in the estimation of ground fertility probabilities. 


\section{Data Set Development - Remote Sensing}

Large scale $(1: 3,000)$ color aerial photographs of the study area were collected on March 27, 1997, April 13, 1998, and March 31,1999 using a calibrated Leica/Wild Heerbrugg RC-30 mapping camera with a $303.860 \mathrm{~mm}$ focal-length lens. The photography was acquired before the emergence of new foliage for the deciduous forest component. The color photographs were scanned at 600 dpi using an Agfa Dual Scan scanner to produce high resolution $(\sim 13 \mathrm{~cm} /$ pixel) digital images. With shared primary branch bifurcation points identified throughout the image segment as control points, images were coregistered using second order mapping polynomials and cubic convolution resampling (Lamar and McGraw submitted).

The evergreen vegetation of the study site was spectrally segmented from other ground covers. Spectral segmentation was completed using a maximum likelihood classification algorithm and a global, fused class decision making process. This process summarized the decisions of local class statistics derived from all three years of radiometrically normalized imagery over the same scene and applied this summary to each year's image (Lamar and McGraw submitted). Due to the relatively coarse spectral resolution of our sensor and the overlapping spectral signatures of the four evergreen components in our study site (hemlock - $\underline{\text { Tsuga canadensis, }}$, mountain laurel - $\underline{\text { Kalmia latifolia, }}$, red spruce -

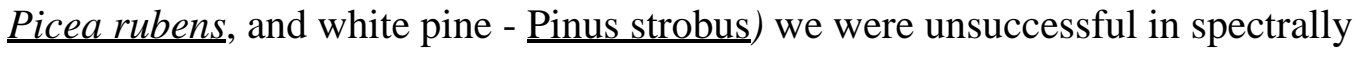
differentiating between evergreen species. A 1998 crown survey, performed by manually delineating individual hemlock crowns on the ground assisted by multiple years of aerial imagery and multiple images from different viewing angles each year, showed that 97\% of the evergreen component in the study site was hemlock (Lamar and McGraw 
submitted). Based on this finding, we will hereafter inclusively refer to the evergreen component as the hemlock component. The assumptions of this broad labeling will be discussed later.

For multitemporal image comparisons, the presence of crown shadows presents a challenge. The occurrence of shadows over an area masks the true nature of the ground cover. For example, if a particular area is classified as hemlock at time t and shadow at time $\underline{t}+1$, the shadows could be masking hemlock in which case no actual change has occurred, or the shadow could be masking an actual change between hemlock and another ground cover. Because of the classification uncertainty of areas exhibiting shadow/hemlock transitions between time periods, we chose to eliminate these areas from consideration prior to further image processing and comparison. This action resulted in any pixel that had been classified as shadow at any time in a multitemporal same scene dataset being re-classified as shadow at all times. While the compounding of shadows amplified the masking of information about the true nature of the ground cover, comparing only two images at a time minimized this effect. Thus, 1997 and 1998 shadows were added to both images within the 1997/1998 image pair and 1998 and 1999 shadows were added to both images of the 1998/1999 image pair.

These binary image pairs were then independently routed through a multi-step spatial segmentation procedure that included Euclidian distance map (EDM) construction, EDM manipulations, watershed segmentation, and minimum blob joining (Chapter 3). This procedure divided the hemlock component of the images into individual population units 
or blobs based on size and shape. Due to the different shapes of hemlock between years, not all segmentation lines were identical for the multitemporal images. Some hemlock pixels were assigned to different blobs in different years. Not only does this condition make no biological sense, since hemlock branches cannot switch trees, it also prohibits the following of unique blobs over time. An automated procedure was developed to reconcile these cross-identified pixels into the same blob for both time periods. Blob reconciliation was based on the connectivity between parcels of pixels considered for reconciliation and their neighbors. A full description of both the spatial segmentation and blob reconciliation procedures can be found in Chapter 3. Processing our aerial imagery through these procedures resulted in the production of two paired data sets, maps of spatially explicit hemlock blobs from 1997 and 1998 and from 1998 and 1999.

\section{Matrix Model}

A stage (size) structured matrix population model (Lefkovitch 1965) was used to describe the population dynamics of our hemlock population based on both ground and aerial data sets. This model projects the size and structure of a population from time $\underline{t}$ to time $\underline{t}+1$ as:

$\mathbf{n}(t+1)=\mathbf{A n}(t) \quad$ Equation 4.1

where $\mathbf{n}$ is a vector whose entries represent the number of population units (individuals for the ground data and blobs for the aerial data) within each size class and $\mathbf{A}$ is the projection matrix whose elements $\underline{\mathrm{a}}_{\mathrm{ij}}$ are transition probabilities; the number of population units in size class $\underline{i}$ at time $\underline{t}+1$ for each unit in size class $\underline{j}$ at time $\underline{t}$. An analysis of the matrix A provides a number of useful population characteristics. The dominant 
eigenvalue ( $\lambda$ ) of $\mathbf{A}$ projects the long-term population growth rate, assuming transition probabilities remain constant over time. The right eigenvector $(\mathbf{w})$ and left eigenvector (v) corresponding to $\lambda$ describe the stable size distribution and size-specific reproductive values of the population respectively. The sensitivity of $\lambda$ to changes in $\underline{a}_{i j}$ is based on these eigenvectors (Caswell 2001) as:

$\partial \lambda / \partial a_{i j}=\mathbf{v}_{i} * \mathbf{w}_{j} /<\mathbf{w}, \mathbf{v}>\quad$ Equation 4.2

Elasticity, or proportional sensitivity values for transition elements was calculated from Caswell (2001) as:

$\begin{array}{ll}\mathrm{e}_{i j}=\frac{a_{i j}}{\lambda} * \frac{\partial \lambda}{\partial a_{i j}} & \text { Equation } 4.3\end{array}$

\section{Life Cycle Comparisons}

The hemlock population modeled using ground and aerial data can be represented as life cycle graphs (Figure 4.1). Several of the differences between collecting ground and aerial data sets are illustrated by the life cycle graphs. The most obvious difference is the inability of remote sensing to detect all segments of the population. This cryptic layer of our hemlock population has been quantitatively described previously (Lamar and McGraw submitted). Nearly $90 \%$ of the small hemlocks (dbh 5-15 cm) were not detected on the aerial imagery. In addition to size, crown density and crown position in the canopy also influenced detection; hemlock with sparse and/or suppressed crowns were more likely to remain undetected from the air. Another difference between the two life cycle graphs is the greater number of potential transitions between stage classes in the 
aerial censused population in comparison to the ground censused population. These additional transitions are partly due to the different hemlock characteristics being sampled by the two methods. On the ground, the dbh of hemlock trees was measured; from the aerial imagery, the visible canopy area of hemlock blobs was measured. Size regression is rarely detected from dbh measurements. Growth in dbh is slow and gradual so that the only potential fates of surviving trees are to remain in the same class or grow to the next larger class. In contrast, changes in visible canopy area can potentially be much more dynamic. Crown regression, due to a number of environmental influences, is a common and readily detected characteristic. Although "true" growth of canopy area is relatively gradual, visible canopy area growth, from an aerial perspective, can be rapid due to the demise of neighboring crowns and the opening of nearby gaps in the forest canopy. 
Figure 4.1. Life cycle of a) individuals censused from ground and b) blobs censused from aerial imagery.

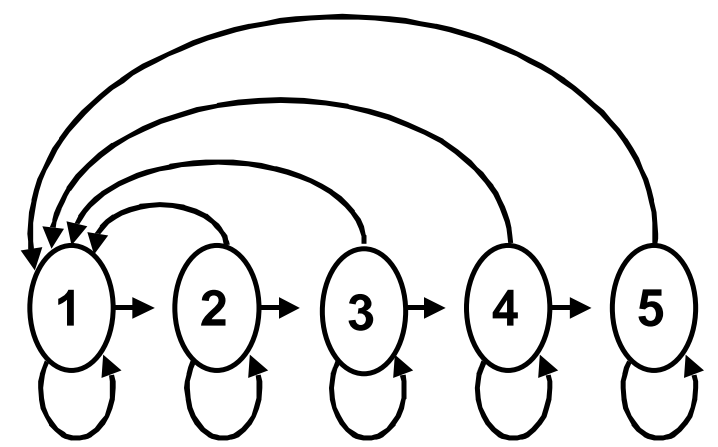

(a)

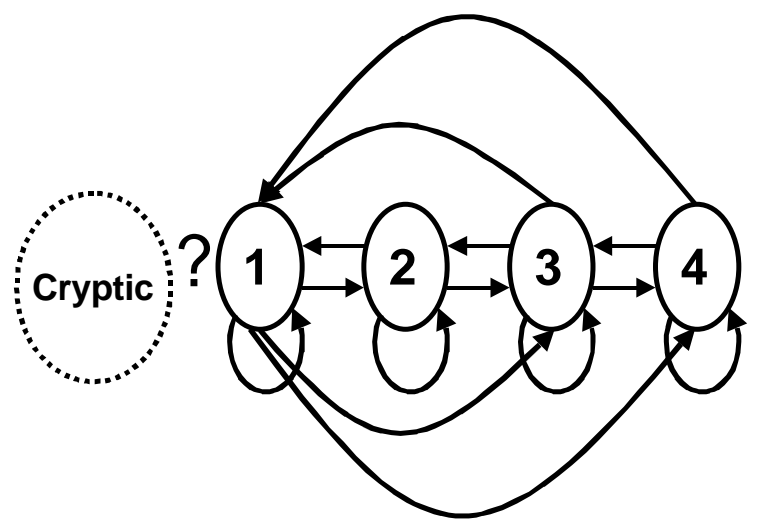

(b) 


\section{Parameter Estimates - Ground}

From the ground data, hemlock individuals were divided into five size classes 1$)<5.0$ cm dbh 2) 5.0 - $15.0 \mathrm{~cm} \mathrm{dbh} \mathrm{3)} 15.1-25.0 \mathrm{~cm} \mathrm{dbh} \mathrm{4)} 25.1-45.0 \mathrm{~cm} \mathrm{dbh} \mathrm{5)}>45.0 \mathrm{~cm} \mathrm{dbh}$. To establish size classes for all individuals $\geq 5.0 \mathrm{~cm}$, we used an algorithm developed by Moloney (1986), that minimized both sampling and distribution errors for the three years of data collection.

Estimates of matrix elements representing growth, regression and stasis were obtained using a maximum likelihood estimate of observed transition frequencies (Caswell 2001) from time $\underline{t}$ to time $\underline{t}+1$ such that

$$
a_{i j}=\frac{m_{i j}}{\sum_{i=1}^{s+1} m_{i j}} \quad \text { Equation } 4.4
$$

with $\underline{\mathbf{s}}$ being number of size classes in the population state vector $\underline{\mathbf{n}}$ and class $\underline{s}+1$ corresponding to individuals of a particular class $j$ that died in the year between censuses. $\mathrm{m}_{\mathrm{ij}}$ is the number of observed transitions from size class $\underset{j}{\mathrm{j}}$ to fate $\underline{\mathrm{i}}$ from one census to the next. Due to the smaller sampling area of size class 1 , only one estimate of this class' stasis and growth transitions was calculated by summing observed transitions from all three years of population data. This one estimate was used for both 1997-98 and 1998-99 ground-based matrix models.

Estimating mean fertility for individuals is challenging for any plant species that produces copious quantities of seed (too many to count), each of which has a very low (difficult to estimate) probability of germinating and surviving to the subsequent census. Therefore indirect estimates are typically used to calculate individual fertility 
probabilities. To do this, an estimate of total number of new recruits per year (M) was obtained by averaging the number of new recruits found in 4 randomly established $20 \mathrm{X}$ $20 \mathrm{~m}$ plots in 1998 and 1999 . Fertility probabilities were then estimated for all adults $(\mathrm{dbh} \geq 10 \mathrm{~cm})$ present in the population the previous year as a function of tree size. Both linear (Clark et al. 1998) and exponential (Ribbens 1994) recruitment patterns with size have been described for hemlock. Pinero et al. (1984) suggested that an exponential increase in fertility with size is the most common pattern found in tree species. We thus estimated fertility probability $\underline{\mathrm{f}}$ of each adult individual $\underline{\mathrm{k}}$ in the population as

$$
f_{k}=\sum_{k}^{\mathrm{dbh}_{k}{ }^{2}} * \mathrm{M} \mathrm{dbh}_{k}^{2} \quad \text { Equation } 4.5
$$

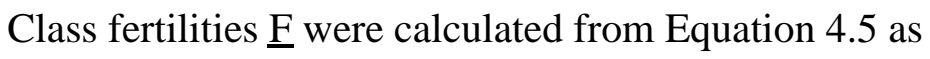

$$
F_{i}=\frac{\sum_{k} f_{k}(i)}{\mathrm{N}_{i}}
$$

where $\mathrm{N}$ is the total number of individuals in size class $i$.

Fertility estimates represented the average number of new recruits (time $\underline{t}+1$ ) per adult of that size class (i) in the population (time $\underline{t}$ ). The timing of sampling (early spring) meant that "new" seedlings had actually survived nearly a year since germination the previous spring. New recruits, thus, reflected both a germination and survival (from birth to the next census) component.

Typically, individuals of a long-lived, low disturbance species such as hemlock experience very little change between census periods. This lack of change can result in 
1) having all individuals in size class $\mathfrak{j}$ at time $\underline{t}$ survive to time $\underline{t}+1$ (in which case $\left.\sum_{i} a_{i j}=1.0\right)$ or 2 ) having no individuals from size class j grow into a larger class between census periods $\left(\underline{\mathrm{a}}_{\mathrm{ij}}=0\right.$ where $\left.\underline{\mathrm{i}}=j+1\right)$. This last condition is not a consideration for individuals being in the largest size class at time $\underline{t}$. Both conditions are the result of the limited nature of our sampling and are not expected to persist over time. Including any of these resulting transition probabilities within our matrix, should either condition occur, distorts our projection of population characteristics. Thus, alternative, and more biologically realistic, transitions were substituted into the matrix.

For any size class that showed no mortality over time we substituted an alternative transition probability into the matrix which calculated an average survival of both that size class (where mortality $=0$ ) and the next smaller size class so that

$$
\text { if } \sum_{i=2}^{5} a_{i j}=1.0 \text { then, } a_{i(i=j) j}(\operatorname{adj})=\left(\sum_{i=2}^{5} a_{i j}+\sum_{i=2}^{5} a_{i(j-1)}\right) / 2
$$

This alternative stasis transition replaced the original stasis transition for the formerly “immortal” size class.

For any size class that showed no growth over time, excluding the largest size class, we calculated the average growth rate of all individuals within the size class, and, based on this rate, projected the average number of individuals per year expected to grow into the next larger size class $\hat{N}_{\mathrm{ij}}($ where $\underline{\mathrm{i}}=\mathrm{i}+1)$ within a five year period. Adjusted estimates of 
growth $a_{i j}(\operatorname{adj})$ where $i=j+1$ and stasis $\mathrm{a}_{i j}(\operatorname{adj})$ where $i=j$ elements for size classes $1 \ldots \underline{S}$ were calculated as:

For all $a_{i j(i=j+1, j<s)}=0$,

$\mathrm{a}_{i j(i=j+1)}(\operatorname{adj})=\left(\hat{N}_{i j(i=j+1)}\right) / \mathrm{N}_{j}$ and $\mathrm{a}_{i j(i=j)}(\operatorname{adj})=\mathrm{a}_{i j(i=j)}-\mathrm{a}_{i j(i=j+1)}(\operatorname{adj}) \quad$ Equation 4.8

where $\mathrm{N}_{\mathrm{i}}=$ number of individuals in size class $\mathrm{j}$ at time $\underline{\mathrm{t}}$.

\section{Parameter Estimates - Remote Sensing}

In order to make comparisons between models produced from traditional ground data and remote sensing data, we attempted to devise corresponding individual and blob size classes as follows. The population of hemlock blobs delineated from aerial imagery was divided into size classes corresponding to the four largest size classes developed for the same population censused on the ground. Class boundaries were determined based on the relationship between dbh measured on the ground and visible canopy area measured from aerial images in the 1998 crown survey. This relationship produced a regression equation:

Visible crown area $($ in pixels $)=37.6585+28.0415(\mathrm{dbh}) \quad \mathrm{p}<0.0001 \quad$ Equation 4.9

Substituting the size class boundaries of the ground data into the regression equation, produced blob size classes (in pixels) of: 1) 178 - 458 2) 459 - 739 3) 740-1300 4) 1300+. Blobs < 178 pixels presented a challenge. The 1998 manually delineated crown 
survey of the study site found a number of the smallest patches of hemlock visible from the air to be separated at such a distance from all identified hemlock crowns that they could not be linked with certainty to any one crown (Lamar and McGraw submitted). These smallest patches represented isolated hemlock branches cut off from the main crown by shadows or other ground covers or crowns belonging to hemlocks with a dbh < $5 \mathrm{~cm}$. Because of the uncertain identity and relative insignificance of these smallest patches, all blobs < 178 pixels were considered "noise" and eliminated from further comparison and description. The elimination of these smallest blobs highlights the difficulty of accurately sampling the smallest elements within our hemlock population using remote sensing.

Fertility probability, besides being a function of parental size, is also expected to be a function of the distance from the seed source to the new recruit (Harper 1977). While individual-based simulation models have incorporated a distance function into estimates of recruitment (Ribbens 1994), most matrix projection models do not include such biological realism. The spatially explicit nature of our aerial data set permitted us to model fertility probabilities as a function of both blob size and distance of adult blobs from each new recruit. Unlike our ground data, the presence of "newborn" blobs within the aerial data sets is not the product of recent germination, but rather usually due to the emergence of new hemlocks into the canopy as a result of local disturbances. Only adult blobs present on the previous year's imagery were considered as possible parents. Adult blobs, as predicted by our regression equation, were defined as all blobs $\geq 318$ pixels, blobs corresponding to trees $\geq 10 \mathrm{~cm}$ dbh. Because most hemlock seed dispersal is within 
tree height (Godman and Lancaster 1990), fertility probabilities were estimated only for adult blobs (k) within $30 \mathrm{~m}$ of each newly emerged blob. As in equation 4.5 , we assume fertility follows an exponential pattern with size such that

Fertility probability ${ }_{k} \propto$ Crown Area $_{\mathrm{k}}{ }^{2} \quad$ Equation 4.10

To model our distance function we rely heavily on the assumptions of Ribbens (1994) who predicted recruitment would follow a Poisson distribution where the mean of the Poisson distribution is determined from the distance between the new recruit and potential parent. Our distance function was

$\begin{array}{ll}\text { Fertility probability } \propto e^{-\mathrm{Dm}^{3}} & \text { Equation } 4.11\end{array}$

where $\mathrm{D}$ is a constant that determines the steepness of decline of fertility probability as distance from new recruit increases and $\mathrm{m}$ is the mean distance (in meters) between all pixels of the potential parent and the new recruit. Ribbens (1994), using a Metropolis algorithm, calculated a hemlock-specific maximum likelihood value for D of 44.720410 $* 10^{-5}$, a value which produced a best fit of field observed and predicted spatial distributions for new recruits. In our model we assumed the same value for D. The relative fertility probability $\underline{\mathrm{f}}$ of each potential hemlock parent blob $\underline{\mathrm{k}}$ with regard to each new recruit 1 was calculated as the product of the size and distance function such that: 


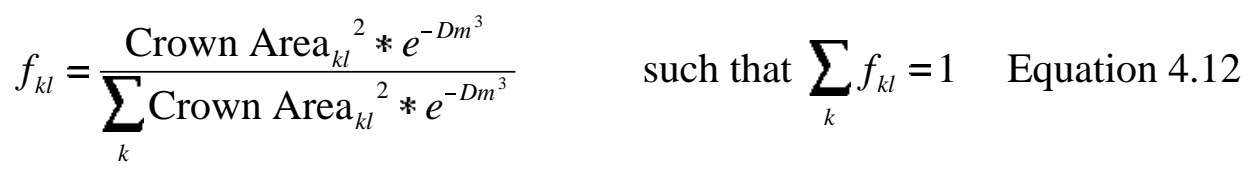

Class fertilities $\underline{\mathrm{F}}_{\mathrm{i}}$ are then calculated as

$F_{i}=\sum_{k l} \mathrm{f}_{k l i} / \mathrm{N}_{i}$

Equation 4.13

where $\mathrm{N}_{i}$ is the total number of blobs in size class $\underline{\mathrm{i}}$.

\section{$\underline{\text { Statistical Comparison }}$}

A randomization, or permutation, test was used to assess variation found in $\lambda$ for the 1997-98 and 1998-99 matrices derived from both ground and aerial-based sampling

(Caswell 2001). A test statistic $\theta=\left|\lambda_{\mathrm{t}}-\lambda_{\mathrm{t}+1}\right|$ was used to conduct a two-tailed test of the null hypothesis that time had no effect. Data on all individuals from both matrices was randomly resampled without replacement to produce a permutated data set maintaining the original sample sizes for both times. The test statistic $\boldsymbol{\theta}^{(i)}$ was calculated from this ith data set and the process repeated for a sample of 3000 random permutations. The probability, given our $\mathrm{H}_{0}$, that $\theta \geq \theta_{\text {obs }}$ was calculated

$$
P\left[\theta \geq \theta_{o b s} \mid H_{o}\right]=\frac{\#\left\{\theta^{(i)} \geq \theta_{o b s}\right\}+1}{3000+1} \quad \text { Equation } 4.14
$$

\section{Results}

Matrix population models of the hemlock population were constructed for 1997-98 and 1998-99 using both aerial (Table 4.1) and ground (Table 4.2) censused data sets. 
Visual inspection of the two types of matrices showed clear differences owing to the contrasting data sources. The matrices derived from ground based data looked as expected for a long lived, low disturbance tree species: low rates of mortality, no regression into smaller size classes, and little growth to larger size classes (Hartshorn 1975, Enright and Ogden 1979, Platt et al. 1988). The matrices derived from the aerial imagery presented a different picture. These matrices exhibited much more "movement" among size classes. Some of these changes, as illustrated in the life cycle figures, were due to the more dynamic nature of the aerial measurements (visible canopy area of blobs) vs. ground measurements (dbh measurements of trees). These changes would tend to have a real impact on the population's future. Other movements between matrix elements, however, were pseudo-transitions caused by uncorrected distortion differences between images. Distortions are inherent in the process of collecting low elevation, aerial imagery and it is unrealistic to expect to eliminate all the resultant errors. Our goal with geometric corrections was to minimize these errors so that the pseudo-transitions do not mask the detection of actual change between images. Image to image registration of image pairs using second order mapping polynomials along with cubic convolution resampling resulted in a deviation between images, as described by root mean square (RMS) error, of 2.8 pixels $(\sim 36 \mathrm{~cm})$ for the 1998/1999 image pair and 2.6 pixels $(\sim 34$ cm) for the 1997/1998 image pair (Lamar and McGraw submitted).

The reconciliation procedure ensured that no pixel is identified with different hemlock blobs in different years, however, because of uncorrected distortion differences it was still possible that the same hemlock crown portion on the ground, when viewed from the 
air, could share no overlapping pixels on multitemportal imagery. In that case, the automated reconciliation could, for example, assign the crown portion as viewed from time $\underline{t}$ to Blob $\mathrm{A}$ and the same crown portion as viewed from time $\underline{\mathrm{t}}+1$ to Blob $\mathrm{B}$. The result would be a pair of pseudo-transitions, a reduction in size for Blob A and an increase in size for Blob B over time and a possible change of size classes. While a significant number of the same type of pseudo-transitions (for example, individuals "growing" from size class 2 to 3) would greatly impact the population projections, given a large enough sample and the expected complementary distribution of individuals on both sides of the size boundaries, we anticipated that these pseudo-transitions should balance themselves out (Figure 4.2). Thus, in the previous example, the number of individuals pseudo-growing from size class 2 to 3 should be balanced by the number of individuals pseudo-regressing from size class 3 to 2 . The negligible effects of these balanced pseudo -transitions on the overall population growth rate is shown in Table 4.3. We thus could reasonably assume that significant differences between matrix projections derived from aerial imagery were due to real changes in the visible canopy area of blobs.

Another distinctive characteristic of matrices derived from aerial imagery was the merging of two population attributes into one transition element. For example, in Table 1, the transitions involving the movement of blobs from the larger classes into size class 1 $\left(\underline{a}_{1}\right.$, where $\left.j>1\right)$, a transition that often is associated exclusively with fertility, consisted of both a fertility component and a regression component. Similarly, transition $\underline{\mathrm{a}}_{24}$, typically a transition describing regression, was comprised of both a regression and fertility component. This 2-component transition is often seen in demographic models of plant 
parts (McGraw and Antonovics 1983, McGraw 1989), but less frequently in models of long-lived genets.

Population characteristics $(\lambda$, stable size distribution, reproductive values, and elasticities) calculated from the aerial and ground derived matrices are summarized in Tables 4.4 and 4.5. Several of these characteristics showed comparable patterns for both aerial and ground-derived matrices. Reproductive values calculated from both type of matrices grew with increasing size classes. Both blobs and individuals belonging to the largest size classes are expected to contribute the most to future population growth. The actual reproductive values associated with the ground censused individuals were much larger than the values linked to aerial censused blobs, reflecting the different definitions of "newborn" individuals and "newborn" blobs in this study.

Elasticity values also showed similar patterns for both ground and aerial-derived matrices. For long-lived trees species the importance of adult survival is critical and well-documented (Silvertown et al. 1996). It is thus not surprising that the largest elasticity values for both types of matrices were associated with transitions where adults (blobs and individuals) remained in the same size class (i.e. survived) over time.

The two methods of gathering data for the population projection matrices resulted in different responses of $\lambda$ over time. No significant increase in $\lambda$ was found between 1997 98 and 1998-99 when using ground-derived matrices, however, the aerial-derived matrices for these same time periods, showed that for the 1997-98 data, the population 
was projected to decline at a rate of $\sim 1 \%$ per year, while the 1998-99 data resulted in a projected long-term increase in population size of $\sim 6 \%$ per year, a significant increase (p $<0.001)$.

A similar pattern of decrease from 1997 to 1998 and increase from 1998 to 1999 was found in other descriptions of the hemlock canopy collected in the air and on the ground during this time frame; a pattern attributed to a severe February, 1998 ice storm. The total number of hemlock pixels classified in the 1997-98 aerial image pair decreased $1.85 \%$; the total number of hemlock pixels classified in the 1998-99 image pair increased 2.38\% (Figure 4.3). Between the 1997 and 1998 censuses, ground measurements of crown density found a net of 137 hemlock crowns dropping at least one density class including 13 crowns belonging to dominant, upper canopy trees (Figure 4.4). In contrast, from the 1998 to 1999 census, a net of 18 hemlock crowns increased to a higher density class. 
Table 4.1. Hemlock population matrices derived from aerial data sets.

Stage at time $\mathrm{t}$

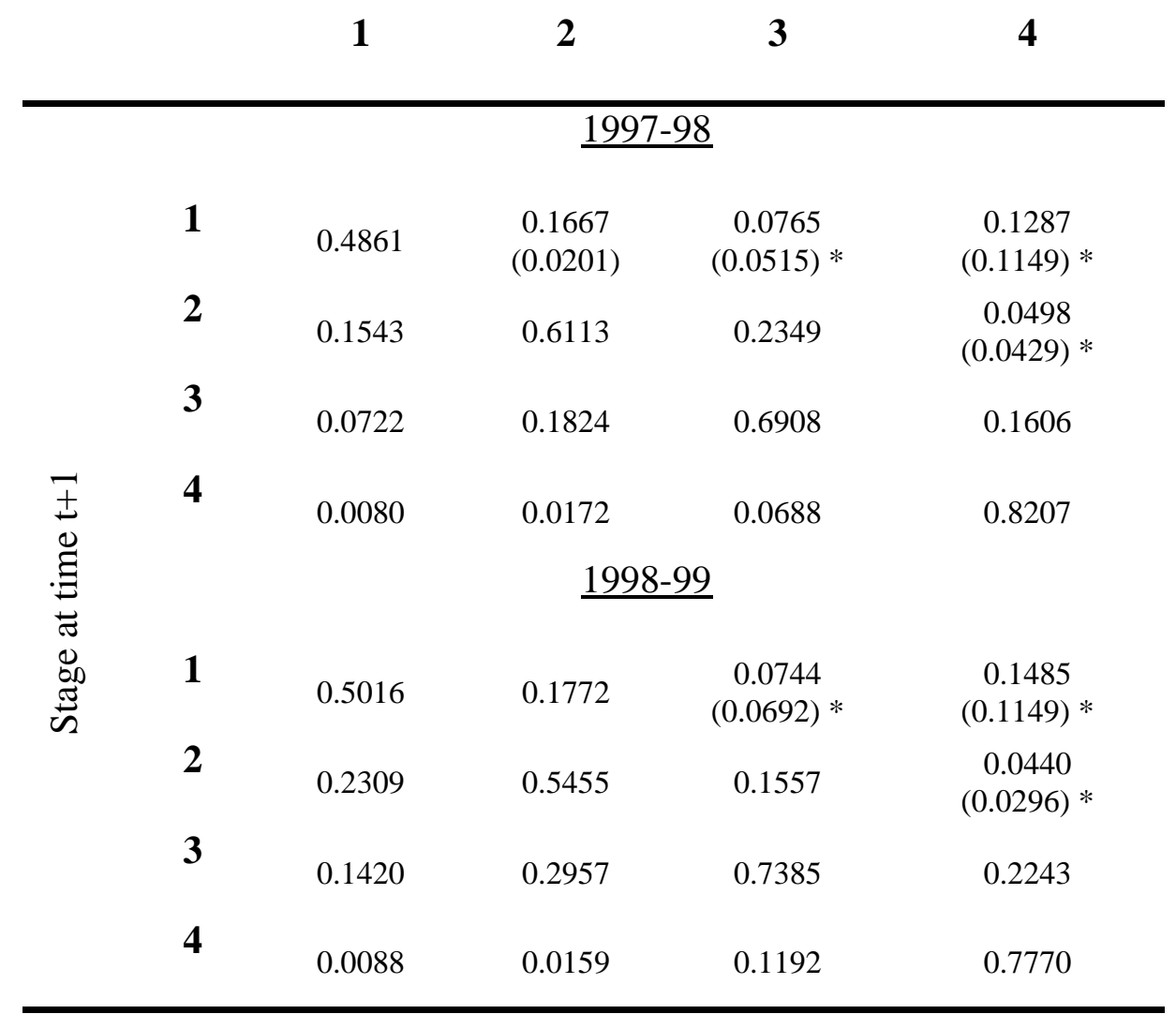

- Fertility probabilities included in ( ) if $>10 \%$ of total transition probability. 
Table 4.2. Hemlock population matrices derived from ground data sets.

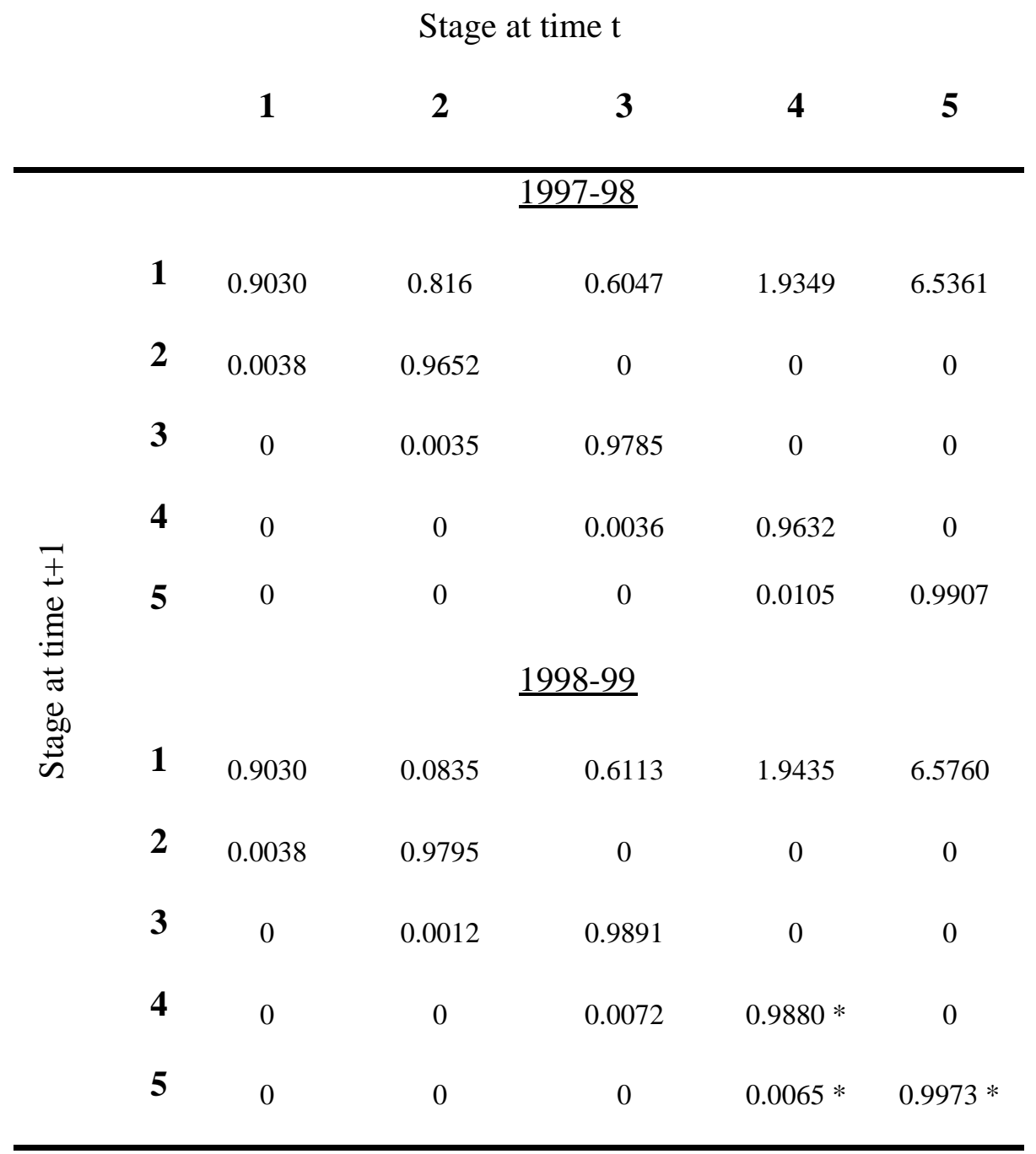

- Elements are adjusted estimates calculated using Equations $4.7\left(\mathrm{a}_{55}\right)$ and $4.8\left(\mathrm{a}_{54}\right.$ and $\left.\mathrm{a}_{44}\right)$. 
Figure 4.2. Blob size distribution. Note the relative balance between numbers of blobs on either side of category boundaries.

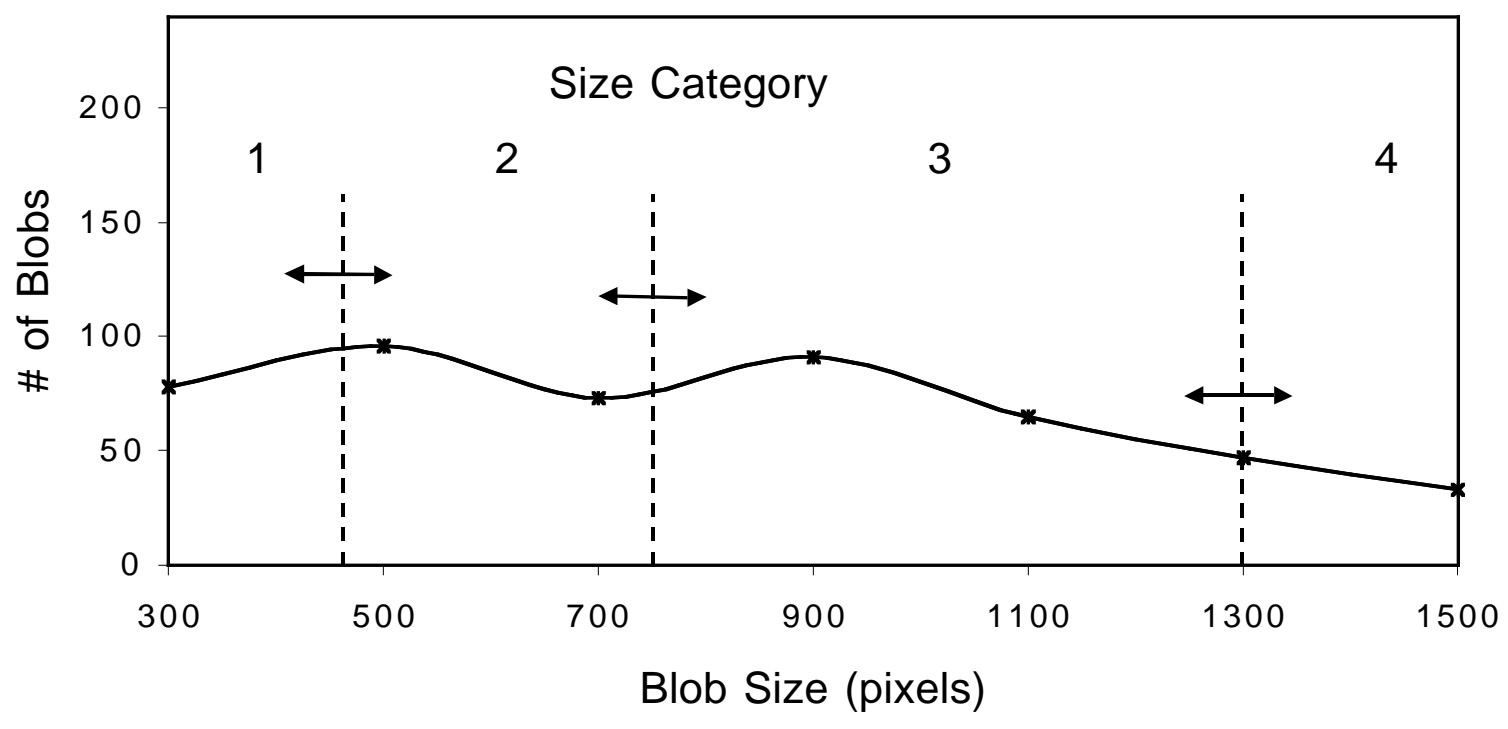

Table 4.3. Effect on $\lambda$ of balanced growth and regression transitions between adjacent size classes, $1998-99$ aerial derived matrix.

\begin{tabular}{l|lrrr}
\hline & \multicolumn{4}{|c}{ \# of balanced transitions (in comparison to actual matrix) } \\
& Class Boundary & -40 & Original & +40 \\
\hline $\boldsymbol{\lambda}$ & $1--2$ & 1.0640 & 1.0604 & 1.0579 \\
& $2--3$ & 1.0640 & 1.0604 & 1.0586 \\
& $3--4$ & 1.0489 & 1.0604 & 1.0646 \\
\hline
\end{tabular}

An example of a pair of balancing transitions is growth from class $2->3$ and regression from class $3->2$. 
Table 4.4. Population characteristics predicted from aerial derived matrices.

AERIAL

\begin{tabular}{|c|c|c|c|c|c|c|c|c|c|}
\hline & & \multicolumn{4}{|c|}{$\underline{1997-98}$} & \multicolumn{4}{|c|}{ 1998-99 } \\
\hline \multicolumn{2}{|l|}{$\lambda$} & \multicolumn{4}{|c|}{$0.9896 * * *$} & \multicolumn{4}{|c|}{$1.0604 * * *$} \\
\hline \multicolumn{2}{|l|}{ Stable Stage } & 1 & 2 & 3 & 4 & 1 & 2 & 3 & 4 \\
\hline \multicolumn{2}{|l|}{ Distribution } & 0.1950 & 0.3051 & 0.3266 & 0.1733 & 0.1756 & 0.2200 & 0.4129 & 0.1915 \\
\hline \multicolumn{2}{|c|}{ Reproductive } & 1.0000 & 1.8581 & 2.5837 & 3.7679 & 1.000 & 1.3415 & 1.6281 & 2.0207 \\
\hline \multicolumn{10}{|l|}{ Values } \\
\hline & 1 & 0.0424 & 0.0228 & 0.0112 & 0.0100 & 0.0543 & 0.0240 & 0.0189 & 0.0175 \\
\hline & 2 & 0.0250 & 0.1550 & 0.0638 & 0.0072 & 0.0335 & 0.0992 & 0.0532 & 0.0070 \\
\hline \multirow[t]{2}{*}{ Elasticities } & 3 & 0.0163 & 0.0643 & 0.2608 & 0.0322 & 0.0250 & 0.0653 & 0.3060 & 0.0431 \\
\hline & 4 & 0.0026 & 0.0089 & 0.0378 & 0.2398 & 0.0019 & 0.0043 & 0.0613 & 0.1853 \\
\hline
\end{tabular}


Table 4.5. Population characteristics predicted from ground derived matrices.

GROUND

\begin{tabular}{|c|c|c|c|c|c|c|c|c|c|c|c|}
\hline & & \multicolumn{5}{|c|}{$97-98$} & \multicolumn{5}{|c|}{ 98-99 } \\
\hline \multicolumn{2}{|l|}{$\lambda$} & \multicolumn{5}{|c|}{0.9946} & \multicolumn{5}{|c|}{1.0025} \\
\hline \multicolumn{2}{|l|}{ Stable Stage } & 1 & 2 & 3 & 4 & 5 & 1 & 2 & 3 & 4 & 5 \\
\hline \multicolumn{2}{|l|}{ Distribution } & 0.8552 & 0.1106 & 0.0240 & 0.0027 & 0.0076 & 0.8350 & 0.1384 & 0.0125 & 0.0063 & 0.0079 \\
\hline \multicolumn{2}{|c|}{ Reproductive } & 1.00 & 24.1 & 179.8 & 636.8 & 1715.5 & 1.00 & 26.2 & 429.5 & 706.7 & 1266.0 \\
\hline \multicolumn{12}{|l|}{ Values } \\
\hline \multirow{5}{*}{ Elasticities } & 1 & 0.0344 & 0.0004 & 0.0006 & 0.0002 & 0.0022 & 0.0311 & 0.0005 & 0.0003 & 0.0005 & 0.0021 \\
\hline & 2 & 0.0035 & 0.1146 & 0 & 0 & 0 & 0.0034 & 0.1463 & 0 & 0 & 0 \\
\hline & 3 & 0 & 0.0031 & 0.1882 & 0 & 0 & 0 & 0.0029 & 0.2185 & 0 & 0 \\
\hline & 4 & 0 & 0 & 0.0024 & 0.0749 & 0 & 0 & 0 & 0.0026 & 0.1803 & 0 \\
\hline & 5 & 0 & 0 & 0 & 0.0022 & 0.5733 & 0 & 0 & 0 & 0.0021 & 0.4093 \\
\hline
\end{tabular}

No significant difference between $\lambda$ 's, $\mathrm{P}=0.194$. 
Figure 4.3. Comparison of total hemlock pixels classified from the aerial imagery, 1997-98 and 1998-99 image pairs.
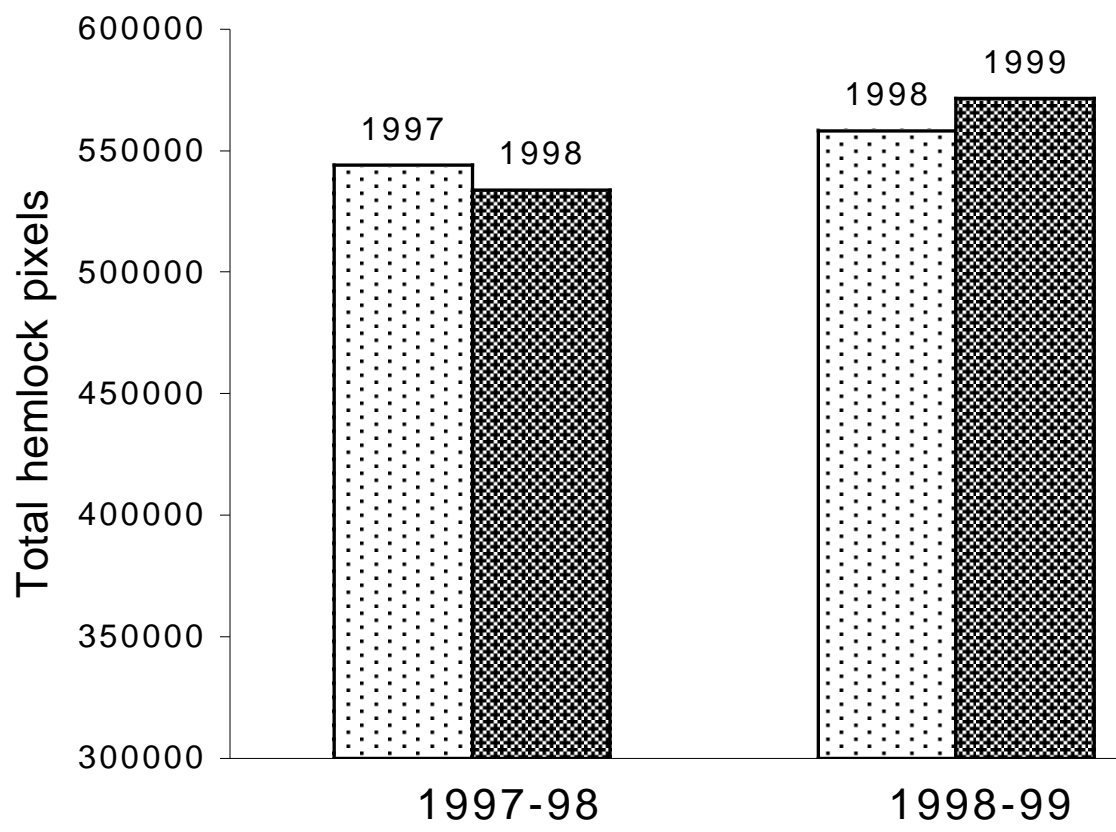
Figure 4.4 Hemlock canopy density changes between 1997-98 and 1998-99, ground data.

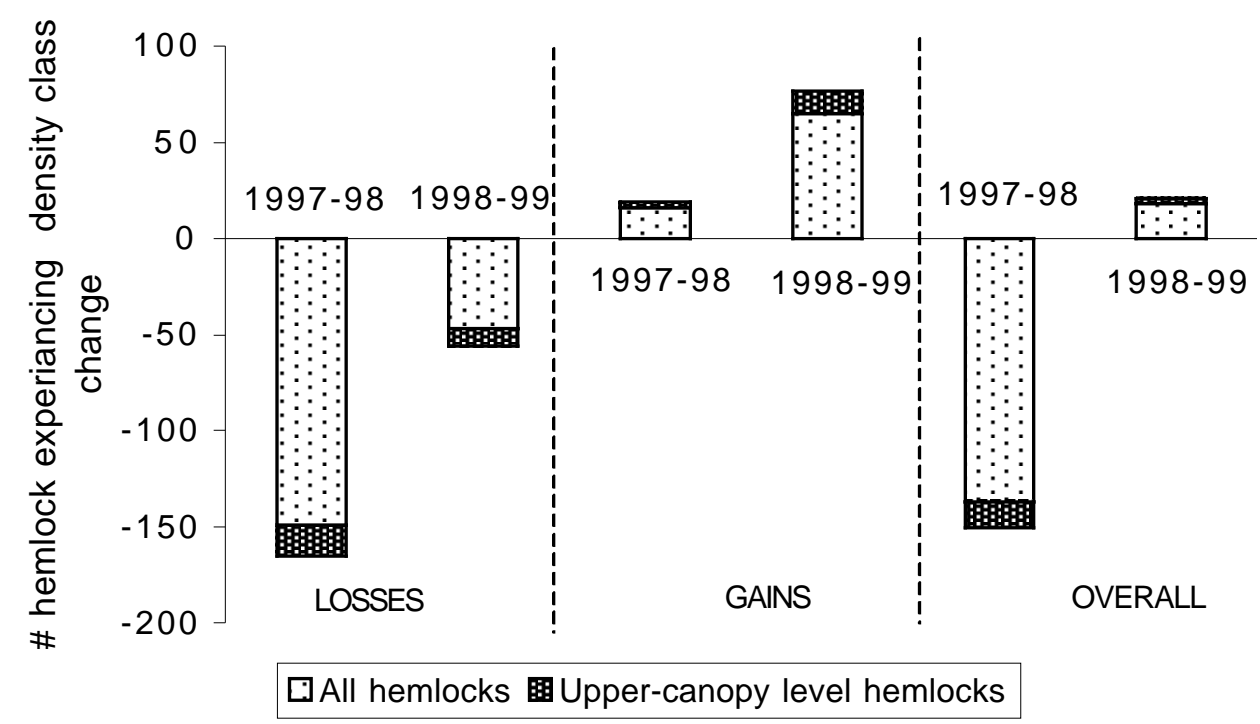




\section{Discussion}

In some respects, censusing plant populations by remote sensing can be viewed as a broad-brush approach to demography. Numerically, a large part of the hemlock population was invisible from the aerial imagery. Most of these hidden trees were small, understory and/or sparsely-foliated individuals (Lamar and McGraw submitted). By establishing a threshold blob size for the visible segment of the population, additional, mostly small trees were eliminated from demographic analysis.

One of the reasons hemlock was selected for this study was that it is spectrally distinctive in the hardwood forest context. However, the inability of our spectral segmentation procedure to distinguish hemlock from other evergreen species meant that our "population" was not exclusively hemlock, but actually included one adult white pine, one adult red spruce, and several clumps of mountain laurel. The impact of this lack of spectral separability was lessened in our study site with $\sim 97 \%$ of the evergreen component being hemlock. Future investigations in more diverse communities will, however, require improved spectral segmentation of species. The coarse spectral resolution of the sensor contributed to our inability to distinguish hemlock. Current and forthcoming sensors with increased spectral resolution combined with radiometric enhancement techniques offer much promise for future spectral segmentation at a species level (May et al. 2003).

Despite the broad-brush approach, aerial demographic sampling can provide important information about a population. The visible segment of the hemlock population was comprised of two components important to future population dynamics: large upper 
canopy hemlock trees and smaller hemlock located in canopy gaps or under lightly branched overstory trees (Lamar and McGraw submitted). Large adult trees have been shown to have a disproportionately high influence on the future dynamics of a population (Hartshorn 1975, Enright and Ogden 1979). Small hemlocks located within a gap or higher light environment experience an increased rate of growth while the gap persists (Hibbs 1982). The alternating periods of growth and suppression due to small but repeated disturbances in the forest upper canopy are often needed by hemlock to reach the upper canopy level (Oliver and Stephens 1977). Therefore, the small visible trees in the study site may have a better chance of contributing to future population growth than trees of similar size hidden from aerial censusing.

The different perspective provided by aerial sampling has both advantages and disadvantages. The division of our aerial censused population into blobs rather than true individual crowns loses the advantage of population units with genetic identity that accompanies the traditional censusing techniques. Yet, blobs and individuals share many other characteristics; the advantages of one sampling perspective over another is not so distinct. Indeed, the majority of blobs show a 1:1 correspondence with actual tree crowns (Chapter 3). Importantly from an ecological perspective, both blobs and individuals can influence their surrounding environments and compete for resources with their neighbors. The cost-effectiveness of sampling large numbers of spatially explicit blobs over large geographic areas is a distinct advantage of aerial sampling, with this advantage becoming greater the larger the censused population. 
The calculation of fertility probabilities is another example of the different perspective provided by remote sensing. The spatially explicit nature of the data permitted the addition of a distance function when calculating individual fertility, adding an element of biological realism not found in non-spatial models. On the other hand, the necessity of defining "newborns" as newly visible blobs within the forest canopy meant the "newborn" might be decades old and the actual parents may be no longer surviving at the time of the parental census, leading to inherent statistical error in calculating fertilities.

Until remote sensing instruments can detect individuals with the same resolution and angular mobility as the human eye (probably a physical impossibility), the census data extracted from these instruments will differ in several respects. The important question is: Does the perspective from the air yield benefits in terms of detecting population change and identifying the causes of this change? This particular study, which is the first to attempt to answer this question in the context of demographic modeling, suggests the answer is yes. $\lambda$ derived from ground data showed no significant change between the 1997-98 and 1998-99 matrices and, indeed, we would not expect ground measurements of dbh to detect sub-lethal crown disturbance events, in this case a February 1998 ice storm. $\lambda$ derived from aerial imagery did, however, show a significant increase. Other data from the air (total hemlock pixels) and ground (crown density class) supported that this was a real change in population status.

Although the pattern of crown density class measurements showed distinct changes between 1997-98 and 1998-99, supporting the findings of the aerial-derived matrices, a 
direct comparison of individual crown density on the ground and a blob's visible canopy area from the air must be made cautiously. Not only should simply the different perspective of the two measurements be expected to cause variability, but the ground measurements also fail to consider the effects of crown damage to neighboring nonhemlock components of the forest and the resulting canopy openings. A National Park Service (NPS) survey following the 1998 ice storm showed $11.3 \%$ of the live trees sampled in upper elevation plots suffered crown damage (Cass 1999). Oaks (Quercus sp.) and Red Maple (Acer rubrum) were the most severely damaged species. The numerous canopy openings that formed within the study site following the ice storm provided a indirect positive impact on the lower canopy level hemlocks. This benefit helped to balance the direct negative impact of the storm on hemlock and explains why, although a net of 137 hemlocks ( 10\% of the population) dropped at least one density class between the 1997 and 1998 censuses, total hemlock pixels measured from the air only dropped $1.85 \%$ and $\lambda$ derived from the aerial imagery remained very close to 1.0 . The direct negative impacts of the storm on hemlock were apparently balanced by the indirect positive impacts caused by the many canopy openings.

The response of hemlock following this disturbance event from 1998-99 is more pronounced in the aerial imagery (both total hemlock pixels and $\lambda$ ) than crown density comparisons. While the net of 18 hemlocks increasing one density class from 1998-99 is certainly a reversal from the 1997-98 data, it is quite possible that the broad boundaries of the density classes failed to detect many additional small increases in crown density. 
Continued improvements in the spectral and spatial resolution of future remote sensing devices should allow ecologists to collect even more detailed population data over larger regional and even sub-continental scales. The cost effectiveness of remote sensing should increase our ability to provide basic demographic information on species of conservation concern. In addition, the ability to follow 100,000 's of spatially explicit individual population units over time within a regional landscape provides many new opportunities for demographic study. For example, by structuring the remotely sensed population by both size and the density of local neighborhoods, the effect of density dependence within a population can be investigated. Overlaying the population information with other layers of spatially explicit environmental data such as soil maps, elevation maps, and surface water maps within a GIS framework allows the investigation of the influence of both local and regional environmental variables on population dynamics. The marriage of remote sensing techniques, GIS analysis and demographic ecological studies promises to answer many fundamental ecological questions, heretofore intractable, regarding the factors that determine population structure and dynamics. 


\section{References}

Allphin, L., and K. T. Harper. 1997. Demography and life history characteristics of the rare kechina daisy (Erigeron kechinensis, Asteraceae). American Midland Naturalist 138:109-120.

Baptista, W. B., W. J. Plat, and R. C. Macchiavelli. 1998. Demography of a shadetolerant tree (Fagus grandifolia) in a hurricane-disturbed forest. Ecology 79:3853.

Busing, R. T. 1995. Disturbance and the population dynamics of Liriodendron tulipifera: simulations with a spatial model of forest succession. Journal of Ecology 83:4553.

Cass, W. 1999. Severity of ice damage to chestnut oak forest within Shenandoah National Park. Pages 15-17 in Shenandoah National Park Resource Management newsletter.

Caswell, H. 2001. Matrix population models, 2nd edition. Sinauer Associates, Inc., Sunderland, Massachusetts.

Clark, J. S., M. Macklin, and L. Wood. 1998. Stages and spatial scales of recruitment limitation in southern Appalachian forest. Ecological Monographs 68:213-235.

Dunning, J. B., D. J. Stewart, B. Danielson, B. R. Noon, T. L. Root, H. Lamberson, and E. E. Stevens. 1995. Spatially explicit population models:current forms and future uses. Ecological Monographs 5:3-11.

Enright, N., and J. Ogden. 1979. Applications of transition matrix models in forest dynamics; Araucaria in Papua New Guinea and Nothofagus in New Zealand. Australian Journal of Ecology 4:3-23. 
Godman, R. M., and L. Lancaster. 1990. Tsuga canadensis in Silvics of North America. USDA Forest Service Agricultural Handbook 654 pp. 604-612.

Golubov, J., M. D. Mandujano, M. Franco, C. Montana, L. E. Eguiarte, and J. LopezPortilla. 1999. Demography of the invasive woody perennial Prosopis glandulosa (Honey mesquite). Journal of Ecology 87:955-962.

Gougeon, F. A. 1995. A crown-following approach to the automatic delineation of individual tree crowns in high spatial resolution aerial images. Canadian Journal of Remote Sensing 21:274-284.

Graetz, R. D. 1990. Remote sensing of terrestrial ecosystem structure: an ecologist's pragmatic view in Remote sensing of biosphere functioning. Edited by R. J. Hobbs and H. A. Mooney. Springer-Verlag, New York pp. 7-30.

Guàrdia, R., José Raventós, and Hal Caswell. 2000. Spatial growth and population dynamics of a perennial tussock grass (Achnatherum calamagrostis) in a badland area. Journal of Ecology 88:950-963.

Hall, F. G., D. B. Botkin, D. E. Strebel, K. D. Woods, and S. J. Goetz. 1991. Large-scale patterns of forest succession as determined by remote sensing. Ecology 72:628640.

Harper, J. L. 1976. The concept of population in modular organisms in Theoretical Ecology. Principles and Applications. Edited by R. M. May. Blackwell Scientific Publications, Oxford pp. 53-77.

Harper, J. L. 1977. Population Biology of Plants. Academic Press, San Diego CA. 
Hartshorn, G. S. 1975. A matrix model of tree population dynamics in Tropical Ecological Systems. Edited by F. B. Golley and E. Medina. Springer-Verlag, New York pp. 41-51.

Hibbs, D. E. 1982. Gap dynamics in a hemlock-hardwood forest. Canadian Journal of Forest Resources 12:522-527.

Huenneke, L. F., and P. L. Marks. 1987. Stem-dynamics of the shrub Alnus incanta ssp. rugosa: transition matrix models. Ecology 68:1234-1242.

Kareiva, P. 1996. Developing a predictive ecology for non-indigenous species and ecological invasions. Ecology 77:1651-1652.

Kaye, T. N., K. L. Pendergrass, K. Finley, and J. B. Kauffman. 2001. The effect of fire on the population viability of an endangered prairie plant. Ecological Applications 11:1366-1380.

Kramer, H. J. 2002. Observation of the Earth and its Environment - Survey of Missions and Sensors, 4th edition. Springer Verlag.

Lamar, W. R., and J. B. McGraw. Submitted. A comparison of a population census of eastern hemlock (Tsuga canadensis L.) on the ground and using aerial photography. Canadian Journal of Remote Sensing.

Lande, R. 1988. Genetics and demography in biological conservation. Science 241:14551460.

Lefkovitch, L. P. 1965. The study of population growth in organisms grouped by stages. Biometrics 21:1-18.

May, D. Z., K. J. Brown, and S. A. Bohlman. 2003. Evaluation of high-resolution, multiband imagery for determining proportions of oak and maple LAI in Black Rock 
Forest, NY. in 88th Annual Meeting, The Ecological Society of America, Savannah, GA.

McGraw, J. B. 1989. Effects of age and size on life histories and population growth of Rhododendron maximum shoots. American Journal of Botany 76:113-123.

McGraw, J. B., and J. Antonovics. 1983. Experimental ecology of Dryas octopetala ecotypes. II. A demographic model of growth, branching, and fecundity. Journal of Ecology 71:899-912.

Menges, E. S. 1990. Population viability analysis for an endangered plant. Conservation Biology 4:52-62.

Miller, I., R. Anderson, W. Burkman, and W. Hoffard. (1992), Forest health monitoring: crown condition rating guide. United States Department of Agriculture, U.S. Forest Service.

Moloney, K. A. 1986. A generalized algorithm for determining category size. Oecologia 69:176-180.

Niemann, K. O. 1995. Remote sensing of forest stand age using airborne spectrometer data. Photogrammetric Engineering and Remote Sensing 61:1119-1127.

Oliver, C. D., and E. P. Stephens. 1977. Reconstruction of a mixed-species forest in central New England. Ecology 58:562-572.

Pacala, S. W. 1989. Plant population dynamic theory in Perspectives in Ecological Theory. Edited by J. Roughgarden, R. May, and S. Levin. Princeton University Press, Princeton, NJ. pp. 54-67. 
Pacala, S. W., C. D. Canham, J. Saponara, J. A. Silander. Jr., R. K. Kobe, and E. Ribbens. 1996. Forest models defined by field measurements: estimation, error analysis and dynamics. Ecological Monographs 66:1-43.

Parker, I. M. 2000. Invasion dynamics of Cytisus scoparius. A matrix model approach. Ecological Applications 10:726-743.

Pinero, D., M. Martinez-Ramos, and J. Sarukhan. 1984. A population model of Astrocaryum mexicanum and a sensitivity analysis of its finite rate of increase. Journal of Ecology 72:977-991.

Platt, W. J., G. W. Evans, and S. L. Rathburn. 1988. The population dynamics of a longlived conifer (Pinus palustris). American Naturalist 131:491-525.

Ribbens, E., John A. Silander, Jr. and Stephen W. Pacala. 1994. Seedling recruitment in forests: calibrating models to predict patterns of tree seedling dispersion. Ecology 75:1794-1806.

Schemske, D. W., B. C. Husband, M. H. Ruckelshaus, C. Goodwillie, I. M. Parker, and J. G. Bishop. 1994. Evaluating approaches to the conservation of rare and endangered plants. Ecology 75:584-606.

Shugart, H. H., and T. M. Smith. 1992. The potential for application of individual-based simulation models for assessing the effects of global change. Annu. Rev. Ecol. Syst. 23:15-38.

Silvertown, J., M. Franco, and E. Menges. 1996. Interpretation of elasticity matrices as an aid to the management of plant populations for conservation. Conservation Biology 10:591-597. 
Silvia, J. F., J. Raventos, H. Caswell, and M. C. Trevisan. 1991. Population responses to fire in a tropical savanna grass. Journal of Ecology 79:345-355.

Souto, D., Tom Luther, and Bob Chianese. 1996. Past and current status of HWA in eastern and Carolina hemlock stands. Pages 9-15 in S. M. Salom, T.C. Tigner, and R.C. Reardon, editor. Proceedings of the first hemlock woolly adelgid review. U.S. Department of Agriculture, Charlottesville, Virginia. 


\section{CHAPTER 5}

\section{General Conclusion}

Until remote sensing instruments can detect individuals with the same resolution and angular mobility as the human eye (probably a physical impossibility), the census data extracted from these instruments will differ in several respects from traditional field sampling. The important question is: Does the perspective from the air yield benefits in terms of describing a population, detecting population change and identifying the causes of this change? This dissertation, which is the first to attempt to answer this question in the context of demographic censusing and modeling, suggests the answer is yes.

In the first study, a census of a hemlock population from an aerial-derived manual crown survey and from traditional ground sampling revealed important similarities and differences between the two perspectives. The most obvious difference in the population data obtained from remote sensing is the absence of a large portion of the total population. In our study, over $60 \%$ of the hemlock population censused on the ground was hidden in the aerial census. Most of these hidden hemlocks were small, suppressed individuals located underneath the upper canopy crowns and in shadows cast by adjacent neighbors. Crown density and crown position also influenced a crown's visibility from the air.

The visible hemlock trees from aerial censusing represented several important components of the population. Nearly all large upper canopy hemlock trees were seen in the aerial imagery. These large adult trees have been shown to have a disproportionately 
high influence on the future dynamics of a population (Hartshorn 1975, Enright and Ogden 1979).

Large hemlock trees were not the only visible segment of the population from the air. Nearly $40 \%$ of the aerially viewed population was comprised of trees within the forest's lower canopy. The visibility of these smaller individuals was attributed to their location within the forest: in canopy gaps or under a sparsely branched hardwood canopy. One would expect that the small visible trees in our study site would have a better chance of contributing to future population growth than trees of similar size hidden from aerial censusing.

In the second study, a new automated methodology was presented to extract unique and comparable population data sets from remotely sensed, multitemporal imagery. The spectral and spatial characteristics of the available imagery dictate the canopy attributes that can be used for segmentation. These characteristics vary considerably depending on site, sensor type, image scale, and timing of image collection. Our segmentation and reconciliation procedures relied on global and local spatial features such as shape, size, and connectivity between hemlock clumps to divide the multi-temporal binary hemlock maps into unique individual population blobs that could be followed over time.

In the third study, matrix population models were constructed from databases derived from the ground and aerial censusing of the hemlock population. Important population characteristics produced by matrix analysis were compared. The overall population 
growth rate $(\lambda)$ derived from ground data showed no significant change between the 1997-98 and 1998-99 matrices and, indeed, one would not expect ground measurements of dbh to detect sub-lethal crown disturbance events, in this case a February 1998 ice storm. $\lambda$ derived from aerial imagery did, however, show a significant increase. Other data from the air (total hemlock pixels) and ground (crown density class) supported the idea that this was a real change in the status of the population.

Continued improvements in the spectral and spatial resolution of future remote sensing devices should allow ecologists to collect even more detailed population data over larger regional and even sub-continental scales. The cost effectiveness of remote sensing should increase our ability to provide basic demographic information on species of conservation concern. In addition, the ability to follow 100,000 's of spatially explicit individual population units over time within a regional landscape provides many new opportunities for demographic study. For example, by structuring the remotely sensed population by both size and the density of local neighborhoods, the effect of density dependence within a population can be investigated. Overlaying the population information with other layers of spatially explicit environmental data such as soil maps, elevation maps, and surface water maps within a GIS framework allows the investigation of the influence of both local and regional environmental variables on population dynamics. The marriage of remote sensing techniques, GIS analysis and demographic ecological studies promises to answer many fundamental ecological questions, heretofore intractable, regarding the factors that determine population structure and dynamics. 


\section{References}

Enright, N., and J. Ogden. 1979. Applications of transition matrix models in forest dynamics; Araucaria in Papua New Guinea and Nothofagus in New Zealand. Australian Journal of Ecology 4:3-23.

Hartshorn, G. S. 1975. A matrix model of tree population dynamics in Tropical Ecological Systems. Edited by F. B. Golley and E. Medina. Springer-Verlag, New York pp. 41-51. 


\section{W. Robert Lamar}

West Virginia University

Department of Biology

Morgantown, WV 26506

rlamar@swva.net

\section{Education and Degrees}

1992 - present

$1976-1980$
Graduate Student, West Virginia University (Morgantown, WV), Department of Biology, Degree (Ph.D.) anticipated: 12/03. Censusing and Modeling the Dynamics of a Population of Eastern Hemlock (Tsuga canadensis L.) Using Remote Sensing. Research Advisor: Dr. James B. McGraw.

BA, Duke University (Durham, NC), Botany Department (Cum Laude).

\section{Professional Experience}

$1988-2001$

$1987-1988$

$1985-1987$

$1984-1985$
Natural Resource Management Specialist, National Park Service, Wilson's Creek National Battlefield.

Lead Park Ranger, Resource Management and Visitor Protection, National Park Service, Wilson's Creek National Battlefield.

Park Ranger, Resource Management and Visitor Protection, National Park Service, Cape Lookout National Seashore.

Park Ranger, Interpretation, National Park Service, Independence National Historical Park.

\section{Publications}

McGraw, J. B., T. A. Warner, T. Key, and W. Lamar. (1998), Advances in high resolution remote sensing for forest ecological studies. Trends in Ecology and Evolution 13:300-301. 


\section{In Preparation}

Lamar, W. R., and J. B. McGraw. Multitemporal censusing of a population of eastern hemlock (Tsuga canadensis $L$.) from remotely sensing imagery using an automated segmentation and reconciliation procedure. For Remote Sensing of Environment.

Lamar, W. R., and J. B. McGraw. A comparison of a population census of eastern hemlock (Tsuga canadensis L.) on the ground and using aerial photography. For Canadian Journal of Remote Sensing.

Lamar, W. R., and J. B. McGraw. A comparison of population models for eastern hemlock (Tsuga canadensis L.) derived from the ground and remotely sensed data. For Ecology.

\section{Scientific Presentations}

Lamar, W. R. 1998. Censusing a population of Eastern Hemlock (Tsuga canadensis) using remote sensing. Bulletin of the Ecological Society of America Abstracts, Baltimore, MD, August 1998.

McGraw, J. B., and W. R. Lamar. 1999. Remote sensing and megademography of trees. Bulletin of the Ecological Society of America Abstracts, Spokane, WA, August 1999.

Lamar, W. R., and J. B. McGraw. 2003. Censusing and modeling the dynamics of a population of Eastern Hemlock (Tsuga canadensis) using remote sensing. Appalachian Remote Sensing Conference, Morgantown, WV, May 2003.

Lamar, W. R., and J. B. McGraw. 2003. Investigation of population dynamics of Eastern Hemlock (Tsuga canadensis) using remote sensing. Bulletin of the Ecological Society of America Abstracts, Savannah, GA, August 2003

\section{Professional Affiliations and Service}

Member of the Ecological Society of America 